Portland State University

PDXScholar

\title{
Electron Backscatter Diffraction (EBSD) Study of Seven Heavily Metamorphosed Chondrites: Deformation Systematics and Variations in Pre- shock Temperature and Post-shock Annealing
}

\author{
Alexander M. Ruzicka \\ Portland State University, ruzickaa@pdx.edu \\ Richard C. Hugo \\ Portland State University
}

Follow this and additional works at: https://pdxscholar.library.pdx.edu/geology_fac

Part of the Geology Commons

Let us know how access to this document benefits you.

\begin{abstract}
Citation Details
Ruzicka, A. M., \& Hugo, R. C. (2018). Electron backscatter diffraction (EBSD) study of seven heavily metamorphosed chondrites: Deformation systematics and variations in pre-shock temperature and postshock annealing. Geochimica et Cosmochimica Acta, 234, 115-147.
\end{abstract}

This Post-Print is brought to you for free and open access. It has been accepted for inclusion in Geology Faculty Publications and Presentations by an authorized administrator of PDXScholar. Please contact us if we can make this document more accessible: pdxscholar@pdx.edu. 


\section{Accepted Manuscript}

Electron Backscatter Diffraction (EBSD) study of seven heavily metamorphosed chondrites: Deformation systematics and variations in pre-shock temperature and post-shock annealing

Alex M. Ruzicka, Richard C. Hugo

PII:

S0016-7037(18)30268-0

DOI: https://doi.org/10.1016/j.gca.2018.05.014

Reference: GCA 10771

To appear in:

Geochimica et Cosmochimica Acta

Received Date:

15 October 2017

Accepted Date:

9 May 2018

Please cite this article as: Ruzicka, A.M., Hugo, R.C., Electron Backscatter Diffraction (EBSD) study of seven heavily metamorphosed chondrites: Deformation systematics and variations in pre-shock temperature and postshock annealing, Geochimica et Cosmochimica Acta (2018), doi: https://doi.org/10.1016/j.gca.2018.05.014

This is a PDF file of an unedited manuscript that has been accepted for publication. As a service to our customers we are providing this early version of the manuscript. The manuscript will undergo copyediting, typesetting, and review of the resulting proof before it is published in its final form. Please note that during the production process errors may be discovered which could affect the content, and all legal disclaimers that apply to the journal pertain. 


\title{
Electron Backscatter Diffraction (EBSD) study of seven heavily
} metamorphosed chondrites: Deformation systematics and variations in pre-shock temperature and post-shock annealing

\author{
Alex M. Ruzicka* and Richard C. Hugo \\ Cascadia Meteorite Laboratory, Portland State University, Department of Geology, 1721 \\ SW Broadway, Portland, OR 97207
}

Submitted to Geochimica et Cosmochimica Acta

March 26, 2018

*Corresponding author (ruzickaa@pdx.edu)

Red shows new or modified Text 
Abstract-- We used electron backscatter diffraction (EBSD) methods to study the crystallography of olivine and other minerals in seven heavily metamorphosed (petrographic type 6 or 6/7) but variably shocked ordinary chondrites from the $\mathrm{H}$ (Kernouvé, Portales Valley), L (Leedey, Bruderheim, Morrow County, Park) and LL (Miller Range (MIL) 99301) groups. MIL 99301 contains a large clast that was analyzed separately. Mesoscale (EBSD) data support and extend inferences based on microscale (TEM) observations and provide good evidence that chondrites were shock-deformed at different temperatures and were variably annealed (sintered) after deformation. Various EBSD deformation intensity metrics adequately and quantitatively represent olivine deformation in meteorites on different scales and in different ways. Mean Grain Orientation Spread (GOS, the average misorientation in a grain) is a robust statistic for overall deformation. We developed an EBSD deformation temperature metric based on olivine misorientation rotation axis data, and an EBSD post-shock annealing metric based on the skewness of olivine GOS distributions. The two parameters together define three groups among the meteorites studied, and these are related to shock stages and ${ }^{40} \mathrm{Ar} /{ }^{39} \mathrm{Ar}$ ages that record impact times. Group 1 includes cold-deformed and little-annealed but highshock-stage (S4 and S5) chondrites (Leedey, Bruderheim, Morrow County) that were affected by impacts at a time ( $<4 \mathrm{Ga}$ ago) when parent bodies were cold. Troilite was deformed and partly recrystallized, developing a lattice preferred orientation (LPO) in Bruderheim and Morrow County that corresponds to a principal compression direction. Olivine $<001>$ axes in Morrow County were partially re-oriented perpendicular to this compression direction. Group 2 includes the hot-deformed but little-annealed MIL 99301_clast that shows good evidence of having formed as a shock melt, and which represents localized shock heating of material that cooled rapidly at a time when parent bodies may have been cold ( $4230 \mathrm{Ma}$ ago, assuming the younger of two published ages for MIL 99301, $4230 \pm 30$ and $4520 \pm 80 \mathrm{Ma}$, corresponds to the clast). Group 3 includes hot-deformed and more-annealed low-shock-stage (S1) chondrites (Kernouvé, Portales Valley, MIL 99301 host, Park) that experienced impacts on warm bodies in the oldest epoch (>4425 Ma, assuming the older of two published ages for MIL 99301 corresponds to host). Group 3 chondrites must have been shocked while warm at the time of impact, at temperatures estimated as $>700-800^{\circ} \mathrm{C}$ and up to $\sim 1000^{\circ} \mathrm{C}$, i.e., at conditions generally corresponding to thermal metamorphism associated with petrographic type 6 grade, and were subsequently buried and annealed in warm parent bodies. Impact at elevated pre- 
shock temperature resulted in partly recrystallized troilite in Park and metallic liquids that crystallized as coarse troilite interstitial to silicates in Portales Valley. For Group 3, data are consistent with impact-redistribution on warm parent bodies that were hot at depth, and support a model of early collisional processing of endogenically-heated chondritic planetesimals. In general, EBSD deformation signatures in each of the meteorites studied are dominated by the effects of the prevailing impact, although there is some evidence for multiple impact effects.

\section{INTRODUCTION}

Collisions were undoubtedly important for the physical and thermal processing of asteroid-sized planetesimals throughout solar system history, but the precise role of these processes is not clear and could have depended on the thermal state of the colliding bodies. On the one hand, impacts on cold planetesimals could have led to localized heating and a small proportion of melting (Rubin, 1995) and formed slow-cooling hot plugs beneath impact craters (Davison et al., 2012, 2013), but would have not resulted in much global heating except possibly for the collision of equal-sized porous planetesimals (Keil et al., 1997; Davison et al., 2010, 2013; Ciesla et al., 2013; however, see Rubin, 1995). Instead of impact-induced heating, fragmentation, displacement, and even catastrophic disruption of planetesimals could have been more important (Stöffler et al., 1988; Keil et al., 1994, 1997). Catastrophic disruption of a cold body is exemplified by the apparent break-up of the L chondrite asteroid $\sim 470$ Ma ago (Keil et al., 1994; Swindle et al., 2014).

On the other hand, there is increasing evidence that collisions between hot planetesimals occurred in the early solar system, and involved a different type of impactrelated thermomechanical processing. Collisions with partly molten planetesimals could have led to a variety of rock types represented by various iron meteorites, stony-iron meteorites, and achondrites (see reviews by Goldstein et al., 2009; Ruzicka, 2014; and Ruzicka et al., 2017; also Keil et al., 1994; Scott et al., 2001; Yang et al., 2007, 2010). Similarly, impacts with non-molten but warm (metamorphosing) planetesimals may have produced more-or-less scrambled chondritic parent bodies with complicated metamorphic stratigraphies (Grimm, 1985; Taylor et al., 1987; Ganguly et al., 2013, 2016; Scott et al., 2014; Ruzicka et al., 2015a; Blackburn et al., 2017). Collisions involving warm bodies are supported by diverse lines of evidence, including cooling rate models, petrologic and chemical data, thermochronometry, and mineral microstructures. Nonetheless, there is 
disagreement about the extent and timing of impact scrambling, with some thermochronometry data suggesting that the $\mathrm{H}$ chondrite parent body (in particular) could have remained substantially intact as an "onion shell" body during thermal metamorphism (Trieloff et al., 2003; Kleine et al., 2008; Harrison and Grimm, 2010; Henke et al., 2013).

In this work, we used electron backscatter diffraction (EBSD) methods to study the crystallography of seven metamorphosed ordinary chondrites, which were previously investigated with optical microscopy (OM) and transmission electron microscopy (TEM) (Ruzicka et al., 2015a), as well as with X-ray microtomography $(\mu \mathrm{CT})$ and for porosity (Friedrich et al., 2017). The overarching goal was to better understand the relationship between shock deformation and thermal processes. More specific goals were to determine whether EBSD metrics could be identified that quantitatively record deformation intensity, deformation temperature, and post-shock annealing conditions, and whether microscale observations made by TEM (Ruzicka et al., 2015a) can be reconciled with the much larger mesoscale (thin section scale) observations by EBSD. We focused on olivine for several reasons: (1) it forms the basis of the widely-used shock stage scale (Stöffler et al., 1991), (2) it is the most abundant mineral in chondrites, (3) it has well-characterized deformation behavior, and (4) it was previously characterized for TEM microstructures in the same meteorites (Ruzicka et al., 2015a). We also studied troilite as it, together with olivine, may be diagnostic for assessing pre-shock temperature (Schmitt, 2000) and could provide additional insights about deformation.

The meteorites studied include chondrites of similar petrographic type (metamorphic grade and texture) (Huss et al., 2006), but different shock stages (Stöffler et al., 1991) and inferred histories. They include H chondrites (Kernouvé-H6 S1, Portales Valley-H6/7 S1), L chondrites (Park—L6 S1; Leedey_L6 S4; Bruderheim—L6 S4; Morrow County—L6 S5) and an LL chondrite (Miller Range (hereafter MIL) 99301-LL6 S1) (Ruzicka et al., 2015a; Friedrich et al., 2017). As typical for shock stage S5 (Stöffler et al., 1991), Morrow County characteristically contains maskelynite, which probably formed as a dense feldspathic melt under high shock pressure (Chen and El Goresy, 2000). The particular shock stage S1 meteorites chosen for study were interpreted based on olivine microstructures, metal grain shape fabrics, porosities, and apparent mismatches between shock indicators as having experienced syn-metamorphic shock, post-shock annealing, or both (Rubin, 2002, 2004; Hutson et al., 2007, 2009; Ruzicka et al., 2015a; Friedrich et al., 2017). In contrast, the shock stage S4 and S5 meteorites were interpreted as having been 
heavily shocked from a cold initial condition with little annealing afterwards (Ruzicka et al., 2015a; Friedrich et al., 2017).

In previous work (Ruzicka et al., 2015a), OM was used to assign a weighted shock stage (mean shock stage) to each specimen according to the method of Jamsja and Ruzicka (2010), and representative areas were prepared via Ar ion milling for TEM analysis of dislocation character and density. For this study, thin sections were mapped using EBSD to determine deformation intensity via misorientation maps, mesoscale slip system analysis via crystal rotation axis figures, and crystallographic texture (i.e., the existence of lattice preferred orientations, or LPOs) via pole figures. LPOs can be a manifestation of deformation occurring under particular conditions, such as temperature (Mainprice and Nicolas, 1989; Ismaïl and Mainprice, 1998; Tommasi et al., 2000; Paschier and Trouw, 2005; Karato et al., 2008; Tkalcec et al., 2013). In MIL 99301, data were evaluated separately for a large, fine-grained clast and the host.

This EBSD study is one of the first to focus on heavily metamorphosed (petrographic type 6) and presumably relatively "dry" ordinary chondrite meteorites, and as such contrasts with EBSD studies of weakly metamorphosed (type 3) and volatile-rich carbonaceous chondrites such as Allende (Watt et al., 2006; Forman et al., 2016, 2017). In the latter chondrites, grain size heterogeneity and water contents could have played a more important role during deformation (Bland et al., 2014; Davison et al., 2016; Tait et al., 2016).

A preliminary report on some aspects of this work was provided by Ruzicka and Hugo (2017).

\section{SAMPLES, METHODS, METRICS AND ANALYTICAL PRECISION}

Samples for EBSD work included Cascadia Meteorite Laboratory (CML) thin sections for Kernouvé (H6, section CML0666-2A), Portales Valley (H6/7, CML0056-3), Park (L6, CML617-1A), MIL 99301 (LL6, CML0422-1), Leedey (L6, CML0504-1A), Bruderheim (L6, CML0618-2A), and Morrow County (L6, CML0497-6A). Sections were prepared for EBSD by hand polishing using a colloidal silica solution (Buehler Mastermet@, product 40-6370-006) for 35-40 minutes, followed by application of a thin (3-5 $\mathrm{nm}$ thick) coat of evaporated carbon.

The SEM-EBSD system used in this work is a Zeiss Sigma Variable Pressure-Field Emission Gun-Scanning Electron Microscope (VP-FEG-SEM), with an Oxford Instruments XMax50 energy dispersive spectrometer (EDS) with silicon-drift detector, and an Oxford Instruments NordlysNano EBSD detector with 4-diode forward scattered electron detectors. For EBSD, the 
SEM was operated at $20 \mathrm{keV}$ accelerating voltage and between 5-10 nA beam current under high vacuum. EDS maps were obtained concurrently with electron backscatter pattern (EBSP, or Kikuchi-pattern) data, and samples were tilted relative to horizontal attitude at the standard $70^{\circ}$. EBSD data were obtained and processed using integrated AZtecHKL (AZtec 3.1, 3.2) and Channel5 software. Crystal match files in HKL, American Mineralogist, and Inorganic Crystal Structure Database (ICSD) databases in AZtec software were used, including the HKL database crystal file "forsterite" ( $a=4.756 \AA, b=10.207 \AA, c=5.980 \AA)$ for olivine. Criteria for grain identification were set at a minimum of five contiguous pixels, and a critical misorientation of $15^{\circ}$, with boundary completion down to $0.5^{\circ}$. The $15^{\circ}$ value for critical misorientation (which defines "grains" as opposed to "subgrains") was used because some olivine grains with apparent internal boundary misorientations that approach this value were found in the more highly deformed chondrites (Bruderheim, Morrow County) of this study.

Both thin-section scale (large area maps, or LAMs) meant to be representative of the entire meteorites, as well as targeted maps with smaller step sizes to better show smaller-scale features, were obtained. For LAMs, data were obtained at $4 \mu \mathrm{m}$ step size (5.7 $\mu \mathrm{m}$ for Bruderheim) and cover 31.8-205.7 $\mathrm{mm}^{2}$ of the meteorites. The combination of step size interval and minimum number of contiguous pixels required for a grain means that LAM data were acquired on grains $\geq 10 \mu \mathrm{m}$ in effective diameter. For targeted maps, data were obtained between 0.76-2.7 $\mu \mathrm{m}$ step size and cover 0.28-5.6 $\mathrm{mm}^{2}$ for each map. Acquisition parameters and metadata for LAMs and targeted maps are documented in Tables EA-1 and EA-2 respectively, in the Electronic Annex.

Data for olivine were used to determine deformation intensity and character via misorientation maps and misorientation profiles, crystallographic texture via pole figures, and mesoscale slip plane analysis via crystal rotation axis (CRA) plots. For each olivine grain, effective grain size ( $d$, the diameter of a circular grain with the same area as measured) and two deformation metrics were extracted, including 1) Grain Orientation Spread (GOS), representing the value of average misorientation in the grain (Brewer et al., 2009), and 2) Maximum Orientation Spread (MOS), representing the value of maximum misorientation in the grain. Similarly, for all olivine pixels in a map, two different types of deformation metrics were determined, including 1) mean Kernal Average Misorientation (KAM), the mean misorientation between a central pixel from its surrounding eight neighbors (Brewer et al., 2009; Bingert et al., 2009), and 2) mean Grain Reference Orientation Deviation angle ( $G R O D$ angle), the mean misorientation of each pixel from a reference, mean orientation of the grain. Statistics on olivine grain boundaries were compiled, including the number of misorientation boundaries of different misorientations and the crystallographic direction of their rotation axes.

We performed no post-acquisition processing of map data to remove wild spikes or zero solutions, i.e., no "grain growth" or "cleaning" was done (Prior et al., 2009; Mishin et al., 2009; 
Brewer and Michael, 2010). Tests indicate that even with relatively "conservative" settings for such post-acquisition processing, statistical artifacts are created (evident for example with changes in a GOS distribution plot, Fig. EA-1 in the Electronic Annex). However, some targeted data with stored EBSPs were reprocessed from originally acquired data using the AZtec Refined Accuracy algorithm, to minimize mis-indexed points and to improve fits with crystal match files (i.e., to decrease mean angular deviation or MAD values). No such reprocessing of LAM data was performed, as EBSPs for large area maps were not stored owing to prohibitively large data file sizes.

In this paper, EBSD maps portray multiple types of data as composited layers. Color is assigned to some property such as GOS, GROD angle, crystal orientation given by inverse pole figure (IPF), or phase identification. Monochrome brightness is assigned to band contrast $(B C)$ that is proportional to the intensity of Kikuchi diffraction bands, which is related to crystallinity.

Pole figure and CRA plots were contoured to determine Multiples of Uniform Density (MUD) values, using $25^{\circ}$ half-width contouring. MUD values progressively $>1$ indicate greater prevalence, and values progressively $<1$ indicate greater deficiency, relative to a uniform spatial distribution. A purposely large value for half-width was chosen to better show broad trends, but it does reduce the maximum and minimum MUD values. In pole figure plots, we took the difference between maximum and minimum MUD values as a crude (but adequate) measure of relative lattice preferred orientation (LPO) strength (LPO strength $=\Delta_{i}=$ maximum MUD - minimum MUD, where $\mathrm{i}$ refers to the identity of a particular crystal plane or direction). Although the numeric value of LPO strength depends on the contouring choice, the latter does not strongly affect assessment of relative preferred orientation strength.

Analytical precision for crystallographic orientation of olivine in this work is estimated as $\leq 0.1-0.2^{\circ}$, with a similar detection limit (cf. Schwarzer et al., 2009). Our estimate is based in part on apparent noise of $\sim \pm 0.1^{\circ}$ in misorientation profiles of olivine for weakly deformed olivine grains (e.g., Fig. $1 \mathrm{~g}$ below), which implies point-to-point analytical precision of this order. In addition, KAM distributions (using bin sizes of $0.05^{\circ}$ and aggregated map data) often show frequency minima at 0.05-0.1 ${ }^{\circ}$ accompanied by an anomalously high frequency of misorientations at $0-0.05^{\circ}$, which can be explained by a difficulty to clearly resolve misorientations $<0.1^{\circ}$, and the erroneous assignment of such very low angle misorientations to the lowest values (i.e., zero). Finally, for the leastdeformed meteorites Kernouvé and Portales Valley, KAM values for olivine sharply decline in frequency below $0.10^{\circ}$ and $0.15^{\circ}$, respectively, consistent with these being approximate detection limits. Altogether, the data imply analytical precisions and detection limits for angular measurements of $\leq 0.1-0.2^{\circ}$ for olivine over both the shorter time intervals needed to collect data for individual grains, and the longer time intervals ( $\sim 2$ days) needed to collect all of the data in large area maps. 


\section{RESULTS}

Tabulated EBSD data for large area maps are presented in Tables 1, 2, and 4, and for targeted maps in Table 3. Table 1 also shows data for conventional shock stage (Stöffler et al., 1991) and weighted shock stage (Jamsja and Ruzicka, 2010) for the meteorites. These data have implications for deformation systematics in olivine and troilite, slip systems in olivine, post-shock annealing, and the significance of lattice preferred orientations, topics explained and discussed in Sec. 4. Here we first present and describe representative EBSD maps for olivine and troilite in these meteorites and the clast in MIL 99301 (Figs. 1-5).

\subsection{Olivine in Portales Valley, Kernouvé, and MIL 99301 host}

The shock stage S1 meteorites Portales Valley (Fig. 1), Kernouvé, and the host lithology for MIL 99301, contain olivine grains that show similar deformation features. These meteorites are dominated by little-deformed olivine with low values for EBSD deformation metrics such as mean $\operatorname{GOS}\left(\operatorname{GOS}_{d>50} \sim 0.63-0.91^{\circ}\right)$, mean MOS $\left(\operatorname{MOS}_{d>50}\right.$ $\left.\sim 3.3-4.0^{\circ}\right)$, mean $K A M\left(K A M_{d>50} \sim 0.31-0.55^{\circ}\right)$, and mean GROD angle $\left(\sim 0.67-0.99^{\circ}\right)$ (Table 1, Fig. 1). (The $d>50$ subscript refers to data for $d>50 \mu \mathrm{m}$ grains.) A significant feature of olivine in these meteorites, however, is the presence of a small population of grains with elevated GOS (Fig. 1a, 1c). This is mainly caused by the presence of grains that contain subgrain boundaries, along which sharp changes in misorientation occur (Fig. 1d, 1f). Aside from the subgrain boundaries, these grains have little misorientation (Fig. 1d, 1f). Elevated-GOS grains in these meteorites occur adjacent to olivine grains that lack subgrain boundaries and that have little misorientation (Fig. 1).

\subsection{Olivine in Bruderheim, Leedey, Morrow County}

Different are the shock stage S4 and S5 meteorites Bruderheim (Fig. 2), Leedey, and Morrow County. Compared to the previous meteorites, these contain more-deformed olivine with higher values for EBSD deformation metrics such as mean GOS $\left(G O S_{\mathrm{d}>50}\right.$ $\left.\sim 3.1-4.1^{\circ}\right)$, mean $\operatorname{MOS}\left(\operatorname{MOS}_{\mathrm{d}>50} \sim 12-15^{\circ}\right)$, mean $K A M\left(K A M_{d>50} \sim 1.5-2.7^{\circ}\right)$, and mean GROD angle ( 3.0-4. $1^{\circ}$ ) (Table 1, Fig. 2). Their olivine grains typically contain subgrain boundaries as well as more gradual but significant changes in misorientations, here termed "warpings" (Fig. 2c, 2e, 2f). Such warpings include, but are not limited to, grains that show lamellar extinction with OM and which are revealed by EBSD to have banded misorientation domains with fold-like misorientations (grain 7 in Fig. 2c, 2e). Olivine grains 
in these meteorites typically contain subparallel fractures and boundaries along which misorientation occurs (Fig. 2c). These features correspond to the "planar fractures" and "planar deformation features" (PDFs) in the Stöffler et al. (1991) shock stage classification and in high-strain-rate experiments (Müller and Hornemann, 1969; Schmitt, 2000; Langenhorst et al., 2002). Some fractures contain open voids or non-crystalline material, others are filled with crystalline material, and still others show lateral displacement (Fig. 2c). The crystalline material in the Bruderheim fractures shown for olivine grains 7 and 8 in Fig. $2 \mathrm{c}$ is dominated by orthopyroxene, diopside, and feldspar that mineralogically resembles the inter-olivine mesostasis in this chondrule area; such mesostasis may have been injected into the fractures.

\subsection{Olivine in Park}

Olivine grains in the shock stage S1 meteorite Park have a somewhat intermediate character. Most of the grains are relatively little-deformed, like those in Portales Valley, Kernouvé, and the MIL 99301 host. But compared to these meteorites, Park has a larger number of more-deformed grains (Fig. 3a, 3b), resulting in higher average values of EBSD deformation metrics, including mean GOS $\left(G O S_{d>50} \sim 1.3^{\circ}\right)$, mean $M O S\left(M O S_{d>50} \sim 5.9^{\circ}\right)$, mean $K A M\left(K A M_{\mathrm{d}>50} \sim 0.49^{\circ}\right)$, and mean GROD angle $\left(\sim 1.3^{\circ}\right)$ (Table 1). The elevated-GOS grains in Park are of two types that differ in their deformation features. Some are dominated by subgrain boundaries with little other internal deformation (grain 20 in Fig. 3c and 3e). These resemble the elevated-GOS grains found in Portales Valley, Kernouvé, and the MIL 99301 host. Other elevated-GOS grains in Park are dominated by more gradual gradients in deformation (warpings) and also contain subgrain boundaries (grain $20 \mathrm{a}$ in Fig. 3c and 3f). Included in the latter grain type are those with lamellar misorientation indicative of fold-like warpings. These are reminiscent of grains in Bruderheim, Leedey, and Morrow County. Thus, olivine in Park has attributes of both lessdeformed and more-deformed meteorites. The two types of elevated-GOS grains overlap in grain sizes and GOS values (grains 20 and 2a in Fig. 3c), and can have crystal sizes and even crystal orientations that resemble nearby low-GOS grains (grain 20b in Fig. 3c). Thus, there is no evidence that differences in grain deformation character depend on grain size, overall location, or crystal orientations.

\subsection{MIL 99301 clast}

MIL 99301 is unique among the meteorites studied in containing a large $(>0.5-\mathrm{cm}-$ diameter), metal- and troilite-poor, crystalline clast with distinctive texture (Fig. 4). Olivine 
grains in the clast, particularly larger grains, have high values of deformation metrics such as GOS compared to olivine in the host (Table 1, Fig. 4a-c). GOS values in clast grains close to the host tend to be high, but not as high as some other larger grains further from the contact (Fig. 4a). In contrast, there is no apparent tendency for GOS values in host olivine to change systematically towards the clast (Fig. 4a). Similarly, KAM values for olivine tend to be slightly higher in the clast close to the clast-host contact, but no spatial variation in $K A M$ is evident in host olivine relative to the clast. Mean deformation metrics for olivine in the clast are similar to or somewhat lower than those in Leedey (Table 1). As in other deformed meteorites, misorientation in clast olivine is caused by many subgrain boundaries as well as by warpings.

The texture of the clast is not chondritic, but instead dominated by fine-grained skeletal-radiating-dendritic olivine that has common crystallographic orientations in different parts of the clast (Fig. 4d-f). The orientation domains for olivine have irregular, interlocking edges (Fig. 4d). Overall, olivine in the clast has a strong lattice preferred orientation (LPO). For clast olivine, there are two dominant, broadly common orientations of $<010\rangle$ that are nearly orthogonal to one another (orange-yellow-green for orientation 1 and blue/red for orientation 2 in the IPFy colors of Fig. 4d, forming two broad clusters in the $<010>$ pole figure plot of Fig. 4e). These two common orientations in $<010>$ are themselves split into two different orientations for $<100>$ and $<001>$ (clearly seen with the blue and red points for orientation 2 in the $<100>$ and $<001>$ pole figure plots of Fig. 4 e). All of this suggests a 3D network of olivine defined by crystal orientation.

Detailed observations were made of the clast-host contact and nearby regions. The contact is somewhat convolute, relatively sharp but marked by a fracture in places, and shows evidence for interfingering between the clast and host metal and troilite (Fig. 4d, 4f). Taenite that appears to be partly in and partly out of the clast in one area of the 2D section has a common crystal orientation (locations $x$ and $y$ in Fig. 4f-g) indicating that it is probably one grain connected in the third dimension. The taenite at location $y$ at the contact is an intergrowth with troilite. This taenite is connected (via intervening kamacite) to more taenite in the host with a different orientation (location z in Fig. 4f-g). Moreover, GOS values in this taenite increase systematically away from the clast into the adjacent host (Fig. 4g). Nearby troilite in contact with and extending away from the clast (Fig. 4f, representing a single grain with the same orientation of troilite in the metal-troilite intergrowth at location y) also shows increased deformation (higher values of KAM) away 
from the clast into the host. No recrystallization textures (interlocking equant grains with high angle grain boundaries meeting at $120^{\circ}$ triple junctions) are evident in either metal or troilite close to the clast-host contact or elsewhere in MIL 99301. However, one area of olivine close to the contact and apparently in the host does contain recrystallized texture (Fig. 4d). GOS values in these grains are low $\left(<1^{\circ}\right)$, as expected for recrystallization.

\subsection{Troilite}

EBSD data for troilite in the seven meteorites are given in Table 4 and Fig. 5. The shock stage S4 and S5 meteorites Leedey, Bruderheim, and Morrow County all contain polycrystalline troilite grains composed of a mix of weakly deformed and strongly deformed grains (Fig. 5a, 5b; Table 4). The weakly-deformed grains are attributed to deformationinduced recrystallization, as they have low GOS values ( $<1^{\circ}$ and typically $<0.5^{\circ}$ ), are bounded by high-angle grain boundaries $\left(>15^{\circ}\right)$ that sometimes meet in equigranular triple junctions, and are often associated with adjacent high-GOS grains that contain subgrain boundaries and warpings (Fig. 5a).

The mixture of recrystallized and deformed troilite grains in these meteorites can be identified in GOS frequency plots, with large area map data indicating a bimodal distribution in Leedey, a prevalence of low-GOS grains with a tail to higher-GOS grains in Bruderheim, and a prevalence of low-GOS grains in Morrow County (Table 4). Troilite in Morrow County has especially coarse polycrystallinity, with domain sizes of $\sim 50-200 \mu \mathrm{m}$ across (Fig. 5b). These characteristics suggest progressive dynamic recrystallization (recrystallization during deformation) of troilite with increasing shock stage (S4 to S5) from Leedey, through Bruderheim, and finally to Morrow County.

The shock stage $\mathrm{S} 1$ chondrite Park also contains polycrystalline troilite, but it is much finer grained than in the shock stage S4-S5 meteorites, with domain sizes typically $\leq 10 \mu \mathrm{m}$ across (Fig. 5c). As for Leedey, Bruderheim, and Morrow County, the troilite in Park contains a mixture of low-GOS (recrystallized) and high-GOS grains (Fig. 5c). In Fig. $5 \mathrm{c}$, deformed grains have GOS values up to $\sim 13-17^{\circ}$ and are larger than the low-GOS grains with values of $\leq 0.5^{\circ}$. This suggests replacement of heavily-deformed grains by smaller recrystallized ones. The GOS frequency distribution based on the large area map of Park differs somewhat from the shock stage S4 and S5 meteorites, showing no bimodality or tails but instead a large spread in values, with many $3-8^{\circ}$ grains and a broad frequency maximum of $\sim 5^{\circ}$ (Table 4 ). 
Very different is troilite in the shock stage $\mathrm{S} 1$ chondrites Portales Valley, Kernouvé, and MIL 99301 host, all of which have weakly-deformed monocrystals (isolated, individual grains) with comparatively few subgrain boundaries (Table 4). However, a unique feature in Portales Valley is a strong lattice preferred orientation created by adjacent grains with the same orientation in large (multi-millimeter) areas (Fig. 5d, Table 4). This suggests that the apparently separate monocrystals in a given 2D section of Portales Valley are actually connected in the third dimension and occur as multi-millimeter-sized crystals in the interstices of silicates. This supports the optical microscopy observation made previously for Portales Valley (Pinault et al., 1999; Scott and Pinault, 1999).

\section{DISCUSSION}

\subsection{Deformation systematics and correspondence with previous work}

EBSD olivine data for the seven meteorites allow an evaluation of the various deformation metrics and a comparison with previous OM and TEM data. Deformation metrics are compared in Fig. 6-8, and other plots are shown in Fig. EA-2, EA-3, and EA-4 in the Electronic Annex. The data collectively provide evidence for systematics in deformation intensity across the range of shock stages ( $\mathrm{S} 1$ to $\mathrm{S} 5$ ) recorded by the seven meteorites and the two lithologies (clast and host) in MIL 99301.

\subsubsection{Deformation metrics}

Mean values of EBSD deformation metrics based on LAM data (Table 1) correlate with one another. Mean KAM, GOS, and MOS are highly correlated $\left(r^{2}\right.$ values of 0.999 for GOS-KAM and 0.980 for MOS-KAM) for Park, the MIL 99301 clast, Leedey, Bruderheim and Morrow County (Fig. 6). Correlations are poorer between mean GROD angle and mean KAM $\left(r^{2}=0.88\right)$ and between mean GROD angle and mean GOS $\left(r^{2}=0.89\right)$ for these meteorites and lithologies. Data for Kernouvé, Portales Valley, and MIL 99301 host slightly fall off the well-defined GOS-KAM and MOS-KAM trends to lower GOS or MOS (or higher KAM) at low values of these parameters (Fig. 6), though it is unclear if this displacement is significant.

The overall correlations shown in Fig. 6 imply that Bruderheim is the most deformed, and Portales Valley and Kernouvé are the least deformed, when all olivine pixels and olivine grains of all sizes are considered. Furthermore, the high correlation coefficients imply that analytical uncertainty (precision) is far less than the $1 \sigma$ (standard deviation) values for GOS and MOS (Fig. 6, Table 1). This suggests the $1 \sigma$ values reflect 
real heterogeneity in the meteorites and not analytical error. This is supported by estimates of analytical precision that imply small errors (Sec. 2), much less the $1 \sigma$ values for GOS and MOS.

Among the various deformation metrics, we consider mean GOS to be one of the most robust statistics for overall deformation. GROD angle is useful for visualizing intragrain deformation (Fig. 1-3), but it is less well correlated with other deformation metrics, making its use as a deformation statistic questionable. Although mean KAM, GOS, and MOS are well correlated, within meteorites GOS varies less than KAM from area to area and so may be less susceptible to spatial variability. For example, mean GOS values for targeted map areas (Table 3) fall within the $1 \sigma$ values for GOS derived from large area maps (Table 1), but KAM varies more widely (Fig. EA-2). We further consider GOS to be superior to MOS as a metric for overall average grain deformation, as the former reflects a central tendency for grain deformation (average orientation spread) whereas the latter is more strongly influenced by deformation excursions (maximum orientation spread). However, compared to GOS, KAM better records deformation on a smaller scale and MOS better highlights grains with deformation extremes.

The relationship between olivine deformation determined from EBSD and optical data is best evaluated by considering larger $(>50 \mu \mathrm{m})$ grains that are the focus of optical studies. Fig. 7 compares weighted shock stage values as determined optically with mean $G O S_{d>50}$ and mean $M O S_{d>50}$ values for $d>50 \mu \mathrm{m}$ grains based on large area maps (Table 1). Good correlations are found $\left(r^{2}=0.94\right.$ for GOS-weighted shock stage, $r^{2}=0.97$ for MOS-weighted shock stage). The slightly higher correlation for MOS implies that it somewhat better represents optical observations. This could indicate that shock stages based on optical observations are slightly biased towards recording misorientation extremes than a more statistically "average" grain misorientation as recorded by GOS. In any case, both EBSD GOS-MOS and OM petrographic data suggest coarse olivine grains record the lowest deformation in Portales Valley and Kernouvé, and the highest in Morrow County (Fig. 7). However, EBSD GOS and MOS data indicate Bruderheim is nearly as deformed as Morrow County for coarse grains, more so than would be expected based on optical petrography.

Fig. 8 compares average geometric dislocation density in olivine based on TEM observations (Ruzicka et al., 2015a) with mean KAM and GOS values based on large area maps. Very different scales are represented by these data: microscale for TEM, and 
mesoscale for EBSD. Nevertheless, Fig. 8 demonstrates that for the L6 chondrites Park, Leedey, Morrow County, and Bruderheim, dislocation density is highly correlated with KAM and GOS $\left(r^{2}\right.$ values of 0.978 for GOS-dislocation density and 0.987 for KAM-dislocation density). The similar correlation coefficients imply that GOS corresponds with dislocation density nearly as well as with $K A M$, which as a measure of small-scale deformation might have been expected to correlate the best with TEM data.

Kernouvé, Portales Valley, and the host for MIL 99301 are displaced dramatically off the GOS-KAM-dislocation density trends to lower dislocation densities (Fig. 8). These three meteorites were identified as having undergone microstructural recovery that concentrated dislocations in subgrain boundaries and reduced overall dislocation densities (Ruzicka et al., 2015a). The significant displacement off the GOS-KAM-dislocation trends to lower dislocation densities for the three meteorites could indicate that TEM observations underestimate the deformation of grains. This could arise by having subgrain boundaries that contain dislocations outside of the TEM field-of-view, leading to artificially low estimates of dislocation densities. This would be more of a potential problem for meteorites that contain olivine with subgrain boundaries and little deformation otherwise.

Altogether, it appears that the mean values of various EBSD metrics such as GOS, MOS, and KAM adequately and quantitatively represent olivine deformation in meteorites on different scales and in different ways. GROD angle is more useful for visualizing intragranular deformation.

\subsubsection{Grain size}

The relationship between deformation intensity and grain size can be evaluated using LAM data by comparing GOS and KAM metrics for coarser $(>50 \mu \mathrm{m})$ and finer $(<50$ $\mu \mathrm{m}$ ) grains (Table 1). This can be expressed compactly in terms of mean $G O S_{d>50} / G O S_{d<50}$ and mean $K A M_{d>50} K A M_{d<50}$ values, with ratio values $>1$ indicating more deformation in coarser grains and ratio values $<1$ indicating less deformation in coarser grains.

The values of these ratios for the different meteorites and lithologies are weakly correlated, with the MIL 99301 clast having the highest values (especially for GOS ratio); and Park, the MIL 99301 host, Bruderheim, and Leedey having the lowest values. An overall relationship between the two ratios is not necessarily surprising, given the overall correlations between the GOS and KAM metrics discussed above. However, these ratios are not directly related to overall deformation intensity (as measured by either GOS or $K A M)$. 
The answer to the question of whether coarser or finer grains are more deformed depends on the metric being used. The data indicate that mean GOS values are consistently higher in coarser grains, and that mean KAM values are consistently lower in coarser grains. That is, data fall into a parameter space with mean $G O S_{\mathrm{d}>50} / G O S_{\mathrm{d}<50}>1$ and mean $K A M_{\mathrm{d}>50} / K A M_{\mathrm{d}<50}<1$ (Fig. EA-3). This seems to indicate that larger grains are always more deformed than smaller grains on the scale of the grains (as measured by GOS), but that larger grains are always less deformed than smaller grains on a smaller, 9pixel scale (as measured by KAM).

A possible explanation for these observations is that deformation is always concentrated in areas of limited spatial extent such as misorientation or subgrain boundaries (either those produced by recovery or directly by deformation as kink bands), which are indeed common in olivine (Table 2). Misorientation of crystals across such deformed bands in coarse grains can cause large portions of the crystals to be rotated into different orientations, contributing much to GOS but less to KAM if the crystal has relatively little additional misorientation between the bands. This would make larger grains appear to have higher GOS values than smaller. If this explanation is correct, one can consider smaller grains as being more deformed than larger (based on KAM), but larger grains as recording and amplifying the effects of deformation bands on a scale larger than the bands (based on GOS). That is, in larger grains deformation bands can be associated with relatively small $K A M$ values for the grains if the deformation bands are small in area, but to larger GOS values if the deformation bands result in crystal rotations. In smaller grains, deformation bands can result in high KAM, but the smaller size of the crystals will limit overall rotation effects in the grain and keep GOS from reaching much higher values. In this way, KAM and GOS values can differ between smaller and larger grains.

\subsection{Origin of the large clast in MIL 99301}

We suggest that the large clast in MIL 99301 (Fig. 4) crystallized as a shock melt that was emplaced into the host as a hot intrusion. The overall texture of the clast and the lattice preferred orientation for olivine in it can be explained by rapid crystallization from a melt, producing fine-grained skeletal-radiating-dendritic olivine with common crystallographic orientations established by rapid growth, and possibly aided by accompanying deformation, of olivine in clusters. The two dominant $<010\rangle$ orientations for olivine in the clast are roughly orthogonal to one another, which could indicate that this was the most kinetically favored way for olivine to crystallize in the melt volume. In any 
case, the two main $<010>$ orientations are each further split into two preferred orientations for $<100>$ and $<001>$, implying rotation of olivine around $<010>$ axes to create the dominant textural fabric of the clast.

The tight fitting and interfingering contact between clast and host can be explained by emplacement of the clast as a hot, ductile, intrusive body. This would have allowed the space between clast and host to become filled more completely than would be the case if the clast was cold and brittle during emplacement.

As textures suggest the clast could have been fully molten initially, deformation of the clast must have occurred after formation of the melt. However, data suggest that the final emplacement process into the host must have been relatively gentle, and that most deformation preceded emplacement. There is no evidence for a spatial gradient in deformation (or annealing) character for host olivine grains with respect to the clast-host contact, as would be expected if the host was deformed (or annealed) as a result of clast emplacement. Higher values of KAM and GOS in clast olivine closer to the clast-host contact suggest deformation of already-crystallized olivine as the clast was emplaced into the host, but this effect involved only slight marginal deformation, indicating that the clast was mostly deformed elsewhere and before final emplacement.

Although the host may have experienced little overall heating during clast emplacement, there is evidence for heating at the immediate clast-host contact. Some host taenite and troilite grains in contact with the clast show a pattern of increasing deformation away from the clast. This suggests either localized partial melting or preferential annealing (recovery) of defects in metal and troilite, both caused by excess heat from the clast melt. For either localized melting or annealing, a steep thermal gradient between clast and host is implied, such as might be expected for a smaller volume of hot clast and larger volume of cold host. We prefer the explanation of partial melting, as it can explain the metal-troilite intergrowth at the contact that is consistent with the formation of an S-bearing metallic melt, and can explain a general lack of subgrain boundaries in the weakly-deformed portions of metal and troilite.

From this discussion we infer that the clast was emplaced while above the metaltroilite eutectic temperature $\left(\sim 950^{\circ} \mathrm{C}\right.$; Usselman, 1975). It also follows that clast olivine was largely deformed above the silicate solidus $\left(\sim 1100^{\circ} \mathrm{C}\right.$; Takahashi, 1983$)$ prior to emplacement. If the clast was deformed during rapid crystallization of a shock melt and 
intruded while still warm into the host, as our observations imply, it would indicate that clast deformation preceded host deformation.

\subsection{Deformation (and pre-shock) temperature}

\subsubsection{Slip system analysis}

Misorientation boundary data for olivine based on large area maps (Table 2) and for targeted areas (Table 3) derived from CRA plots allow inferences to be made of the slip systems that were responsible for deformation (de Kloe et al., 2002; Farla et al., 2011). The rotation axis produced by a dislocation array is determined by the Burger's vector $\mathbf{b}$ (slip direction), the dislocation character (edge or normal), and the slip plane. Edge dislocations, which are constrained to lie in a given slip plane, produce rotation axes parallel to $\mathbf{b} \times \mathbf{n}$, where $\mathbf{n}$ is the slip plane normal (Raleigh, 1965, 1968; Kirby and Wegener, 1978; Lloyd et al., 1997). Conversely, screw dislocation arrays, which can slip on any close-packed plane containing $\mathbf{b}$, produce rotation axes parallel to $\mathbf{n}$. Thus, for example, a CRA plot intensity maximum at [100] can be explained by $\mathbf{b}=[001]$ edge arrays on (010), or by $\mathbf{b}=[001]$ screw arrays on (100).

For our purposes, most critical is ascertaining slip direction, which for olivine is mainly either $c$-type [001] slip at lower temperature, or a-type [100] slip at higher temperature (Raleigh, 1967, 1968; Carter and Ave'Lallemant, 1970; Carter, 1971; Phakey et al., 1972; Green and Radcliffe, 1972; Blacic and Christie, 1973; Green, 1976; Gueguen and Nicolas, 1980; Mainprice and Nicolas, 1989; Tommasi et al., 2000; Tielke et al., 2016). In laboratory experiments at low pressure (5-33 kb), low presumed water content, and strain rates of $\sim 10^{-3}$ to $10^{-6} \mathrm{~s}^{-1}$, $\mathrm{c}$-type slip is prevalent below $700{ }^{\circ} \mathrm{C}$, whereas a-type slip begins to appear above $700-800{ }^{\circ} \mathrm{C}$ and becomes prevalent above $900-1000{ }^{\circ} \mathrm{C}$ (Raleigh, 1968; Carter and Ave' Lallemant, 1970; Carter, 1971; Goetze, 1978; Gueguen and Nicolas, 1980; Mainprice and Nicolas, 1989; Karato et al., 2008). This behavior is due to temperature dependence of lattice friction (Pierl's barrier) of a-type and $c$-type slip systems (Mussi et al., 2014; Durinck et al., 2007). At low temperature, the lower lattice friction of $c^{-}$ type dislocations favors their formation despite a longer Burger's vector. At high temperature, lattice friction is overcome thermally and a-type slip becomes favored. Moreover, at the lowest temperature, the lower lattice friction on $c$-type edge segments relative to screw segments leads to faster propagation and annihilation of edge segments (Durinck et al., 2007; Demouchy et al., 2013; Mussi et al., 2014; Idrissi et al., 2016), producing a characteristic microstructure dominated by near-perfect screw orientation 
(Green, 1976; Phakey et al., 1972; Gaboriaud et al., 1981). As the temperature increases, the still-predominant $c$-type dislocations become curved, and cross-slip on $\{\mathrm{hk} 0\}$ planes is activated.

Although the slip system in olivine has a well-established dependence on temperature, other variables can be important, such as strain rate (Raleigh, 1968; Carter and Ave'Lallemant, 1970; Carter, 1971; Tielke et al., 2016), deviatoric stress (Goetze, 1978; Karato et al., 2008; Tielke et al., 2016), pressure (Carter and Ave' Lallemant, 1970; Carter, 1971), and water content (Karato et al., 2008). In our analysis we assume that temperature is the principal control on slip direction. Strain rate and pressure have a counteracting tendency on the transition temperature of $c$-type to a-type slip, with increasing strain rate increasing, and increasing pressure decreasing, the transition temperature (Carter and Ave' Lallemant, 1970; Carter, 1971). This has the result that the transition temperature for conditions relevant for shock (with representative strain rate $\sim 10^{8}$ $\mathrm{s}^{-1}$, Carter, 1971; and representative pressure of $\sim 10 \mathrm{GPa}$, Stöffler et al., 1991 and Sharp and DeCarli, 2005) is approximately the same as in experiments, using the strain rate and pressure dependencies quoted by Carter (1971). With high water contents, $c$-type slip is promoted, even at high temperatures (Karato et al., 2008). However, we infer that water probably did not play a major role in the deformation of type 6 ordinary chondrites, which are relatively dry (Jarosewich, 1990).

As overall deformation increases in olivine from one meteorite to another, the number of misorientation boundaries of all angles increases (Table 2), with a greater proportion of higher-angle $\left(2-10^{\circ}\right)$ and lesser proportion of lower-angle $\left(0.5-2^{\circ}\right)$ boundaries (Fig. EA-4). This suggests that much of the deformation in olivine from the chondrites is associated with $2-10^{\circ}$ subgrain boundaries. Besides recording more significant deformation, the $2-10^{\circ}$ misorientations are arguably better determined than $<2^{\circ}$ misorientations, leading us to focus on the former more.

Fig. 9 shows CRA plots for all meteorites and lithologies based on large area map data, illustrating misorientation rotation axis directions for $2-10^{\circ}$ boundaries in an olivine crystal frame. The plots in Fig. 9 are arranged in terms of increasing mean $G O S_{d>50}$ values. As shown in this figure, broad maxima in rotation axes tend to occur in low-index $<100>$, $<010>$, and $<001>$ directions of olivine, but patterns vary by meteorite.

Fig. 10 schematically shows how the data in Fig. 9 can be interpreted in terms of slip systems in olivine and how these correlate with temperature. Evidently, different slip 
systems in olivine were activated in different meteorites, consistent with differences in deformation temperature.

\subsubsection{Olivine slip systems for Leedey, Bruderheim, Morrow County}

Rotation axes in $<100>$ directions are especially common for Leedey, Bruderheim, and Morrow County (Fig. 9f-h). This can be explained by c-type slip (Fig. 10), which is consistent with the prevalence of $\mathbf{b}=[001]$ (mainly screw) dislocations in these meteorites (Ruzicka et al., 2015a), and with shock deformation in general (Ashworth and Barber, 1975; Sears et al., 1984; Ashworth, 1985; Langenhorst et al., 1995; Leroux, 2001). For Leedey, CRA data imply almost exclusively $(100)[c]$ or $(010)[c]$ slip, whereas for Bruderheim and especially Morrow County, the data imply an increasing proportion of $\{$ hk0\}[C] slip (Fig. 10). These meteorites may have experienced differences in dynamic (shock-induced) heating. Microhardness experiments on olivine indicate that (100)[c] slip is predominant at temperatures $<600^{\circ} \mathrm{C}$, and that both this and $\{110\}[c]$ slip occur at temperatures $>600^{\circ} \mathrm{C}$ (Gaboriaud et al., 1981). This could indicate heating to $>600^{\circ} \mathrm{C}$ for Morrow County, and to $<600^{\circ} \mathrm{C}$ for Leedey, with Bruderheim intermediate. Dynamic heating for Morrow County was previously suggested based on TEM microstructures (Ruzicka et al., 2015a).

Moreover, rotation axis directions in Morrow County extend all the way to $<010>$ (Fig. 9h). <010> rotation axes can be explained by slip in either the $<001>$ or $<100>$ directions, or by slip in both directions, such as for (001)[a] edge, (100)[c] edge, or (010)[a or $c$ ] screw (Fig. 10). For Morrow County, a-type slip is confirmed by the presence of some $\mathbf{b}=[100]$ dislocations in olivine (Ruzicka et al., 2015a). Given that a-type slip begins to appear at temperatures above $\sim 700-800^{\circ} \mathrm{C}$, Morrow County olivine could have been heated briefly to these temperatures. This compares to a temperature increase of $\sim 700$ $900{ }^{\circ} \mathrm{C}$ estimated for shock stage S5 meteorites such as Morrow County, assuming the applicability of shock experiment calibrations (Stöffler et al., 1991; Schmitt, 2000).

Given all available data, we suggest an impact heating temperature of $\sim 700{ }^{\circ} \mathrm{C}$ for

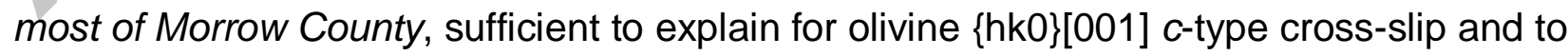
begin initiation of a-type slip.

\subsubsection{Olivine slip systems for Portales Valley, Kernouvé, and MIL 99301 host}

The CRA patterns for Portales Valley, Kernouvé, and the MIL 99301 host are similar, with rotation axis maxima in the $<100>$ direction, and weaker secondary maxima in the $<001>$ (all three meteorites) and <010> directions (Kernouvé, MIL 99301 host) (Fig. 
9a-c). For Kernouvé, a CRA band extends from $<100>$ to $<010>$. Unlike for other meteorites, the three meteorites have partial (Portales Valley, Kernouvé) to complete (MIL 99301) CRA bands between $<100>$ and $<001>$ (Fig. 9).

These data for Portales Valley, Kernouvé, and the MIL 99301 host imply slip in multiple systems, such as (010)[c], (010)[a], (001)[a], and \{hk0\}[C] (Fig. 9, 10). This is consistent with the presence of both $\mathbf{b}=[001]$ and $\mathbf{b}=[100]$ dislocations in these meteorites, sometimes observed together in the same subgrain boundaries (Ruzicka et al., 2015a). In addition, some $\mathbf{b}=[101]$ dislocations were found in subgrain boundaries (in Portales Valley, possibly present in the other meteorites). These are not known to constitute an active slip direction in olivine (Tommasi et al., 2000), but their presence could indicate interaction of $\mathbf{b}=[001]$ and $\mathbf{b}=[100]$ dislocations during deformation (Gaboriaud and Denanot, 1982; Ruzicka et al., 2015a). Mixed boundaries with different proportions of both a-type and ctype slip could explain the distinctive trace of rotation axes extending between the $<100>$ and $<001>$ directions in the three meteorites. Based on the CRA patterns, Portales Valley has fewer such mixed boundaries and MIL 99301 host the most (Fig. 9a-c). Overall, the presence of both a-type and $c$-type slip in these meteorites can explain their CRA patterns. Elevated temperature $\left(>700-800{ }^{\circ} \mathrm{C}\right.$ ) for deformation in Portales Valley, Kernouvé, and the MIL 99301 host is implied based on the presence of significant a-type slip.

\subsubsection{Olivine slip systems for Park and MIL 99301 clast}

CRA plots for olivine in Park and the MIL 99301 clast have a prevalent <010> rotation maximum (Fig. 9d-e). Rotation axis directions extend from $<010>$ part way to $<100>$, and for the MIL 99301 clast, there is a secondary maximum in the $<100>$ direction. A prevalence of rotation around $<010>$ in olivine from the MIL 99301 clast based on the CRA pattern is consistent with pole figure data and the crystallographic texture of the clast (Sec. 3.4, 4.2).

We attribute the CRA patterns for Park and MIL 99301 clast to the presence of multiple slip systems, with both $c$-type and a-type slip, consistent with the presence of both $\mathbf{b}=[001]$ and $\mathbf{b}=[100]$ dislocations in Park (Ruzicka et al., 2015a). (The MIL 99301 clast was not studied with TEM.) Given the lower prevalence of pure c-type slip compared to Leedey, Bruderheim, and Morrow County, higher deformation temperatures for Park and the MIL 99301 clast are implied, at least $>700-800^{\circ} \mathrm{C}$ (Fig. 10). Elevated deformation temperature was previously inferred for Park based on a variety of TEM data (Ruzicka et al., 2015a), and is consistent with the inferred origin of the MIL 99301 clast by shock 
melting and accompanying deformation (Sec. 4.2). For the clast, olivine deformation may have largely occurred at $>1100^{\circ} \mathrm{C}$ (Sec. 4.2).

\subsubsection{Slip system systematics and EBSD deformation temperature metric}

A critical parameter is the proportion of a-type and $c$-type slip. In none of the meteorites examined is a-type slip dominant. Thus, we generally ascribe a maximum deformation temperature of $\sim 1000{ }^{\circ} \mathrm{C}$ to all of them, although the MIL clast could have been deformed at somewhat higher temperatures. On the other hand, as discussed above the prevalence of c-type slip in some meteorites suggests deformation temperatures as low as $<600{ }^{\circ} \mathrm{C}$.

The fraction $f$ of rotation axis directions centered on low-index directions of olivine as inferred from large area map data are summarized in Table 2 for three different misorientation angles, and are plotted in a ternary diagram in Fig. 11 for $2-10^{\circ}$ and $0.5-2^{\circ}$ misorientations. We identify data points in Fig. 11 plotting towards the $<100>$ vertex as indicative of low-temperature slip, towards the $<001>$ vertex as high-temperature slip, and towards the $<010>$ vertex as intermediate-temperature slip (with the latter assuming a combination of $<100>$ and $<001>$ slip directions), consistent with Fig. 10 and the discussion above. This ternary diagram ignores spatial complexities in the CRA plots and considers only the relative proportion of axes in the low-index directions, but more clearly shows these relative proportions.

In Fig. 11, 2-10 ${ }^{\circ}$ misorientation data for Leedey, Bruderheim, and Morrow County plot strongly in the low-temperature slip regime, and Park plots strongly in the intermediate-temperature slip regime. MIL 99301 host, MIL 99301 clast, Kernouvé, and Portales Valley plot in a more central region of the diagram, not strongly in any of the endmember regimes, but clearly not in the low-temperature regime.

For $0.5-2^{\circ}$ misorientations, most data tend to plot in a more central region of the ternary compared to the $2-10^{\circ}$ data (Fig. 11). This could indicate that $2-10^{\circ}$ misorientations generally provide more discriminating information about slip systems. The exceptions are for those weakly-deformed meteorites (MIL 99301 host, Kernouvé, and Portales Valley) that have a higher proportion of $0.5-2^{\circ}$ misorientations (Table 2, Fig. EA-4). The $0.5-2^{\circ}$ data more clearly suggest higher deformation temperatures for Kernouvé and MIL 99301 host than for Portales Valley (Fig. 11).

We use a metric for inferred relative deformation temperature, designated $\left(\mathrm{f}_{<001>}+\right.$ $\mathrm{f}_{<010\rangle}$ ), which is equal to the sum fraction of rotation axis directions in $<001>$ and $\left.<010\right\rangle$ 
based on $2-10^{\circ}$ misorientations (Table 2). This parameter measures the prevalence of slip systems other than for pure $c$-type slip. With this formulation, data points plotting further from the $<100>$ rotation direction in Fig. 11 correspond approximately to higher temperature. The deformation temperature parameter increases in the sequence (brackets indicate similar values, Table 2): [Bruderheim $\leq$ Leedey Morrow County] $<$ [Portales Valley $\leq$ Kernouvé $\leq$ MIL 99301 host $\sim$ MIL 99301 clast] $<$ [Park].

The proposed metric should give a first-order indication of relative deformation temperature. But it does not accurately distinguish the small differences in dynamic heating inferred for the first three meteorites, which may have been heated too briefly to result in much a-type slip. Also, the metric has inherent uncertainty at the high-temperature end. If it is reformulated to weight $<001>$ rotations twice as much as $<010>$ rotations (under the assumption that the former reflects pure a-type slip whereas the latter probably reflects both a-type and c-type slip), MIL 99301 host and Park would have nearly the same implied high temperature. Finally, inferences about temperatures depend on the particular misorientation angles chosen to define slip systems, as mentioned above.

Thus, given the uncertainties we cannot be too sure about the details of the relative sequence given by the deformation temperature parameter. However, the metric is sensitive to the overall proportion of $c$-type and a-type slip, and on this basis we can be fairly sure that deformation temperatures for Park, MIL 99301 host, MIL 99301 clast, Kernouvé, and Portales Valley were higher than for Leedey, Bruderheim, and Morrow County. The data also strongly suggest that among the least-deformed meteorites, Portales Valley was less hot during deformation than Kernouvé or MIL 99301 host.

Except for the MIL 99301 clast, which could have been deformed during impact melting and transport (Sec. 4.2), another important inference is that the deformation temperature metric must reflect pre-shock conditions. This is because even in the most strongly shocked chondrites (Bruderheim and Morrow County), dynamic heating effects were modest, as evidenced by their dominant low-temperature slip signature. Other meteorites that were less strongly shocked must have experienced even less dynamic heating. Thus, deformation temperature parameter must reflect ambient temperature (preshock temperature) in the parent body at the time of shock deformation, except in some cases of shock melting. For Portales Valley, Kernouvé, MIL 99301 host, and Park, estimated temperatures during deformation were $\sim 700-1000^{\circ} \mathrm{C}$. This is similar to the peak 
temperatures for petrographic type 6 metamorphism (Huss et al., 2006), suggesting that impacts could have occurred during thermal metamorphism.

We investigated the sensitivity of the temperature parameter to EBSD mapping area size and location, by using data for large area maps (Table 2) and targeted maps (Table 3), with results shown in Fig. EA-5. The temperature parameter generally gives consistent results for a given meteorite, especially for the more strongly deformed meteorites Leedey, Bruderheim, Morrow County, and MIL 99301 clast. The data diverge the most for Portales Valley targeted maps that were chosen to highlight grains with prominent subgrain boundaries. This suggests that the precise choice of mapping area is not overly critical for an approximate estimate of the temperature parameter, although spurious results can be obtained for localized areas in meteorites dominated by grains with prominent subgrain boundaries and otherwise lightly-deformed grains.

Although the characterization of overall olivine slip directions is best made using large area map data, misorientation profiles can be used to investigate specific olivine grains. For example, in grain 7 of Bruderheim (Fig. 2), there is evidence for $c$-type slip, to create rotation axes of $\sim<401>$ and $\sim<410>$ as inferred from two different profiles at high angles to each other. In Portales Valley (Fig. 1), there is evidence for $c$-type slip (to create the subgrain boundary in grain 71 a with $\sim<100>$ rotation axis, and the overall misorientation in grain $71 \mathrm{~b}$ of $\sim<401>$ ) as well as a-type slip (subgrain boundary in grain 71a with $\sim<13>$ misorientation). Finally, in Park (Fig. 3), there is evidence for both $c$-type and a-type slip in grain 20 (subgrain boundaries with $\sim<10>$ and $\sim<104>$ rotation axes, respectively), and probably also in grain 20a ( $<141>$ rotation as a combination of both $c$ and a-type slip, and $\sim<110>$ rotation as likely cross-slipping $c$-type screw arrays). Grain $20 \mathrm{c}$ in Park shows a subgrain boundary with $\sim<403>$ rotation axis (Fig. 3), which could be an example of boundary containing both $\mathbf{b}=[001]$ and $\mathbf{b}=[100]$ dislocations. These data for individual grains are generally consistent with inferences made using large area map data, in that they point to low-temperature deformation for Bruderheim, and high-temperature deformation for Portales Valley and Park.

\subsection{Post-shock annealing}

\subsubsection{EBSD evidence for annealing}

The presence in Portales Valley, Kernouvé, and MIL 99301 host of olivine grains with picket-fence subgrain boundaries with few other dislocations was interpreted as evidence for dislocation climb caused post-shock annealing (Ruzicka et al., 2015a). With 
EBSD, this is manifested as grains with subgrain boundaries and little other misorientation. Such grains are indeed conspicuous in EBSD maps of these three meteorites (e.g., grain 71a in Fig. 1d), as well as in Park (e.g., grains 20 and 20c in Fig. 3c). They tend to be among the larger $(d>50 \mu \mathrm{m})$ grains, and occur among many others that lack subgrain boundaries and that have lower GOS values (Fig. 1a, 3a). These data are interpreted to indicate sintered meteorites that experienced dislocation climb and recovery in olivine, concentrating deformation in subgrain boundaries, or removing deformation altogether by the migration of subgrain boundaries out of grains (see below).

In contrast, deformed meteorites such as Bruderheim (Fig. 2), Leedey, Morrow County, and MIL 99301 clast contain olivine grains with many subgrain boundaries (Table 2), but also significant misorientation outside of subgrain boundaries. That is, deformation is present both in deformation zones/bands (subgrain boundaries) as well as distributed throughout the grains. This is consistent with relatively little post-deformation recovery for these meteorites.

In terms of GOS-distribution signatures, the presence of a small number of elevated-GOS grains amidst many other lower-GOS grains creates a skewed distribution (with "positive skewness"), best shown by Kernouvé, MIL 99301 host, and Portales Valley (Fig. 1b, c). These are the same three meteorites identified with TEM as having experienced significant recovery (Ruzicka et al., 2015a). Park also has a high-GOS tail, but it is not as skewed (Fig. 3b), with a larger proportion of grains having deformation outside of subgrain boundaries (grain 20a in Fig. 3c) creating a larger proportion of higherGOS grains. This can be explained as incomplete post-deformation dislocation climb and annealing, which left residual deformation outside of subgrain boundaries.

\subsubsection{EBSD annealing parameter}

We use a metric for inferred relative post-shock annealing based on GOS distribution in larger $(d>50 \mu \mathrm{m})$ grains, equal to (mean $G O S_{d>50}$ /median $G O S_{d>50}$ ), shown in Table 1 (large area maps) and Table 3 (targeted maps). Median values tend to be closer to the peak frequency (mode) in the distribution, whereas mean is influenced more by grains with atypically elevated GOS values. An elevated (mean $G O S_{d>50} /$ median $G O S_{d>50}$ ) ratio should be proportional to the extent of annealing, if skewed distributions were caused by annealing. The annealing parameter increases in the sequence (brackets indicate similar values, Table 1): [Morrow County $\leq$ MIL 99301 clast Bruderheim Leedey] < [Kernouvé $\leq$ MIL 99301 host] < [Portales Valley]. 
Fig. 12 compares the EBSD annealing parameter based on large area map data with an inferred annealing parameter derived from TEM, the FFB (free/(free+bound)) dislocation ratio (Ruzicka et al., 2015a; cf. Goetze and Kohlstedt, 1973). As an annealing parameter, FFB depends on analysis of a sufficiently representative area to allow accurate characterization of the number of dislocations present in subgrain boundaries ("bound dislocations") to those not present in such boundaries ("free dislocations"). Fig. 12 shows that the two methods for estimating annealing agree in general, though not in detail, for all meteorites except Park. That is, both methods suggest low degrees of annealing for Leedey, Bruderheim, and Morrow County, and high degrees of annealing for Portales Valley, Kernouvé, and MIL 99301 host. The methods diverge more for Park, with EBSD evidence suggesting more annealing than implied by TEM data.

We suggest that annealing extent is more reliably determined by EBSD methods, owing to the larger area and number of grains that can be examined. This is especially true for meteorites such as Park in which annealing effects are less pervasive. However, the two methods generally agree for the other meteorites, indicating consistency between mesocale (EBSD) and microscale (TEM) annealing effects, and supporting the validity of the proposed EBSD annealing parameter.

To quantify relative annealing we use data for $d>50 \mu \mathrm{m}$ grains, as larger grains give a clearer signature of annealing; that is, higher (mean GOS/median GOS) values for "annealed" compared to "non-annealed" meteorites (Table 1). This could indicate that in smaller grains, subgrain boundaries were more likely to be destroyed during the annealing process, by migration of boundaries to (high angle) grain boundaries.

Annealing parameter for the sintered meteorites Park, MIL 99301 host, Kernouvé, and Portales Valley correlate inversely with weighted shock stage and olivine mean GOS values (Table 1). That is, Park is most deformed but least annealed, whereas Kernouvé and Portales Valley are least deformed and most annealed. This supports evidence that shock stage and deformation in chondritic olivine were lowered by post-shock annealing in some cases (Rubin, 2002, 2003, 2004; Rubin and Jones, 2003; Hutson et al., 2007; Ruzicka et al., 2015a; Friedrich et al., 2017).

Post-shock annealing evidently affected all of the shock stage S1 meteorites of this study (Portales Valley, Kernouvé, MIL 99301 host, Park). Given the relatively small number of meteorites examined, however, it does not necessarily follow that all shock stage S1 chondrites were annealed, or that annealing always resulted in shock stage S1. 
EBSD data for the clast in MIL 99301 and the shock stage S4 and S5 chondrites Leedey, Bruderheim and Morrow County are consistent with less (possibly negligible) postshock annealing, implying that post-shock annealing was not the result of dynamic heating effects associated with strong shocks.

Although the value of (mean $G O S_{d>50} /$ median $G O S_{d>50}$ ) appears to be generally valid as an annealing parameter, brecciation can lead to erroneous interpretations. This is seen with the combined dataset for MIL 99301 host + clast, which gives a high value of (mean $G O S_{d>50}$ /median $G O S_{d>50}$ ) (Table 1). The high value here reflects the presence of deformed olivine grains in the clast and the more numerous weakly-deformed olivine grains in the host, leading to high skewness in the GOS distribution that simulates annealing, but which in this case is caused by the admixture of more highly deformed material. In MIL 99301, this admixture is obvious from the spatial variations in GOS, KAM, and GROD angle associated with distinct lithologies.

We investigated the sensitivity of the EBSD annealing parameter to mapping area size and location, by comparing data for large area maps and targeted maps, using data in Tables 1 and 3, and shown in Fig. EA-5. The annealing parameter generally gives consistent results for the more highly-deformed meteorites and lithologies, including Leedey, Bruderheim, Morrow County and MIL 99301 clast, although data disperse for one smaller area of MIL 99301 clast. In addition, data scatter more widely for targeted areas in Portales Valley and Park. Overall, the EBSD annealing parameter is more sensitive to mapping area and location than the deformation temperature parameter (Sec. 4.3). Thus, large area maps should be used to quantify annealing. This can be understood by the need to have a sufficiently large grain population from which to determine a representative GOS distribution.

\subsection{Implications of troilite deformation and recrystallization}

Based on shock deformation experiments performed at two different starting temperatures $\left(20^{\circ} \mathrm{C}\right.$ and $647^{\circ} \mathrm{C}$ ), Schmitt (2000) suggested that the deformation character of troilite and olivine could be used together to discriminate between low- and high-temperature deformation depending on shock intensities. Schmitt found that with low starting temperature, at low shock pressure olivine and troilite are deformed, whereas at high shock pressure, olivine becomes more deformed and troilite recrystallizes. With elevated starting temperature, at low shock pressure olivine is less-deformed and troilite 
recrystallizes, whereas at high shock pressure, olivine becomes more deformed and troilite melts (Schmitt, 2000).

The data for Leedey, Bruderheim, and Morrow County (strongly deformed olivine and partly recrystallized troilite) fit the criteria for low pre-shock temperature and strong deformation. This conclusion is consistent with evidence for dominantly "cold" but strong olivine deformation in these meteorites (Sec. 4.1, 4.3).

Furthermore, the data for olivine and troilite in Park (weakly deformed olivine, recrystallized troilite) fit the criteria of high-temperature deformation as originally proposed by Schmitt (2000). Although post-shock annealing probably played a role in the formation of Park (Sec. 4.4), it does not appear to explain the data for troilite. Extensive annealing of troilite is inconsistent with relatively high GOS values for troilite in Park (Table 4). Moreover, it is unlikely that annealing was responsible for the recrystallization textures of the troilite. This annealing would be expected to produce low-angle subgrain boundaries (as for olivine in Park), not domains with high-angle grain boundaries (as for troilite in Park). Moreover, fine domain sizes of recrystallized troilite grains in Park can likewise be attributed to limited post-shock annealing; much annealing would tend to coarsen grains. Thus, we suggest that the recrystallization-deformation character of troilite in Park largely reflects a high pre-shock temperature. This conclusion is compatible with inferences for deformation temperature and post-shock annealing based on olivine (Sec. 4.3, 4.4), if annealing effects in Park were relatively modest.

The monocrystals of troilite found with similar crystallographic orientations in localized areas of Portales Valley probably indicate the formation of multi-millimeter grains by grain growth interstitial to silicates (Sec. 3.5). Such growth was previously attributed either to crystallization from S-bearing metallic liquid (Pinault et al., 1999; Scott and Pinault, 1999; Ruzicka et al., 2005; Tomkins et al., 2013) or by reaction involving an interstitial vapor (Rubin et al., 2001), following shock deformation that produced metallic melt veins (Pinault et al., 1999; Scott and Pinault, 1999; Rubin et al., 2001; Ruzicka et al., 2005).

We favor a metallic melt origin of the troilite in Portales Valley for the following reasons: (1) the very low porosity of Portales Valley (Friedrich et al., 2017) makes vapor deposition/reaction unlikely, as it would seem impossible to create a nearly zero-porosity rock from one that contained sufficient gas to create so much troilite (Fig. 5d); (2) it is problematic to explain coarse troilite grains forming by metamorphism, given that other 
metamorphosed chondrites lack this texture (although it is true that post-deformation annealing in Portales Valley was especially intense-- Sec. 4.4); and (3) the texture and composition of metal-troilite vein networks in Portales Valley can be explained by an interconnected melt system that produced troilite as a late crystallization product from a melt (Pinault et al., 1999; Scott and Pinault, 1999; Ruzicka et al., 2005; Tomkins et al., 2013).

Thus, Portales Valley troilite data are best explained by crystallization from interstitial melts, creating a strong $L P O$ that reflects formation of a limited number of coarse crystals. Interstitial melts in this meteorite were probably created in response to deformation (Kring et al., 1999; Rubin et al., 2001; Ruzicka et al., 2005; Tomkins et al., 2013). Troilite would have crystallized after shock deformation, before or during the annealing of olivine (Kring et al., 1999; Rubin et al., 2001; Ruzicka et al., 2005), explaining low GOS values for troilite.

There are different ways to explain the weakly-deformed troilite monocrystals in MIL 99301 host and Kernouvé. They could represent grains that (1) like Portales Valley crystallized from metallic melts associated with impact, or (2) formed as single, weaklydeformed crystals during metamorphism (Sec. 4.4). In favor of the first possibility is evidence for high pre-shock temperatures in MIL 99301 host and Kernouvé (Sec. 4.3; Ruzicka et al., 2015a), which could have facilitated the formation of S-rich metallic melts (Ruzicka et al., 2005). In addition, coarse interstitial troilite has been observed in some samples of Kernouvé, possibly produced by melting (Scott and Pinault, 1999). Against this possibility is the lack of troilite monocrystals in Park, which shows evidence for hightemperature deformation (Sec. 4.3), implying that high pre-shock temperatures alone did not necessarily lead to melted troilite monocrystals. Moreover, although our samples of MIL 99301 host and Kernouvé contain localized areas of troilite grains with similar orientations, these areas are smaller than in Portales Valley and not populated by as many troilite grains, making the evidence for coarse interstitial troilite less convincing. We therefore cannot rule out that troilite grains in MIL 99301 host and Kernouvé crystallized from melts nor the possibility that they are weakly-deformed separate grains.

\subsection{Significance of lattice preferred orientation for olivine and troilite}

Data for lattice preferred orientations for olivine in Table 1 and troilite in Table 4 are derived from LAM pole figure plots, which are shown in Fig. 13 for selected cases. A 
complete set of pole figures for all meteorites is shown in Fig. EA-6 (olivine) and EA-7 (troilite).

There is no doubt that the large clast in MIL 99301 has a strong olivine LPO $\left(\Delta_{<010>}\right.$ $\sim 6.5$, Fig. 13a), as was described previously (Sec. 3.4). This fabric probably reflects rapid crystallization from a shock melt with concomitant deformation as the clast was transported and emplaced into the MIL 99301 host region (Sec. 4.2).

The next highest, but much lower, olivine LPO strength value is for Morrow County $\left(\Delta_{<001>} \sim 0.90\right)$. The pole figure for Morrow County olivine shows a broad $<001>$ girdle around a broad point maximum in $\langle 010\rangle$, with no apparent tendency for preferred orientations in $<100>$ (Fig. 13b). We suggest that this relatively weak LPO for Morrow County reflects shock deformation. The LPO pattern somewhat resembles the predicted LPO of $<001>$ and $<010>$ girdles for low-temperature olivine deformation, and is significantly different than expected for high-temperature deformation (Tommasi et al., 2000). Given evidence for strong, low-temperature deformation and little post-shock annealing in Morrow County (Sec. 4.1, 4.3, 4.4), we ascribe the weak olivine LPO in Morrow County to primarily "cold" but strong (shock stage S5) deformation.

Other meteorites do not show significant olivine LPOs. We suggest this is because they experienced weaker shocks. Alternatively, fabrics conceivably could have been established and then destroyed, either by impact-reworking or by especially intense annealing. Although impact-reworking is possible, any later impacts could not have been very strong for the S1 meteorites, and is unlikely for S4 Bruderheim, given troilite LPO data (below), which suggests minimal later disturbance of grains in the meteorite. Significant annealing certainly occurred for the sintered chondrites (Portales Valley, Kernouvé, MIL 99301 host, and Park), but the ability of annealing to destroy LPOs is questionable in the absence of significant later stress, and significant post-shock annealing can be discounted for the shock stage S4 and S5 chondrites (Leedey, Bruderheim, Morrow County).

Thus, we speculate that only the strongest shocks such as affected Morrow County, or rapidly cooled shock melts such as the MIL 99301 clast, may be capable of generating appreciable olivine LPOs in chondrites. Weak LPOs are not unexpected in cases where total strain is relatively low (Tommasi et al., 2000), as may be the case for olivine in most of the chondrites studied here.

Our data for olivine LPO further suggests that the potential deformation mechanism of hot isostatic pressing (HIP), caused by compaction as a result of overburden pressure at 
elevated temperature (Gail et al., 2015), was not significant in creating LPOs for olivine in the chondrites. If this mechanism were important, one would expect the most evidence for it in the sintered chondrites, yet no significant LPO for olivine is found for these meteorites.

For troilite there appear to be four different pole figure patterns among the meteorites studied. Portales Valley, Kernouvé, and MIL 99301 show one pattern, exemplified by Portales Valley (Fig. 13c). In all three meteorites, there are three discrete, preferred orientations for the $\{0001\}$ basal plane that appear to be randomly distributed together with some lesser maxima (Fig. 13c, Fig. EA-7). All three meteorites have troilite monocrystals (Sec. 3.5), and all three could have grown interstitial troilite grains during crystallization from a melt (Sec. 4.5). This would produce grains that appear to be disconnected in two dimensions but which are actually connected in the third dimension, consistent with the pole figure data.

A second troilite pole figure type is shown by Bruderheim and Morrow County. This features a single, broad maximum for poles to the $\{0001\}$ plane (Fig. 13d-e). The poles for $\{11-20\}$ planes form a diffuse girdle around $\{0001\}$, and those for $\{10-12\}$ are weakly aligned parallel to $\{0001\}$ (Fig. 13d-e). Experiments indicate that the $\{0001\}$ basal plane in pyrrhotite (which has similar structure to troilite) tends to re-orient perpendicular to the maximum compressive stress direction (Kübler, 1985; Niederschlag and Siemes, 1996). Moreover, in deformation experiments (Niederschlag and Siemes, 1996), the pyrrhotite pole figure patterns for $\{0001\},\{11-20\}$, and $\{10-12\}$, including the broadness of these patterns, are similar to those for troilite in Bruderheim and Morrow County. Given that Bruderheim and Morrow County were heavily shocked (Sec. 3.2, 4.1, 4.5), this suggests that the troilite LPO patterns for Bruderheim and Morrow County reflect uniaxial shock compaction. We infer that the main compression direction during shock was oriented lower-right to upper left in Bruderheim (Fig. 3d), and up-down in Morrow County (Fig. 3e).

In Morrow County, the LPO patterns for troilite and olivine appear to be geometrically related. Olivine (Fig. $13 \mathrm{~b}$ ) shows a tendency for $<001>$ to lie parallel to the $\{0001\}$ planes of troilite (i.e., perpendicular to $\{0001\}$ poles, Fig. 13e). This implies that olivine $<001>$ axes were rotated perpendicular to the compression direction. A similar relationship between $<001>$ for olivine and $\{0001\}$ in troilite is seen for Bruderheim, but the olivine LPO is weaker in Bruderheim.

A third troilite pole figure pattern is shown by Park. Although the LPO strength is somewhat weak $\left(\Delta_{\{0001\}} \sim 0.94\right)$, the pole figure pattern is distinctive and systematic, with a 
girdle of $\{0001\}$ poles around a preferred $\{11-20\}$ pole direction (Fig. 13f). This pattern resembles experimental deformation of pyrrhotite (Niederschlag and Siemes, 1996) when there is a large "mismatch" angle between the compression direction and the original $c$ axis direction, especially at the highest temperatures $\left(300-400{ }^{\circ} \mathrm{C}\right)$ and the greatest strains.

In light of these data, there are at least two ways to explain the LPO for troilite in Park. (1) Troilite could have been deformed at high temperatures, consistent with other evidence in the meteorite for high ambient temperatures during olivine and troilite deformation (Sec. 4.3, 4.5). In experiments (Niederschlag and Siemes, 1996), however, high temperatures alone do not suffice to yield the kind of LPO seen for Park, although deformation temperatures in Park ( 800-1000 ${ }^{\circ} \mathrm{C}$, Sec. 4.3.4, 4.3.5) could have been much higher than in the experiments $\left(300-400{ }^{\circ} \mathrm{C}\right)$. (2) Park could have experienced two shock events, the first to orient the $\{0001\}$ planes of troilite perpendicular to the compression direction, the second with a compression direction at high angles to the first. This would have the effect of smearing a single preferred orientation for $\{0001\}$ poles in Park (first impact) into a band as a result of rotation of the $\{0001\}$ planes (second impact). For Park, we suggest that two impacts with at least one dominant one occurring at high temperature can explain the data.

The final troilite LPO pattern is shown by Leedey. It is vaguely similar to the pattern for Bruderheim and Morrow County in that there is one main $\{0001\}$ orientation, but different in that the $\{0001\}$ maximum is much less broad (Fig. 13f). The Leedey pattern also lacks the broad $\{11-20\}$ girdle around the $\{0001\}$ pole maximum, despite having a higher LPO strength than for Bruderheim and Morrow County (Table 4). Finally, there are additional, lesser maxima in the Leedey plot (Fig. 13f), as one might expect for randomly oriented grains. Thus, the troilite pole figure data for Leedey may not indicate uniaxial compression. We suggest instead that it reflects differently oriented grains that were partly recrystallized during shock (Sec. 3.5, 4.5), thereby creating additional grains that inherited the orientations of the precursor grains and enhancing LPO strength. We infer that weaker shock deformation in Leedey compared to Bruderheim and Morrow County (Sec. 3.5, 4.1) inhibited troilite from reorienting during shock compaction. If so, a "strong" S4 or S5 shock stage may be needed to significantly compact and re-orient troilite.

\subsection{Implications for parent bodies}


The results of this study have implications for collisional processes and the thermal processing of ordinary chondrite parent bodies and the meteorites derived from them. We first consider the relationship between the inferred deformation-temperature parameter and the annealing parameter (Fig. 14). Data distribute into three groups.

\subsubsection{Group 1}

Group 1 in Fig. 14 consists of meteorites (Leedey, Bruderheim, Morrow County) that have low values of both temperature and annealing parameter. This can be explained by derivation of the meteorites from source regions that were cold at the time of impact deformation, and that cooled rapidly after shock. This implies cold parent bodies at the time of impact, with subsequent cooling of the meteorites in proximity to cold material, either on or in the parent body or as an ejecta fragment. With these conditions, shock damage in olivine was largely preserved (shock stage S4 and S5).

\subsubsection{Group 2}

Group 2 consists of a single example, the MIL 99301 clast. This clast has a high value of temperature parameter, but a low value of annealing parameter. The clast likely formed as a shock melt that cooled rapidly afterwards. It appears to have been emplaced into the host while the clast was hot (Sec. 4.2). The clast provides evidence for intense, localized shock heating, but shock heating and melting effects were localized to the clast itself, and the melt was evidently emplaced into a much larger volume of cooler host material that aided fast cooling. Deformation of olivine in this clast may have been associated with rapid cooling during crystallization at high temperatures following shock melting, prior to emplacement in the host (Sec. 4.2). As with Group 1, there is no evidence for post-shock annealing of olivine.

\subsubsection{Group 3}

Group 3 consists of meteorites (Portales Valley, Kernouvé, MIL 99301 host, Park) that have high values of deformation temperature and annealing parameters. The high value of temperature parameter arose because the parent body source areas were warm at the time of impact deformation (Sec. 4.3). Three different parent bodies (H, L, LL) represented by the four meteorites were hot-deformed, implying that impacts into warm planetesimals were not uncommon. The high value of annealing parameter indicates slow cooling following impact, suggesting that the meteorite source areas were buried in warm parent bodies following impact. Post-shock annealing helped remove deformation and decrease olivine shock stages (Sec. 4.4). 
Fig. 14 indicates an inverse relationship between the temperature and annealing parameters for Group 3. We cannot be sure that this trend is significant as it based on only four data points, and given the uncertainties in how the temperature and annealing parameters are determined. But the trend is consistent with independent data on ages and shock stages (see below), and may be real. It can be explained by impact-redistribution in warm parent bodies, as discussed below.

At one end of the Group 3 trend is Park. Of the four meteorites, it appears to have been hottest at the time of impact, but the least annealed after impact. This implies transport from a hotter to cooler area of the parent body (Ruzicka et al., 2015a) as a result of a large (potentially catastrophic) impact. Park may be a good example of impact scrambling of a globally heated chondritic parent body (Grimm, 1985; Taylor et al., 1987), with hotter, type 6 material brought to a cooler area after a disruptive large impact.

At the other end of the Group 3 trend is Portales Valley (Fig. 14). It evidently was least hot at the time of impact, but most annealed after impact. This implies it formed hot, though perhaps closer to a cooling surface, and was not moved to an appreciably cooler portion of the parent body. This thermal history is consistent with the formation of Portales Valley in a slowly-cooling hot basement region of the parent body directly below an impact crater (Kring et al., 1999; Ruzicka et al., 2005; Scott et al., 2014). Metallic veins could represent liquefied metallic melt dikes injected into country rock by the force of impact (Rubin et al., 2001; Ruzicka et al., 2005; Tomkins et al., 2013). The crater above the basement could have been filled with low-thermal-conductivity fallback ejecta to help keep subcrater areas thermally insulated.

Kernouvé may have formed in a similar way to Portales Valley, as it also has some coarse metal veins (Friedrich et al., 2013, 2017; Scott et al., 2014) and is next in the apparent temperature-annealing trend of Group 3. Compared to Portales Valley, it appears to have been warmer at the time of impact, and less annealed after impact. It likely formed in a hot area, possibly in a deeper hot basement region proximal to an impact crater, but the lower degree of annealing implies it could have been transported to a somewhat cooler region following impact. The source region may have been somewhat to the side of an impact crater where there was upward-directed flow. Alternatively, the source region could have been the deep interior of a hot parent body that was uplifted by upward-directed flow following a large impact (Ciesla et al., 2003). 
MIL 99301 host is intermediate to Kernouvé and Park in temperature-annealing character (Fig. 14). Compared to these meteorites, an intermediate amount of impactredistribution from hotter to cooler areas for MIL 99301 host is implied, more than for Kernouvé, and less than for Park.

The data for Group 3 meteorites bear on the relationship between collisions and heating models for chondritic parent bodies. There are two possible models. (1) Parent bodies may have been endogenically heated (e.g., by decay of short-lived radiogenic ${ }^{26} \mathrm{Al}$ ) and experienced concurrent collisions (Grimm, 1985; Taylor et al., 1987; Harrison and Grimm, 2012; Ganguly et al., 2013, 2016; Scott et al., 2014; Blackburn et al., 2017). (2) Parent bodies may have been exogenically heated by impacts (Rubin, 1995; Davison et al., 2012, 2013). As discussed below, our data favor the first model.

For endogenic heating, planetesimals can be warm both before and after impact, readily explaining why deformation temperature and annealing are both elevated for Group 3 meteorites. Further, the inverse trend between temperature and annealing can be explained by impact-redistribution in warm parent body interiors, as noted above. A single impact variable, impactor energy (proportional to impactor size and velocity), could have controlled the redistribution on such hot bodies. In general, larger (more energetic) impacts should result in more redistribution than smaller (Stöffler et al., 1988; Davison et al., 2012, 2013; Ciesla et al., 2013), with cooling and redistribution being the main effect of larger impacts on warm bodies (Ciesla et al., 2013). Specifically, the data can be reconciled with progressively larger impacts in the sequence Portales Valley < Kernouvé < MIL 99301 host $<$ Park. The same sequence is implied for initial relative depth in internally heated bodies. Thus, a model of impacts occurring on endogenically heated bodies is consistent with the data.

In contrast, a purely exogenic heating mechanism is problematic. Our results indicate a subordinate role for direct impact heating; what is needed instead is a warm target together with deformation (Sec. 4.3). It has been shown that impact events can produce hot plugs on parent bodies that can cool slowly, at least at low temperatures (Davison et al., 2012). At a minimum, the Group 3 meteorites would have to form in such plugs, and while still hot, be impacted again. However, they could not have been transported to a cool area outside of a hot plug by the second impact, as this would be counter to the evidence for slow post-impact cooling in the meteorites. Thus, either the second impact involved little impact-redistribution, or the parent body was warm all over 
the surface. Similarly, it is unlikely that two or more consecutive impacts in a relatively short time frame would be repeated in four out of four meteorites from three separate parent bodies, unless the impact flux was so high as to cover most of the parent bodies in warm plugs. However, such widespread (global) heating by impacts is unlikely (Keil et al., 1997; Davison et al., 2012, 2013). Finally, with the exogenic heating model there is no obvious explanation for the inverse trend shown by Group 3 meteorites; only ad hoc explanations for this could be devised.

Therefore, our data cannot be easily reconciled with an exogenic-heating parent body model, but are compatible with a model in which warm parent bodies were affected by impacts.

\subsubsection{Relationship of groups to Ar ages}

The EBSD groups are related to collision times that are thought to be recorded by ${ }^{40} \mathrm{Ar} /{ }^{39} \mathrm{Ar}$ ages. Fig. 15 shows the relationship between ${ }^{40} \mathrm{Ar} /{ }^{39} \mathrm{Ar}$ ages and the inferred annealing and temperature parameters. Two ages have been determined for MIL 93301 indicative of multiple impacts (Dixon et al., 2004). We here assign the older age to the host and the younger age to the clast, as it is apparent that the clast was intruded into the host (Sec. 4.1) and must therefore have formed later. Bruderheim (L6) and Morrow County (L6) have essentially the same age (Turner, 1969; Ruzicka et al., 2015b) which corresponds to the $470 \mathrm{Ma}$ impact on the L chondrite parent body that could have destroyed this body and created numerous fragments (Swindle et al., 2014, and references therein). Kernouvé (H6) and Portales Valley (H6/7) have Ar ages that overlap, $4469 \pm 6 \mathrm{Ma}$ (Trieloff et al., 2003) and 4467.5 $\pm 13.4 \mathrm{Ma}$ (Bogard and Garrison, 2009), respectively, indicating Ar degassing either in the same event or in different early events.

Fig. 15 indicates a strong relationship between annealing parameter and temperature parameter with Ar age. High values of both annealing parameter and temperature parameter occur only for older (>4425 Ma) Ar ages. Given that both parameters reflect the existence of warm parent bodies, this strongly suggests that chondritic parent bodies (H, L, LL) were warm only in the earliest epochs. This is potentially consistent with radiogenic heating of parent bodies by ${ }^{26} \mathrm{Al}$ (Henke et al., 2013; Monnereau et al., 2013). In contrast, strong impacts such as produced the S4 and S5 meteorites occurred at later times ( $<4000 \mathrm{Ma}$ ago) but were not associated with significant heating owing to dominantly cold bodies at these times. Significant transient heating is 
implied by the MIL 99301 clast at a time (possibly 4230 Ma ago) when the parent bodies may have been cold.

Insets in Fig. 15 show an expanded Ar age scale for the four oldest (Group 3) meteorites. These insets reveal apparent age-related trends for the four meteorites. An inverse trend between annealing parameter and age (Fig. 15a inset) can be explained by variations in cooling rate that caused Ar closure temperature to be reached at different times, sooner with faster cooling. This is consistent with the interpretation of the annealing parameter. Thus, faster cooling for Park can explain both lower annealing parameter and higher Ar age, and slower cooling for Portales Valley can explain both higher annealing parameter and younger age. If this explanation is correct, it implies minimal disturbance of the source regions during a cooling cycle from high to low temperatures following impact. Moreover, a positive trend is seen between temperature parameter and age (Fig. 15b inset). This trend can be explained by differences in cooling rates as explained above, or by differences in impact ages and variations in parent body temperatures (hotter at earlier times), or both. Detailed thermal modeling, not performed here, as well as additional data, could be helpful in explaining details of the age trends for Group 3 meteorites.

The apparent differences in cooling rate, Ar closure times, and parent body temperatures for Group 3 meteorites are correlated also with the extent of shock deformation in the meteorites. As the meteorite with the oldest Ar age, Park has the most significant olivine deformation remaining (e.g., highest GOS value), whereas the meteorites with the lowest Ar ages, Portales Valley and Kernouvé, have the least significant olivine deformation remaining (Sec. 4.2). This relationship between Ar ages and olivine deformation could be evidence for longer annealing durations leading to more reduction of apparent shock deformation in olivine. Furthermore, based on existing EBSD and Ar age data, post-shock annealing capable of reducing olivine shock stage can be attributed to early impacts on warm parent bodies.

\subsection{Effects of single and multiple impacts on EBSD signatures}

Given that meteorites and the MIL 99301 clast can be assigned to three groups of differing deformation character and $\mathrm{Ar}$ ages (Sec. 4.7), the question arises as to how single and multiple impacts establish signatures detectable with EBSD techniques. Although it is certain that each of the meteorites in this study was affected by multiple impacts, our results imply that EBSD signatures were associated mainly with single impacts, or with multiple impacts occurring at about the same time under similar 
conditions. Group 3 meteorites show evidence for hot deformation and post-shock annealing compatible with impacts on warm parent bodies, have old $\mathrm{Ar}$ ages, and can be explained in terms of variable burial and excavation from an internally heated parent body, with no obvious evidence for any later impact events under different conditions. This includes much later collisions that would have had to liberate the meteoroids from what were likely cold source bodies, themselves ejected from likely cold parent bodies (Burbine et al., 2002). Any such later impact events were evidently too weak to overprint the early deformation record, to increase shock stages beyond $\mathrm{S} 1$, or to result in significant heating and reset Ar ages.

Similarly, Group 1 meteorites show evidence only for late shocks on cold parent bodies, with no evidence for any of the early hot-deformation or annealing processes recorded by Group 3 meteorites. In these cases, the late shock events could have been sufficiently strong to re-set deformation characteristics, increase shock stages to S4 or S5, and result in significant heating to reset Ar ages. In Bruderheim and Morrow County, which show evidence for uniaxial shock compression to create lattice preferred orientation for troilite (Sec. 4.6), any later impact events must have been weak so as to not significantly disturb the troilite crystal orientations. The situation may be analogous to what is inferred for establishing shape preferred orientation (SPO) for metal in chondrites, in which foliations represent only the latest, strongest impact event (Friedrich et al., 2014).

Nonetheless, our data do provide some evidence for multiple impacts. The most obvious example is MIL 99301, which contains clast and host of differing deformation character established in two different impact events (Sec. 4.2, 4.7). The deformation character of each lithology was preserved despite obvious impact-induced mixing. That is, the deformation character of host was not overprinted, despite incorporation of a more strongly deformed melt clast. This could be because clast incorporation in the host involved small strains and only a small temperature perturbation (Sec. 4.2). If deformation or heating during clast incorporation were more significant, deformation signatures in the host may well have been overprinted.

The ability to recognize two different impact events in MIL 99301 is aided by the distinctive difference in texture between host and clast. If impact-mixing were on a smaller scale or involved admixture of less distinctive material, the evidence for multiple impacts might go unnoticed. In this case, the prevalent component (by area) in a meteorite would likely dominate the impact signature recorded by EBSD techniques. 
Another likely example of multiple impacts is given by Park. This meteorite has a troilite LPO pattern that could reflect the occurrence of two impacts (Sec. 4.6). Although Park shows good evidence for hot deformation and post-shock annealing (Sec. 4.3, 4.4, 4.5), it is unclear which of the two inferred impacts was associated with these conditions. It is possible that both impacts occurred at closely spaced intervals under similar conditions.

This is supported by Ar plateau age data for Park, which shows evidence for only one early impact (Ruzicka et al., 2015b). Thus, if there were two impacts, they could have both occurred early and under similar conditions, yielding similar EBSD signatures. This is in contrast to MIL 99301, which shows Ar age evidence for two different impacts at significantly different times (Dixon et al., 2004) and which could have been associated with the host and clast lithologies we studied.

\section{CONCLUSIONS}

(1) Various EBSD deformation metrics adequately and quantitatively represent olivine deformation in meteorites on different scales and in different ways. Mean GOS (Grain Orientation Spread) is a robust deformation statistic that correlates well with both weighted shock stage determined by $\mathrm{OM}$ and with geometric average dislocation density determined by TEM. For grains with effective diameter $d>50 \mu \mathrm{m}$ most comparable to OM observations, mean $\operatorname{GOS}_{d>50}$ varies from $\sim 0.6^{\circ}$ for Portales Valley and Kernouvé (shock stage S1) to $\sim 4.1^{\circ}$ for Bruderheim (S4) and Morrow County (S5). Care must be taken to distinguish between deformation in finer $(d<50 \mu \mathrm{m})$ and coarser $(d>50 \mu \mathrm{m})$ olivine grains as values of deformation metrics depend on grain size.

(2) EBSD data suggest that different meteorites varied in their temperatures of deformation and amount of post-shock annealing they experienced. Signatures for hot deformation and post-shock annealing in the same meteorites (Portales Valley, Kernouvé, MIL 99301 host, Park) can be explained by impacts occurring on endogenically-heated planetesimals in the earliest epoch of solar system history. Signatures for cold deformation and minimal post-shock annealing in other meteorites (Leedey, Bruderheim, Morrow County) can be explained by collisions affecting cold asteroidal bodies later in solar system history.

(3) Hot-deformed meteorites studied here (Portales Valley, Kernouvé, MIL 99301 host, Park) were likely shocked while being thermally metamorphosed to type 6 grade at temperatures $>700-800{ }^{\circ} \mathrm{C}$ and $\leq 1000^{\circ} \mathrm{C}$. High ambient temperatures during impact 
deformation promoted partial recrystallization of troilite in Park, and the formation of intergranular metallic liquids out of which troilite crystallized, in at least Portales Valley and possibly also in Kernouvé and MIL 99301. All four meteorites, but to lesser extent Park, were sintered by burial in warm materials following shock, which obliterated some deformation in olivine and lowered their shock stages to $\mathrm{S} 1$.

(4) Cold-deformed meteorites studied here (Leedey, Bruderheim, Morrow County) experienced minimal post-shock annealing. Differences in impact strengths resulted in some variations. These include (a) differences in transient, dynamic heating, with the least for shock stage S4 Leedey (bulk heating to $<600^{\circ} \mathrm{C}$ ) and the most for shock stage S5 Morrow County (bulk heating to $\sim 700^{\circ} \mathrm{C}$ ); (b) partial to more complete recrystallization of troilite, increasing in the sequence Leedey, Bruderheim, and Morrow County; and (c) establishment of an LPO for troilite in Bruderheim and Morrow County and a weak olivine LPO in Morrow County as a result of uniaxial shock compaction.

(5) A large clast in MIL 99301 shows good evidence of having crystallized as a shock melt that was emplaced into a cooler host as a hot intrusive body. This clast records high-temperature deformation and subsequent fast cooling. It may have formed by localized impact melting at a time when parent bodies were cold.

(6) EBSD signatures were largely established as a result of the predominant impact event in the meteorites studied, although there is evidence for multiple impacts affecting MIL 99301 (manifested by differences in large clast and host) and Park (manifested by a distinctive troilite LPO signature). Any late impacts that occurred to eject meteoroids from source bodies left no discernible EBSD signatures.

\section{ACKNOWLEGMENTS}

NASA grant support (NASA Origins and PME programs, grant NNX10AH336 and Supplement) is gratefully acknowledged for prior related research and for the EBSD system that was used in this work. We also thank curators Laurence Garvie, Rhiannon Mayne, and Linda Welzenbach for earlier loans of samples used in this study, and Patricia Clay, Katherine Joy, and Henner Busemann for collaboration on Ar dating of Park and Morrow County. Finally, we thank Drs. Luke Daly and Edward Scott for comments that helped improve the quality of this manuscript and Associate Editor Sasha Krot for suggestions and editorial work.

\section{APPENDIX A: SUPPLEMENTARY DATA}


Supplementary data (Electronic Annex) associated with this article can be found in the online version. 


\section{REFERENCES}

Ashworth J.R. (1985) Transmission electron microscopy of L-group chondrites, 1. Natural shock effects. Earth Planet. Sci. Lett. 73, 17-32.

Ashworth J.R. and Barber D.J. (1975) Electron petrography of shock-deformed olivine in stony meteorites. Earth Planet. Sci. Lett. 27, 43-50.

Bingert J.F., Livescu V. and Cerreta E.K. (2009) Characterization of shear localization and shock damage with EBSD. In Electron Backscatter Diffraction in Materials Science (eds. A. J. Schwartz, M. Kumar, B.L. Adams, D.P. Fields), Chapter 22, 301-315. Springer Science+Business Media, New York.

Blacic J.D. and Christie J.M. (1973) Dislocation substructure of experimentally deformed olivine. Contrib. Mineral. Petrol. 42, 141-146.

Blackburn T., Alexander C.M.O'D., Carlson R., and Elkins-Tanton L.T. (2017) The accretion and impact history of the ordinary chondrite parent bodies. Geochim. Cosmochim. Acta 200, 201-217.

Bland P.A., G.S. Collins, T.M. Davison, N.M. Abreu, F.J. Ciesla, A.R. Muxworthy, and J. Moore 2014. Pressure-temperature evolution of primordial solar system solids during impact-induced compaction. Nature Communications 5, 5451, doi: 10.1038/ncomms6451.

Bogard D.D. and Garrison D.H. (2009) Ar-Ar and I-Xe ages and thermal histories of three unusual metal-rich meteorites. Geochim. Cosmochim. Acta 73, 6965-6983.

Bogard D., Hörz F. and Johnson P. (1987) Shock effects and argon loss in samples of the Leedey L6 chondrite experimentally shocked to 29-70 GPa pressures. Geochim. Cosmochim. Acta 51, 2035-2044.

Brewer L.N. and Michael J.R. (2010) Risks of "cleaning" electron backscatter diffraction data. Microscopy Today 18, 10-15.

Brewer L., Field D.P. and Merriman C.C. (2009) Mapping and assessing plastic deformation using EBSD. In Electron Backscatter Diffraction in Materials Science (eds. A. J. Schwartz, M. Kumar, B.L. Adams, D.P. Fields), Chapter 18, 251-262. Springer Science+Business Media, New York.

Burbine T.H., McCoy T.J., Meibom A., Gladman B. and Keil K. (2002) Meteoritic parent bodies: Their number and identification. In Asteroids III (eds. W.F. Bottke, Jr., A. Cellino, P. Paolicchi, and R. Binzel), pp. 653-667. University of Arizona Press: Tucson.

Carter N.L. and Ave'Lallemant H.G. (1970) High-temperature flow of dunite and peridotite. Geol. Soc. Am. Bull. 81, 2181-2202. 
Carter N.L. (1971) Static deformation of silica and silicates. J. Geophys. Res 76, 55145540 .

Chen M. and El Goresy A. (2000) The nature of maskelynite in shocked meteorites: not diaplectic glass but a glass quenched from shock-induced dense melt at high pressures. Earth Planet. Sci. Lett. 179, 489-502.

Ciesla F.J., Davison T.M., Collins G.S. and O'Brien D.P. (2013) Thermal consequences of impacts in the early solar system. Meteorit. Planet. Sci. 48, 2559-2576.

Davison T.M., Collins G.S. and Ciesla F.J. (2010) Numerical modelling of heating in porous planetesimal collisions. Icarus 208, 468-481.

Davison T.M., Ciesla F.J., and Collins G.S. (2012) Post-impact thermal evolution of porous planetesimals. Geochim. Cosmochim. Acta 95, 252-269.

Davison T.M., O'Brien D.P., Ciesla F.J. and Collins G.S. (2013) The early impact histories of meteorite parent bodies. Meteorit. Planet. Sci. 48, 1849-1918.

Davison T.M., Collins G.S. and Bland P.A. (2016) Mesoscale modeling of impact compaction of primitive solar system solids. Astrophys. J. 821, 68.

de Kloe R., Drury M. and Farrer J.K. (2002) Determination of activated slip systems in experimentally deformed olivine-orthopyroxene polycrystals using EBSD. Micros. Microanal. 8 (Supplement S02), 680-81.

Demouchy S., Tommasi A., Ballaran T.B., Cordier P. (2013) Low strength of Earth's uppermost mantle inferred from tri-axial deformation experiments on dry olivine crystals. Phys Earth Planet Inter 220, 37-49.

Dixon E.T., Bogard D.D., Garrison D.H. and Rubin A.E. (2004). ${ }^{39} \mathrm{Ar}-{ }^{40} \mathrm{Ar}$ evidence for early impact events on the LL parent body. Geochim. Cosmochim. Acta 68, 3779-3790.

Durinck J., Devincre B., Kubin L., Cordier P. (2007) Modeling the plastic deformation of olivine by dislocation dynamics simulations. Am. Mineral. 92,1346-1357.

Farla R.J.M., Fitzgerald J.D., Kokkonen H., Halfpenny A., Faul U.H. and Jackson I. (2011) Slip-system and EBSD analysis on compressively deformed fine-grained polycrystalline olivine. Geological Society, London, Special Publications 360, 225235.

Forman L.V., Bland P.A., Timms N.E., Collins G.S., Davison T.M., Ciesla F.J., Benedix G.K., Daly L., Trimby P.W., Yang L. and Ringer S.P. (2016) Hidden secrets of deformation: Impact-induced compaction within a CV chondrite. Earth Planet. Sci. Lett. 452, 133-145.

Forman L.V., Bland P.A., Timms N.E., Daly L., Benedix G.K., Trimby P.W., Collins G.S. and Davison T.M. (2017) Defining the mechanism for compaction of the CV chondrite parent body. Geology 45 559-562. 
Friedrich J.M., Ruzicka A., Rivers M.L., Ebel D.S., Thostenson J.O. and Rudolph R.A. (2013) Metal veins in the Kernouvé (H6 S1) chondrite: Evidence for pre- or synmetamorphic shear deformation. Geochim. Cosmochim. Acta 116, 71-83.

Friedrich J. M., Weisberg M.K. and Rivers M.L. (2014) Multiple impact events recorded in the NWA $7298 \mathrm{H}$ chondrite breccia and the dynamical evolution of an ordinary chondrite asteroid. Earth Planet. Sci. Lett. 394, 13-19.

Friedrich J.M., Ruzicka A., Macke R.J., Thostenson J.O., Rudolph R.A., Rivers M.L. and Ebel D.S. (2017) Relationships among physical properties as indicators of high temperature deformation or post-shock thermal annealing in ordinary chondrites. Geochim. Cosmochim. Acta 203, 157-174.

Gaboriaud R.J., Darot M., Guegen Y. and Woirgard J. (1981) Dislocations in olivine indented at low temperatures. Phys. Chem. Minerals 7, 100-104.

Gaboriaud R.J. and Denanot M.-F. (1982) Étude d'un sous-joint de dislocations dans l'olivine naturelle. Bull. Minéral. 105, 181-187.

Gail H.P., Henke S. and Trieloff M. (2015) Thermal evolution and sintering of chondritic planetesimals-II. Improved treatment of the compaction process. Astronomy \& Astrophysics 576, A60.

Ganguly J., Tirone M., Chakraborty S. and Domanik K. (2013) H-chondrite parent asteroid: A multistage cooling, fragmentation and re-accretion history constrained by thermometric studies, diffusion kinetic modeling and geochronological data. Geochim. Cosmochim. Acta 105, 206-220.

Ganguly J., Tirone M. and Domanik K. (2016) Cooling rates of LL, L and H chondrites and constraints on the duration of peak thermal conditions: Diffusion kinetic modeling and implications for fragmentation of asteroids and impact resetting of petrologic types. Geochim. Cosmochim. Acta 192, 135-148.

Goezte C. (1978) The mechanisms of creep in olivine. Phil. Trans. R. Soc. Lond. A. 288, $99-119$.

Goetze C. and Kohlstedt D.L. (1973) Laboratory study of dislocation climb and diffusion in olivine. J. Geophys. Res. 78, 5961-5971.

Goldstein J.I., Scott E.R.D. and Chabot N.L. (2009) Iron meteorites: Crystallization, thermal history, parent bodies, and origin. Chemie der Erde-Geochemistry 69, 293325.

Green H.W., II (1976) Plasticity of olivine in peridotites. In Electron Microscopy in Mineralogy (ed. H.-R. Wenk). Springer-Verlag, Berlin. Ch. 6.6, pp. 443-464. 
Green H.W. II and S.V. Radcliffe (1972) Deformation processes in the upper mantle. In Flow and Fracture of Rocks, Geophys. Monogr. 16, 139-156.

Grimm R.E. (1985) Penecontemporaneous metamorphism, fragmentation, and reassembly of ordinary chondrite parent bodies. J. Geophys. Res. 90, 2022-2028.

Gueguen Y. and Nicolas A. (1980) Deformation of mantle rocks. Ann. Rev. Earth Planet. Sci. 8, 119-144.

Harrison K.P. and R.E. Grimm (2010) Thermal constraints on the early history of the Hchondrite parent body reconsidered. Geochim. Cosmochim. Acta 74, 5410-5423.

Henke S., Gail H.P., Trieloff M. and Schwarz W.H. (2013) Thermal evolution model for the $\mathrm{H}$ chondrite asteroid-instantaneous formation versus protracted accretion. Icarus 226, 212-228.

Huss G.R., Rubin A.E. and Grossman J.N. (2006) Thermal metamorphism in chondrites. In Meteorites and the Early Solar System II (eds. D.S. Lauretta and H.Y. McSween Jr.), 567-586. University of Arizona Press: Tucson.

Hutson M., Hugo R., Ruzicka A. and Killgore M. (2007) Annealing after shock: Evidence from olivine microstructures in Portales Valley. Meteorit. Planet. Sci. 42, Abstract \#5072.

Hutson M.L., Hugo R., Ruzicka A.M. and Rubin A.E. (2009) Olivine microstructures in the Miller Range 99301 (LL6) ordinary chondrite. Lunar Planet Sci. XXXX, Abstract \#1081, Lunar and Planetary Institute.

Idrissi H., Bollinger C., Boioli F., Schryvers D. and Cordier P. (2016) Low-temperature plasticity of olivine revisited with in situ TEM nanomechanical testing. Science Advances 2 (3), AAAS e1501671-e1501671. doi:10.1126/sciadv.1501671

Ismaïl W.B. and Mainprice D. (1998) An olivine fabric database: an overview of upper mantle fabrics and seismic anisotropy. Tectonophysics 296, 145-157.

Jamsja N. and Ruzicka A. (2010) Shock and thermal history of NWA 4859, an annealed impact-melt breccia of LL-chondrite parentage containing unusual igneous features and pentlandite. Meteorit. Planet. Sci. 45, 828-849.

Jarosewich E. (1990) Chemical analyses of meteorites: A compilation of stony and iron meteorite analyses. Meteorit. Planet. Sci. 25, 323-337.

Karato S.I., Jung H., Katayama I. and Skemer P. (2008) Geodynamic significance of seismic anisotropy of the upper mantle: new insights from laboratory studies. Annu. Rev. Earth Planet. Sci. 36, 59-95.

Keil K., Haack H. and Scott E.R.D. (1994) Catastrophic fragmentation of asteroids: Evidence from meteorites. Planet. Space Sci., 42, 1109-1122. 
Keil K., Stöffler D., Love S.G. and Scott E.R.D. (1997) Constraints on the role of impact heating and melting in asteroids. Meteorit. Planet. Sci. 32, 349-363.

Kirby S.H. and Wegner M.W. (1978) Dislocation substructure of mantle-derived olivine as revealed by selective chemical etching and transmission electron microscopy. Phys. Chem. Minerals 3, 309-330.

Kleine T., Touboul M., Van Orman J.A., Bourdon B., Maden C., Mezger K. and Halliday A.N. (2008) Hf-W thermochronometry: closure temperature and constraints on the accretion and cooling history of the $\mathrm{H}$ chondrite parent body. Earth Planet. Sci. Lett. 270, 106-118.

Kring D.A., Hill D.H., Gleason J.D., Britt D.T., Consolmagno G.J., Farmer M., Wilson S. and Haag R. (1999) Portales Valley: A meteoritic sample of the brecciated and metal-veined floor of an impact crater on an $\mathrm{H}$ chondrite asteroid. Meteorit. Planet. Sci. 34, 663-669.

Kübler L. (1985) Deformation mechanisms in experimentally deformed single crystals of pyrrhotite, Fe 1-x S. Phys. Chem. Minerals 12, 353-362.

Langenhorst F., Joreau P. and Claude-Doukhan J. (1995) Thermal and shock metamorphism of the Tenham chondrite: A TEM examination. Geochim. Cosmochim. Acta 59, 1835-1845.

Langenhorst F., Poirier J.-P., Deutsch A. and Hornemann U. (2002) Experimental approach to generate shock veins in single crystal olivine by shear melting. Meteorit. Planet. Sci. 37, 1541-1553.

Leroux H. (2001) Microstructural shock signatures of major minerals in meteorites. Eur. J. Mineral. 13, 253-272.

Lloyd G. E., Farmer A.B. and Mainprice D. (1997) Misorientation analysis and the formation and orientation of subgrain and grain boundaries. Tectonophysics $\mathbf{2 7 9}$, 55-78.

Mainprice D. and Nicolas A. (1989) Development of shape and lattice preferred orientations: application to the seismic anisotropy of the lower crust. J. Structural Geol. 11, 175-189.

Mishin O.V., Godfrey A. and Jensen D.J. (2009) Analysis of deformation structures in FCC materials using EBSD and TEM techniques. In Electron Backscatter Diffraction in Materials Science (eds. A. J. Schwartz, M. Kumar, B.L. Adams, D.P. Fields), Chapter 19, 263-275. Springer Science+Business Media, New York.

Monnereau, M., Toplis M.J., Baratoux D. and Guignard J. (2013) Thermal history of the Hchondrite parent body: Implications for metamorphic grade and accretionary timescales. Geochim. Cosmochim. Acta 119, 302-321. 
Müller W.F. and Hornemann U. (1969) Shock-induced planar deformation structures in experimentally shock-deformed olivine from chondritic meteorites. Earth Planet. Sci. Lett. 7, 251-264.

Mussi A., Cordier P., Demouchy S. and Vanmansart C. (2014) Characterization of the glide planes of the [001] screw dislocations in olivine using electron tomography. Phys. Chem. Minerals 41, 537-545.

Niederschlag E. and Siemes H. (1996) Infulence of initial texture, temperature and total strain on the texture development of polycrystalline pyrrhotite ores in deformation experiments. Textures \& Microstructures 28, 129-148.

Passchier C.W. and Trouw R.A.J. (2005) Microtectonics ( $2^{\text {nd }}$ Ed). Springer. 366 pp.

Phakey P., Dollinger G. and Christie J. (1972) Transmission electron microscopy of experimentally deformed olivine crystals. In Flow and Fracture of Rocks, Geophys. Monogr. 16,139-156.

Pinault L. J., Scott E. R. D., Bogard D. D. and Keil K. (1999). Extraordinary properties of the metal-veined, $\mathrm{H} 6$ Portales Valley chondrite: Evidence for internal heating versus shock-melting origins. Lunar Planet. Sci. Conf. 30, 1999.

Prior D.J., Mariani E. and Wheeler J. (2009) EBSD in the Earth Sciences: Applications, common practice, and challenges. In Electron Backscatter Diffraction in Materials Science (eds. A. J. Schwartz, M. Kumar, B.L. Adams, D.P. Fields), Chapter 26, 345360. Springer Science+Business Media, New York.

Raleigh C.B. (1965) Glide mechanism in experimentally deformed minerals. Science 150, 739-741.

Raleigh C.B. (1967) Plastic deformation of upper mantle silicate minerals. Geophys. J. Royal Astron. Soc. 14, 45-49.

Raleigh C.B. (1968) Mechanisms of plastic deformation of olivine. J. Geophys. Res. 73, 5391-5406.

Rubin A.E. (1995) Petrologic evidence for collisional heating of chondritic asteroids. Icarus 113, 156-167.

Rubin A.E. (2002) Post-shock annealing of Miller Range 99301 (LL6): Implications for impact heating of ordinary chondrites. Geochim. Cosmochim. Acta 66, 3327-3337.

Rubin A.E. (2003) Northwest Africa 428: Impact-induced annealing of an L6 chondrite breccia. Meteorit. Planet. Sci. 38, 1499-1506.

Rubin A.E. (2004) Postshock annealing and postannealing shock in equilibrated ordinary chondrites: Implications for the thermal and shock histories of chondritic asteroids. Geochim. Cosmochim. Acta 68, 673-689. 
Rubin A. E. and Jones R. H. (2003) Spade: An H chondrite impact-melt breccia that experienced post-shock annealing. Meteorit. Planet. Sci. 38, 1507-1520.

Rubin A. E., Ulff-Møller F., Wasson J.T. and Carlson W.D. (2001) The Portales Valley meteorite breccia: Evidence for impact induced melting and metamorphism of an ordinary chondrite. Geochim. Cosmochim. Acta 66, 323-342.

Ruzicka A. (2014) Silicate-bearing iron meteorites and their implications for the evolution of asteroidal parent bodies. Chemie der Erde-Geochemistry 74, 3-48.

Ruzicka A.M. and Hugo R.C. (2017) EBSD analyses of seven ordinary chondrites: Deformation metrics and implications for parent body thermal histories. Meteorit. Planet. Sci., Abstract \#6368

Ruzicka, A., Killgore M., Mittlefehldt D.W. and Fries M.D. (2005) Portales Valley: Petrology of a metallic-melt meteorite breccia. Meteorit. Planet. Sci. 40, 261-295.

Ruzicka A., R. Hugo and M. Hutson (2015a) Deformation and thermal histories of ordinary chondrites: Evidence for post-deformation annealing and syn-metamorphic shock. Geochim. Cosmochim. Acta 163, 219-233.

Ruzicka A.M., Clay P.M., Hugo R., Joy K.H. and Busemann H. (2015b) Contrasting early and late shock effects on the $\mathrm{L}$ chondrite parent body: Evidence from $\mathrm{Ar}$ ages and olivine microstructures for two meteorites. Meteorit. Planet. Sci., Abstract \#5177.

Ruzicka A., Haack H., Scott E.R.D., and Chabot N. (2017) Iron and stony-iron meteorites: evidence for the formation, crystallization and early impact histories of differentiated planetesimals. In Planetesimals: Early Differentiation and Consequences for Planets, Chapter 7 (Cambridge University Press).

Schmitt R.T. (2000) Shock experiments with the H6 chondrite Kernouvé: Pressure calibration of microscopic shock effects. Meteorit. Planet. Sci. 35, 545-560.

Scott E. R. and Pinault L. J. (1999) Partial melting and incipient segregation of troilite and metal in winonaites, acapulcoites, IAB and IIE irons, and fine-grained $\mathrm{H} 6$ chondrites. Lunar Planet. Sci. Conf. 30, 1507.

Scott E.R., Haack H. and Love S.G. (2001) Formation of mesosiderites by fragmentation and reaccretion of a large differentiated asteroid. Meteorit. Planet. Sci. 36, 869-881.

Scott E.R.D., T.V. Krot T.V., Goldstein J.I. and Wakita S. (2014) Thermal and impact history of the $\mathrm{H}$ chondrite parent asteroid during metamorphism: Constraints from metallic Fe-Ni. Geochim. Cosmochim. Acta 136, 13-27

Schwarzer R.A., Field D.P., Adams B.L., Kumar M. and Schwartz A.J. (2009) Present state of electron backsctatter diffraction and prospective developments. In Electron 
Backscatter Diffraction in Materials Science, $2^{\text {nd }}$ Edition (eds. A.J. Schwartz, M. Kumar, B.L. Adams, D.P. Field), Springer, 231-249.

Sears D.W., Ashworth J.R., Broadbent C.P. and Bevan A.W.R. (1984) Studies of artificially shock-loaded H group chondrite. Geochim. Cosmochim. Acta 48, 343-360.

Sharp T.G. and DeCarli P.S. (2005) Shock effects in meteorites. In Meteorites and the Early Solar System II (eds. D.S. Lauretta and H.Y. McSween, Jr.), 653-677. The University of Arizona Press: Tucson.

Stöffler D., A. Bischoff, V. Buchwald and A.E. Rubin (1988) Shock effects in meteorites. In Meteorites and the Early Solar System (eds. J. F. Kerridge, M. S. Matthews), 165202. The University of Arizona Press: Tucson.

Stöffler D., Keil K. and Scott E.R.D. (1991) Shock metamorphism in ordinary chondrites. Geochim. Cosmochim. Acta 55, 3845-3867.

Swindle T.D., Kring D.A. and Weirich J.R. (2014) ${ }^{40} \mathrm{Ar} /{ }^{39} \mathrm{Ar}$ ages of impacts involving ordinary chondrite meteorites. Geological Society of London, Special Publications 378, 333-347. doi: 10.1144/SP378.6

Tait A.W., Fisher K.R., Srinivasan P. and Simon J.I. (2016) Evidence for impact induced pressure gradients on the Allende CV3 parent body: consequences for fluid and volatile transport. Earth Planet. Sci. Lett. 454, 213-224.

Takahashi E. (1983) Melting of a Yamato L3 chondrite (Y-74191) up to 30 kbar. National Institute Polar Research Memoirs 30, 168-180.

Taylor G.J., Maggiore P., Scott E.R.D., Rubin A.E. and Keil K. (1987) Original structures and fragmentation and reassembly histories of asteroids: Evidence from meteorites. Icarus 69, 1-13.

Tielke J.A., Zimmerman M.E. and Kohlstedt D.L. (2016) Direct shear of olivine single crystals. Earth Planet. Sci. Lett. 455, 140-148.

Tkalcec B.J., Golabek G.J. and Brenker F.E. (2013) Solid-state plastic deformation in the dynamic interior of a differentiated asteroid. Nature Geoscience 6, 93-97.

Tommasi A., Mainprice D., Canova G. and Chastel Y. (2000) Viscoplastic self-consistent and equilibrium-based modeling of olivine lattice preferred orientations: Implications for the upper mantle seismic anisotropy. J. Geophys. Res. (Solid Earth) 105(B4), 7893-7908.

Tomkins A.G., Weinberg R.F., Schaefer B. F. and Langendam A. (2013) Disequilibrium melting and melt migration driven by impacts: Implications for rapid planetesimal core formation. Geochim. Cosmochim. Acta 100, 41-59. 
Trieloff M., Jessberger E.K., Herrwerth I. and Hopp J. (2003) Structure and thermal history of the $\mathrm{H}$-chondrite parent asteroid revealed by thermochronometry. Nature $\mathbf{4 2 2}$, 502-506.

Turner G. (1969) Thermal histories of meteorites by the $\mathrm{Ar}^{39}-\mathrm{Ar}^{40}$ method. In Meteorite Research (ed. P.M. Millman), 407-417. D. Reidel, Dordrecht, Holland.

Usselman T.M. (1975) Experimental approach to the state of the core; Part I, The liquidus relations of the Fe-rich portion of the Fe-Ni-S system from 30 to $100 \mathrm{~kb}$. Am. J. Sci. 275, 278-290.

Watt L.E., Bland P.A., Prior D.J. and Russell S.S. (2006) Fabric analysis of Allende matrix using EBSD. Meteorit. Planet. Sci. 41, 989-1001.

Yang J., Goldstein J.I. and Scott E.R.D. (2007) Iron meteorite evidence for early formation and catastrophic disruption of protoplanets. Nature 446, 888-891.

Yang J., Goldstein J.I. and Scott E.R. (2010) Main-group pallasites: Thermal history, relationship to IIIAB irons, and origin. Geochim. Cosmochim. Acta 74, 4471-4492. 


\section{FIGURE CAPTIONS}

Figure 1. Portales Valley (PV) EBSD data. (a) Portion of large area map (LAM) showing Grain Orientation Spread (GOS) values for olivine grains (color) + band contrast $(B C)$ for other pixels (monochrome). The box marks the area covered in part d. (b) Normalized number of grains vs. GOS values for olivine (relative to maximum $=1536$ grains with 0.15 $0.20^{\circ}$ GOS, LAM data); PV olivine grains mostly have GOS $<1^{\circ}$ (blue colors). (c) Same as part b except logarithmic frequency of grains, emphasizing the presence of elevated-GOS grains (2-8 ${ }^{\circ}$, blue-green to green colors) in PV, visible also in part a. (d) Portion of large area map centered on chondrule showing Grain Orientation Deviation angle (GROD angle) for olivine (color) $+\mathrm{BC}$ (monochrome). Olivine grain boundaries ( $>15^{\circ}$ misorientation) are shown by silver lines, subgrain boundaries are shown by other colors (red $=2-4^{\circ}$, yellow $=$ $4-7^{\circ}$, blue $=7-15^{\circ}$ misorientation). Grains $71 \mathrm{a}$ and $71 \mathrm{~b}$ represent grains with elevated GOS $\left(\sim 3^{\circ}\right)$ and low GOS $\left(<1^{\circ}\right)$, respectively. Lines A-B and C-D indicate locations of misorientation profiles shown in parts $\mathrm{f}$ and $\mathrm{g}$. (e) Normalized number of pixels vs. GROD angle (relative to maximum $=26310$ pixels with $0.15-0.17^{\circ}$ GROD angle, LAM data); PV olivine grains mostly have GROD angle values $<2^{\circ}$ (blue and blue-green colors). (f) Misorientation profile A-B in grain 71a (orientation relative to first point), which crosses subgrain boundaries at $x\left(\sim 4.5^{\circ}\right.$ misorientation with rotation axis $\left.\sim<113>\right)$ and $y\left(\sim 5^{\circ}\right.$ misorientation with rotation axis $\sim<100>$ ). (g) Misorientation profile $C-D$ (orientation relative to first point) along $<001>$ trace of grain $71 \mathrm{~b}$, which shows apparent noise of $\sim$ $\pm 0.1^{\circ}$ superposed on overall variation of $\sim 0.7^{\circ}$ with $\sim 401>$ misorientation rotation axis. Acronyms as in Sec. 2.

Figure 2. Bruderheim (Brd) EBSD data. (a) Portion of large area map showing GOS values for olivine grains (color) $+B C$ (monochrome). (b) Normalized number of grains vs. GOS values for olivine (relative to maximum = 537 grains with 2.10-2.15 $\mathrm{GOS}$, LAM data); Brd olivine grains mostly have GOS 1-7० (blue-green to yellow-green colors). (c) Portion of 4field targeted map centered on a chondrule showing GROD angle for olivine (color) $+B C$ (monochrome). Grains 7, 7a, 7b and 8 have typical GOS values for $\operatorname{Brd}\left(\sim 5^{\circ}, \sim 2^{\circ}, \sim 4^{\circ}\right.$ and $\sim 4^{\circ}$, respectively), with subparallel fractures and boundaries along which misorientation occurs. Planar fractures sometimes are filled with crystalline material (e.g., black arrows, grains 7 and 8) and sometimes have lateral displacement (paired arrows, grain 7b). Lines 
A-B and C-D represent locations of misorientation profiles shown in parts e and f. Apparent offset of crystalline fracture in the upper left of grain 8 is a montage artifact. (d) Normalized number of pixels vs. GROD angle (relative to maximum $=3274$ pixels with $2.30-2.32^{\circ}$ GROD angle, LAM data), with color coding the same as for part c; for Brd olivine, GROD angle values of $\leq 9^{\circ}$ (blue to yellow-green) are common, and sometimes exceed $15^{\circ}$. (e) Misorientation profile A-B (orientation relative to first point) along the $\sim<001>$ trace of grain 7, across optically-visible lamellar extinction, showing sudden changes (subgrain boundaries) and more gradual changes (warping), with an overall misorientation rotation axis between $A$ and $B$ of $\sim<401>$. (f) Misorientation profile $C-D$ (orientation relative to first point) along the $\sim<010>$ trace of grain 7 , showing overall warping and some sudden changes, with an overall misorientation rotation axis between C and D of $\sim<10>$. Acronyms as in Fig. 1 and Sec. 2.

Figure 3. Park EBSD data. (a) Portion of large area map showing GOS values for olivine grains (color) + BC (monochrome). The box marks the area covered in part c. (b) Normalized number of grains vs. GOS values for olivine (relative to maximum $=2066$ grains with $0.20-0.25^{\circ} \mathrm{GOS}$, LAM data); Park olivine grains mostly have GOS $<2^{\circ}$ (blue and blue-green colors) with a long "tail" to higher values (green colors, $\sim 1 \%$ of maximum at $5^{\circ}$ GOS) . (c) Portion of targeted Area 2 including top portion of relict chondrule and adjacent area showing GROD angle for olivine (color) $+B C$ (monochrome). Olivine grain boundaries $\left(>15^{\circ}\right.$ misorientation) are shown by silver lines, subgrain boundaries are shown by other colors (red $=2-4^{\circ}$, yellow $=4-7^{\circ}$, blue $=7-15^{\circ}$ misorientation). Grains 20 and $20 \mathrm{a}$ have similar GOS values $\left(\sim 2^{\circ}\right)$ but different types of internal deformation, dominated in grain 20 by subgrain boundaries and in grain 20 a by warping. A variety of misorientation rotation axes occur in these grains. Grain 20b is representative of a low-GOS grain $\left(<1^{\circ}\right)$ and has a similar orientation (normal [530]) as grain 20a (normal [521]). Lines A-B and C-D mark the locations of misorientation profiles shown in parts e and f. (d) Normalized number of pixels vs. GROD angle (relative to maximum $=20055$ pixels with $0.23-0.25^{\circ}$ GROD angle, LAM data), with color coding the same as for part c; for Park olivine, GROD angle values of $\leq 4^{\circ}$ (blue to green) are common. (e) Misorientation profile A-B (orientation relative to first point) in grain 20 , which crosses three subgrain boundaries that have different rotation axes but which are grossly subparallel to $\sim<001>$. (f) Misorientation profile C-D (orientation relative to first point) along the $\sim<001>$ trace of grain 20 a showing 
dominant warping, with misorientation rotation axis (center-right) of $\sim<141>$. Acronyms as in Fig. 1 and Sec. 2.

Figure 4. MIL 99301 (MIL) EBSD data. (a) Portion of large area map showing GOS values for olivine grains (color) $+B C$ (monochrome). The approximate outline for part $\mathrm{d}$ is indicated. (b) Normalized number of grains vs. GOS values for olivine in host (relative to maximum $=994$ grains with $0.30-0.35^{\circ}$ GOS, LAM data); MIL host olivine grains mostly have GOS $<1^{\circ}$ (blue colors). (c) Normalized number of grains vs. GOS values for olivine in clast (relative to maximum $=84$ grains with $0.70-0.75^{\circ} \mathrm{GOS}$, LAM data); MIL clast olivine grains commonly have GOS $\leq 6-7^{\circ}$ (blue to green colors). (d) 6-field targeted map covering portion of clast (above) and host (below and right) showing inverse pole figure (IPFy) orientations of olivine in $y$ (top-down) direction (color) $+B C$ (monochrome). Box marks the location of part $\mathrm{f}$; black arrow at right indicates interfingering contact between clast (colored) and coarse host metal (bright); white arrow and $\mathrm{R}$ indicate recrystallized olivine. (e) Pole figures for clast olivine grains shown in two forms: scattered data with IPFy colors (top); and contoured data (below, 1 point per pixel) in terms of MUD (multiples of uniform density) values (6-field targeted data, 335919 grains, upper hemisphere equal-area projection; for contour plots, minimum MUD $=0.01$ as blue, maximum MUD $=6.56$ as red, contouring performed with $25^{\circ}$ contour half-width). Data indicate a strong lattice preferred orientation for olivine in the clast (orientation 1 and 2 for $<010>$, split into two parts (2a and $2 \mathrm{~b}$ for orientation 2) for $<100>$ and $<001>$ ). (f) Portion of 6 -field targeted map showing phases (colors) $+B C$ (monochrome). The clast is fine grained and interfingers with host metal (fcc $\mathrm{Fe}=$ taenite) and troilite. Some chromite pixels in the two largest host grains have been mis-indexed as fcc Fe (known to be taenite from chemical and other data). (g) Orientations and approximate GOS values for taenite in the 3 locations ( $x, y, z)$ shown in part $f$. Orientations at $x$ and $y$ for grains in contact with the clast are similar; GOS increases away from the clast. Acronyms as in Fig. 1 and Sec. 2.

Figure 5. EBSD data for troilite. (a) Portion of 5-field targeted map in Leedey showing $G R O D$ angle for troilite grains (color) $+B C$ for other pixels (monochrome). Troilite grain boundaries $\left(>15^{\circ}\right.$ misorientation) are shown by silver lines, subgrain boundaries are shown by other colors (red $=2-4^{\circ}$, yellow $=4-7^{\circ}$, blue $=7-15^{\circ}$ misorientation). $R=$ recrystallized grains. (b) Portion of large area map for Morrow County showing inverse pole figure (IPFX) 
orientations for troilite grains (color) $+B C$ (other pixels). Grains are coarsely polycrystalline. (c) Portion of targeted Area 3 in Park showing GOS values for troilite (color) $+B C$ for other pixels. Troilite is finely polycrystalline with a mixture of high-GOS (deformed) and low-GOS (recrystallized) grains. $M=$ bcc metal (deformed + recrystallized, possible martensite texture). (d) Portion of large area map for Portales Valley showing inverse pole figure (IPFX) orientations for troilite grains (color) $+B C$ for other pixels. Grains are monocrystalline, but have similar orientations (e.g., A, B, C, indicated by similar colors) in multi-millimeter domains. Acronyms as in Fig. 1 and Sec. 2.

Figure 6. Relationship between various EBSD deformation parameters for olivine, shown by mean Kernel Average Misorientation (KAM) and (a) mean MOS (Maximum Orientation Spread) and (b) mean GOS as determined from EBSD large area map data (Table 1). Bar lengths equal $1 \sigma$ in GOS and MOS. Meteorite abbreviations: $\mathrm{Krn}=$ Kernouvé, $\mathrm{PV}=$ Portales Valley, MIL = MIL 99301. Acronyms as in Fig. 1 and Sec. 2.

Figure 7. Relationship between EBSD and OM deformation parameters for olivine. Shown are weighted shock stage in olivine determined optically (Ruzicka et al., 2015a; Friedrich et al., 2017), and (a) mean GOS and (b) mean MOS values determined from EBSD large area maps for grains with effective diameters greater than $50 \mu \mathrm{m}\left(G O S_{d>50}\right.$ and $M O S_{d>50}$ values) (Table 1), the same size range used to determine shock stage. Bar lengths equal 1б. Data for MIL 99301 includes both host and clast. Acronyms as in Fig. 1, Fig. 6 and Sec. 2.

Figure 8. Relationship between olivine EBSD and TEM data, shown by average geometric dislocation density $\left(\rho_{g}\right)$ in TEM areas determined by Ruzicka et al. (2015a), and (a) mean KAM and (b) mean GOS determined by EBSD in large area maps (Table 1). Meteorite abbreviations: $\mathrm{Krn}=$ Kernouvé, PV = Portales Valley, MIL = MIL 99301. Acronyms as in Fig. 1 and Sec. 2.

Figure 9. Crystal Rotation Axis (CRA) plots for olivine showing the direction of rotation axes in crystal coordinates, for boundaries with $2-10^{\circ}$ misorientations based on large area map data (Table 2) arranged according to increasing mean $G O S_{d>50}$. Plots are equal area and contoured ( $25^{\circ}$ half width) in terms of MUD values, with redder areas indicating higher 
MUD values and bluer indicating lower MUD values. Maxima tend to occur in low-index $<100>,<010\rangle$, and $<001>$ directions but patterns vary by meteorite. Acronyms as in Fig. 1 , Fig. 4 and Sec. 2.

Figure 10. Possible slip systems for olivine in the CRA-plot format (Fig. 9). Colors are coded to represent implied deformation temperature (progressively warmer from blue to green, yellow, orange, and red; grey "a+ c slip" indicates a special case not directly related to deformation temperature). See Text. Modified after de Kloe et al. (2002). Acronyms as in Fig. 9 and Sec. 2.

Figure 11. Ternary diagram illustrating rotation axis directions for misorientation boundaries in olivine, in terms of MUD values in the $\langle 100\rangle,\langle 010\rangle$, and $<001\rangle$ directions of olivine (Table 2, LAM data). Data are shown both for $0.5-2^{\circ}$ and $2-10^{\circ}$ misorientations; lines connect meteorites and MIL lithologies. Data for Leedey, Bruderheim, and Morrow County indicate a prevalence of misorientation rotation axes in the $<100\rangle$ direction, suggestive of low-temperature deformation, whereas data for Park, MIL 99301 (host and clast), Portales Valley (2-10 misorientation data), and Kernouvé indicate a higher prevalence of misorientation rotations axes in the $<010>$ or $<001>$ directions, suggestive of higher-temperature deformation (see Text). Meteorite symbol patterns and abbreviations as in Figs. 6-8; acronyms as in Fig. 1, Fig. 9 and Sec. 2.

Figure 12. Comparison of inferred olivine annealing parameters for mesoscale EBSD and microscale TEM data, based on (mean $G O S_{d>50} /$ median $G O S_{d>50}$ ) in large area maps (Table 1), and average \% free/(free+bound) dislocation ratios, respectively. Both EBSD and TEM data suggest annealing for Portales Valley, Kernouvé, and the MIL 99301 host; EBSD data suggest Park was also annealed. Meteorite symbol patterns and abbreviations as in Figs. 6-8, acronyms as in Fig. 1 and Sec. 2.

Figure 13. Pole figure plots (equal area, upper hemisphere, 1 point per grain) based on LAM data for (a) olivine in MIL 99301 clast, (b) olivine in Morrow County, (c) troilite in Portales Valley, (d) troilite in Bruderheim, (e) troilite in Morrow County, (f) troilite in Leedey. Plots are contoured ( $25^{\circ}$ half width) in terms of MUD values, with redder areas indicating 
higher MUD values and bluer indicating lower MUD values (though scales are different for each part). Acronyms as in Fig. 1, Fig. 4 and Sec. 2.

Figure 14. Relationship between inferred olivine annealing parameter (mean $\mathrm{GOS}_{\mathrm{d}>50} /$ median $\left.\mathrm{GOS}_{\mathrm{d}>50}\right)$ and inferred deformation temperature parameter $\left(\mathrm{f}_{<001>}+\mathrm{f}_{<010>}\right.$ for 2-10 misorientations) derived from large area maps (Tables 1,2). Data fall into three groups, labeled 1 (Bruderheim, Leedey, Morrow County), 2 (MIL 99301 clast), and 3 (Portales Valley, Kernouvé, MIL 99301 host, Park). Meteorite symbol patterns and abbreviations as in Figs. 6-8; acronyms as in Fig. 1 and Sec. 2.

Figure 15. Relationship between ${ }^{40} \mathrm{Ar} /{ }^{39} \mathrm{Ar}$ ages and olivine EBSD large area map metrics including (a) inferred annealing parameter (mean $G O S_{d>5}$ dmedian $G O S_{d>50}$ ), and (b) inferred deformation temperature parameter (fraction of $\langle 001\rangle$ and $\langle 010\rangle$ rotation axes, 2 $10^{\circ}$ misorientations). Insets show an expanded scale for the four oldest meteorites $(\mathrm{H}, \mathrm{L}$, and $\mathrm{LL}$ refer to the groups of these meteorites). ${ }^{40} \mathrm{Ar} /{ }^{39} \mathrm{Ar}$ age plateau data, from oldest to youngest: Park (4528.0 $\pm 4.6 \mathrm{Ma}$; Ruzicka et al., 2015b); MIL 99301 (4520 \pm 80 and 4230 $\pm 30 \mathrm{Ma}$; Dixon et al., 2004); Kernouvé (4469 \pm 6 Ma; Trieloff et al., 2003); Portales Valley (4467.5 \pm 13.4 Ma; Bogard and Garrison, 2009); Leedey (3800 $\pm 100 \mathrm{Ma}$; Bogard et al., 1987 and Swindle et al., 2014); Bruderheim (465 \pm 30 Ma; Turner, 1969 and Swindle et al., 2014); and Morrow County (460 \pm 10 Ma; Ruzicka et al., 2015b). MIL 99301 host and clast are assigned to the older and younger of the two ages for this meteorite, respectively. Dashed lines show hypothetical trends. Symbols and abbreviations are as in Fig. 6-8; acronyms as in Fig. 1 and Sec. 2. 
Fig. 1
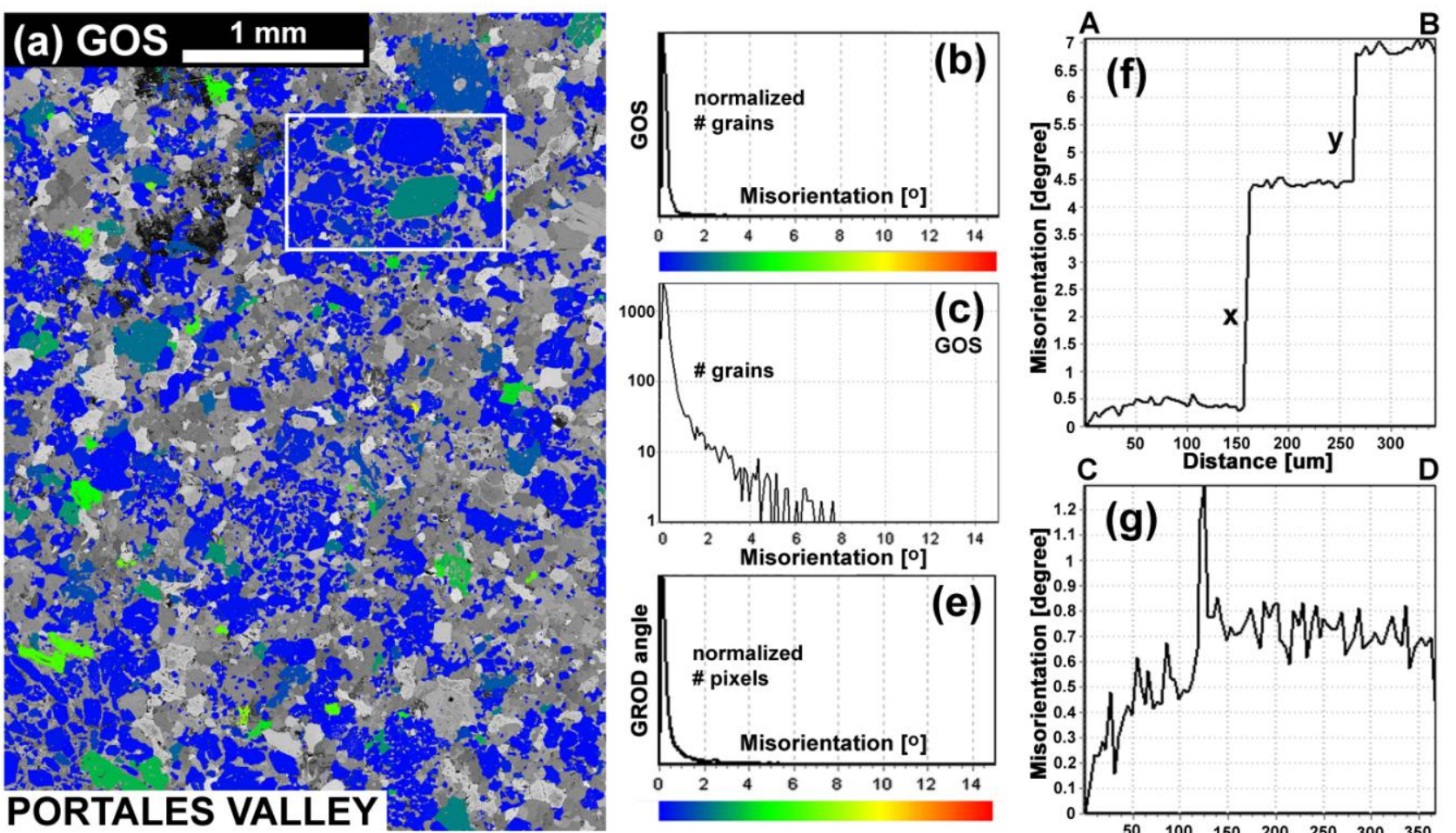

\section{(d) GROD angle}

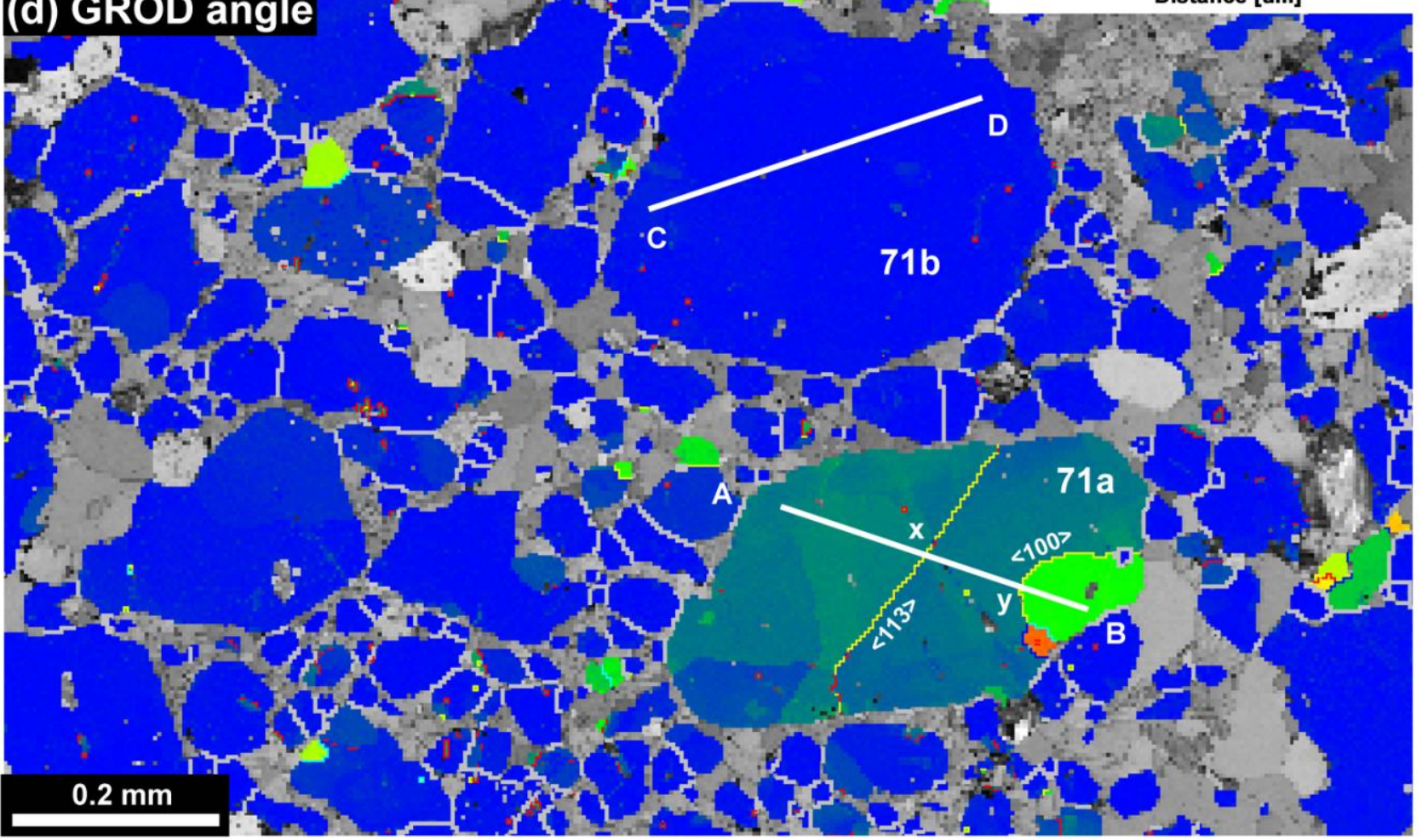


Fig. 2

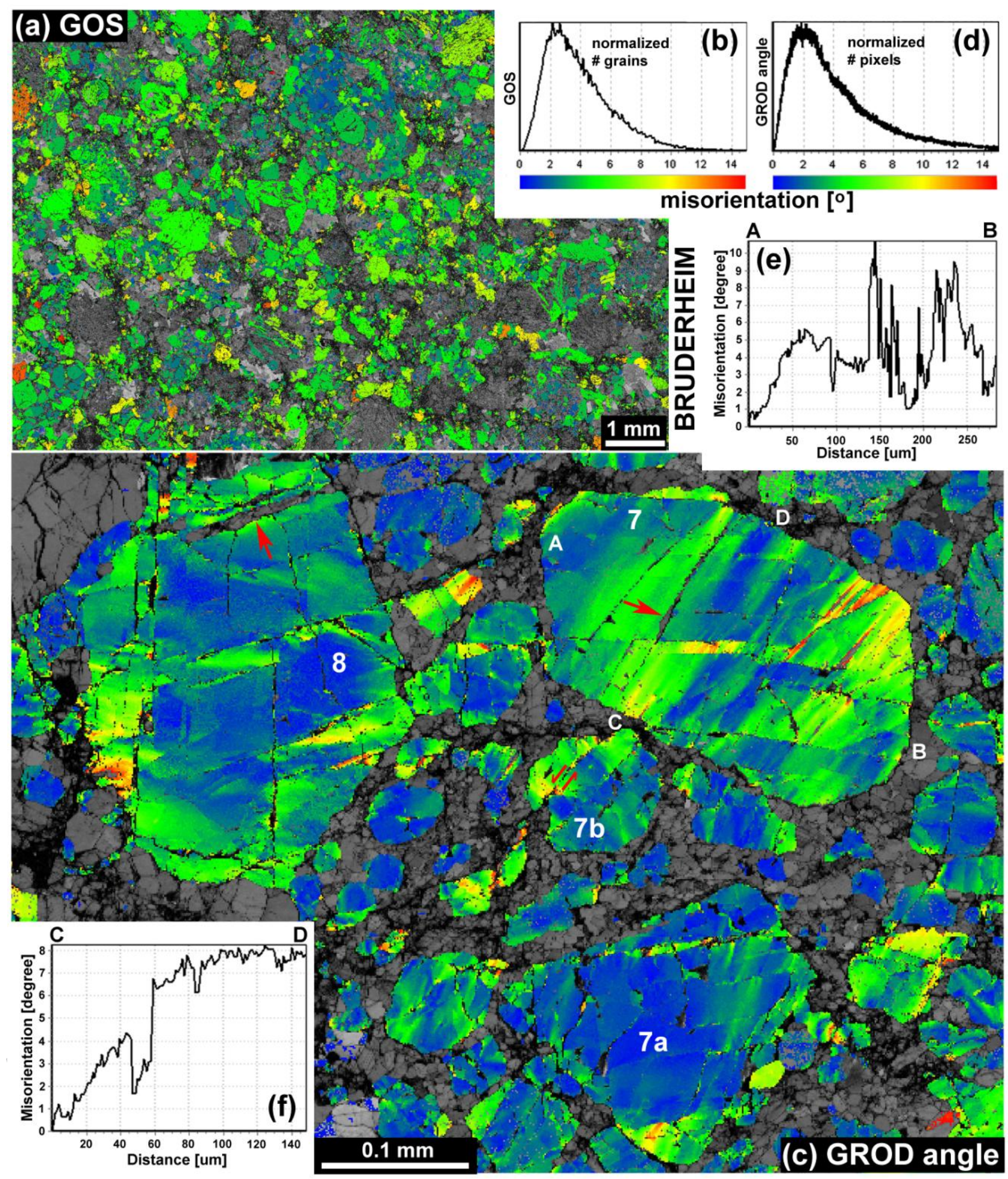


Fig. 3

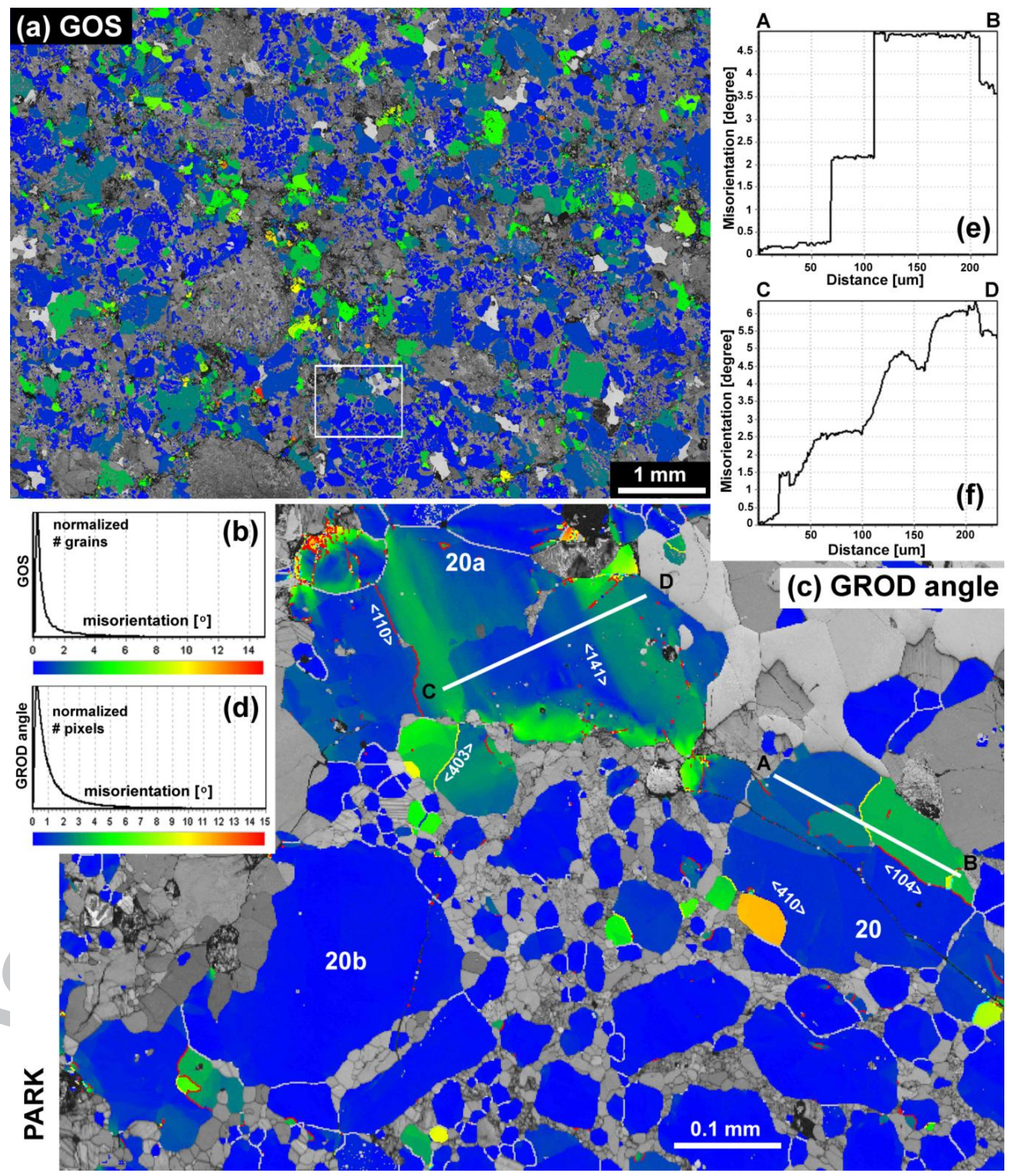


Fig. 4

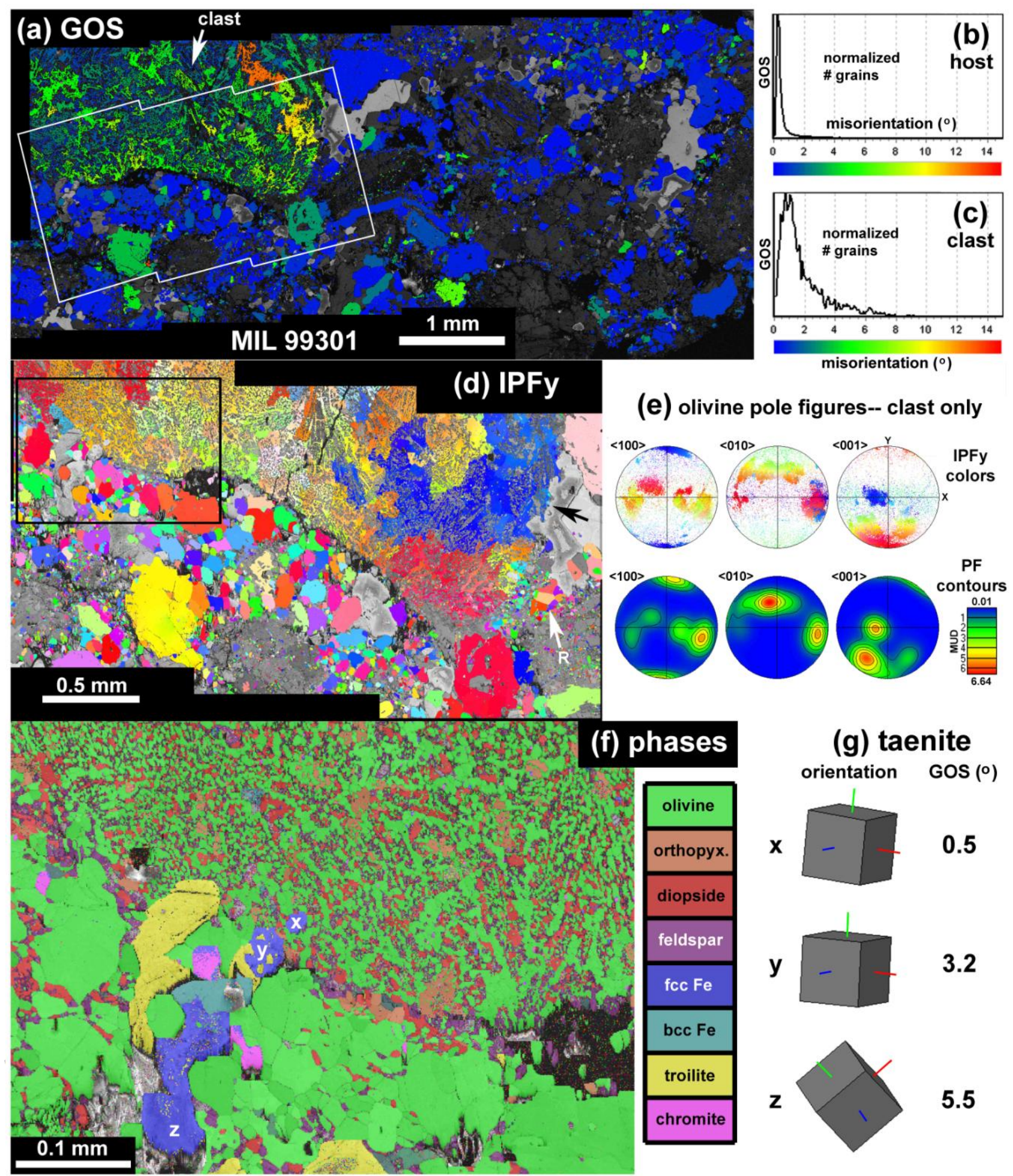


Fig. 5

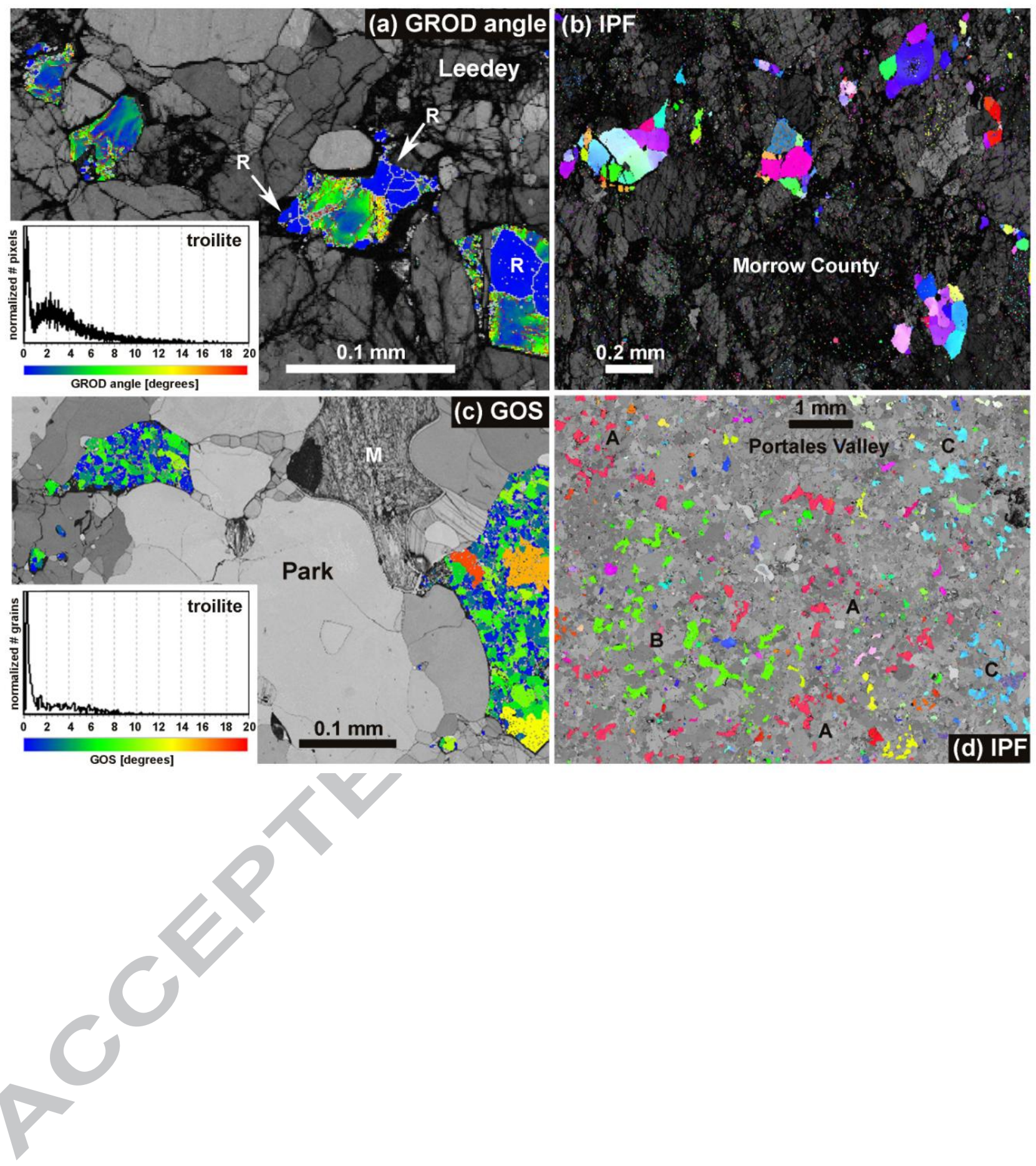


Fig. 6
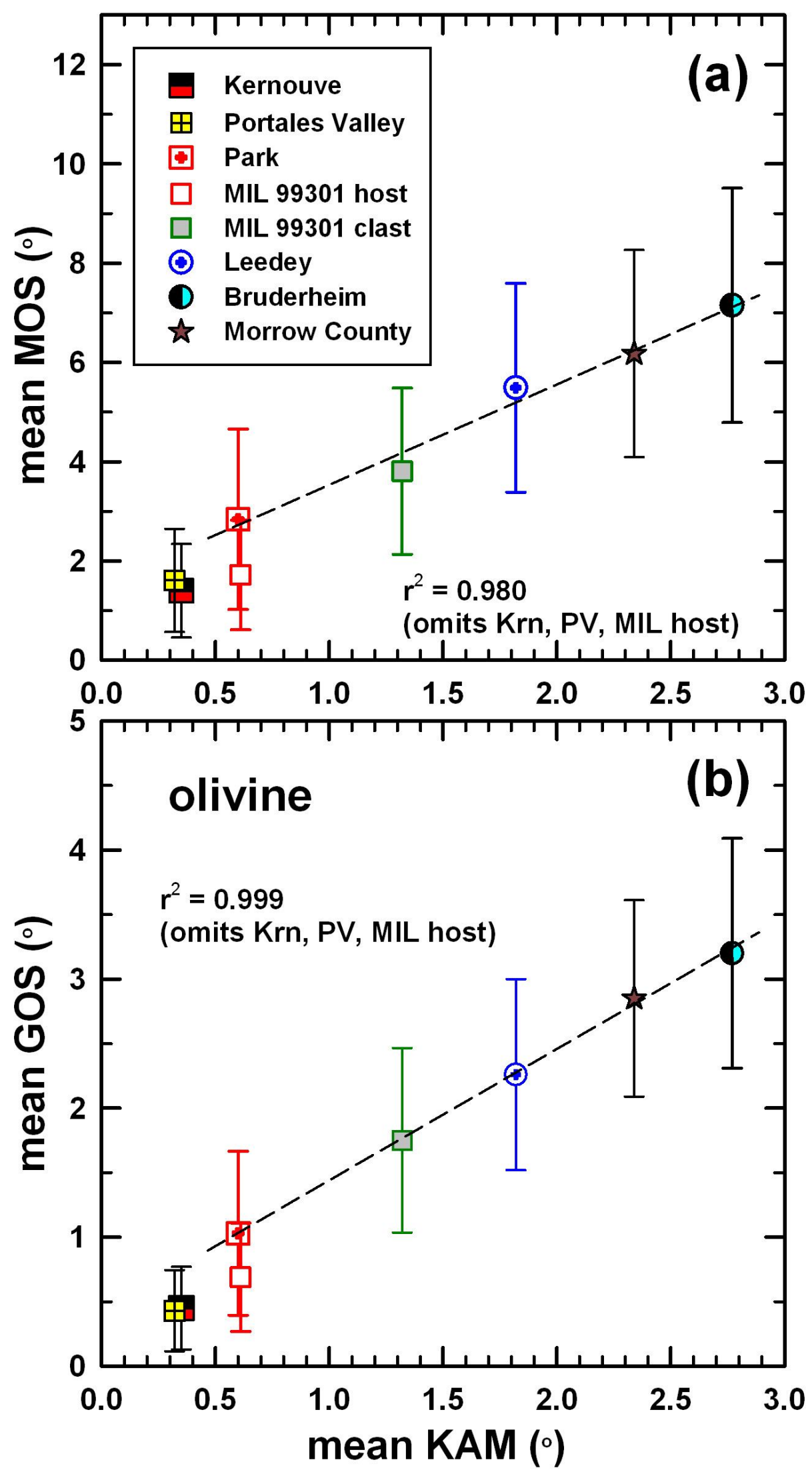
Fig. 7

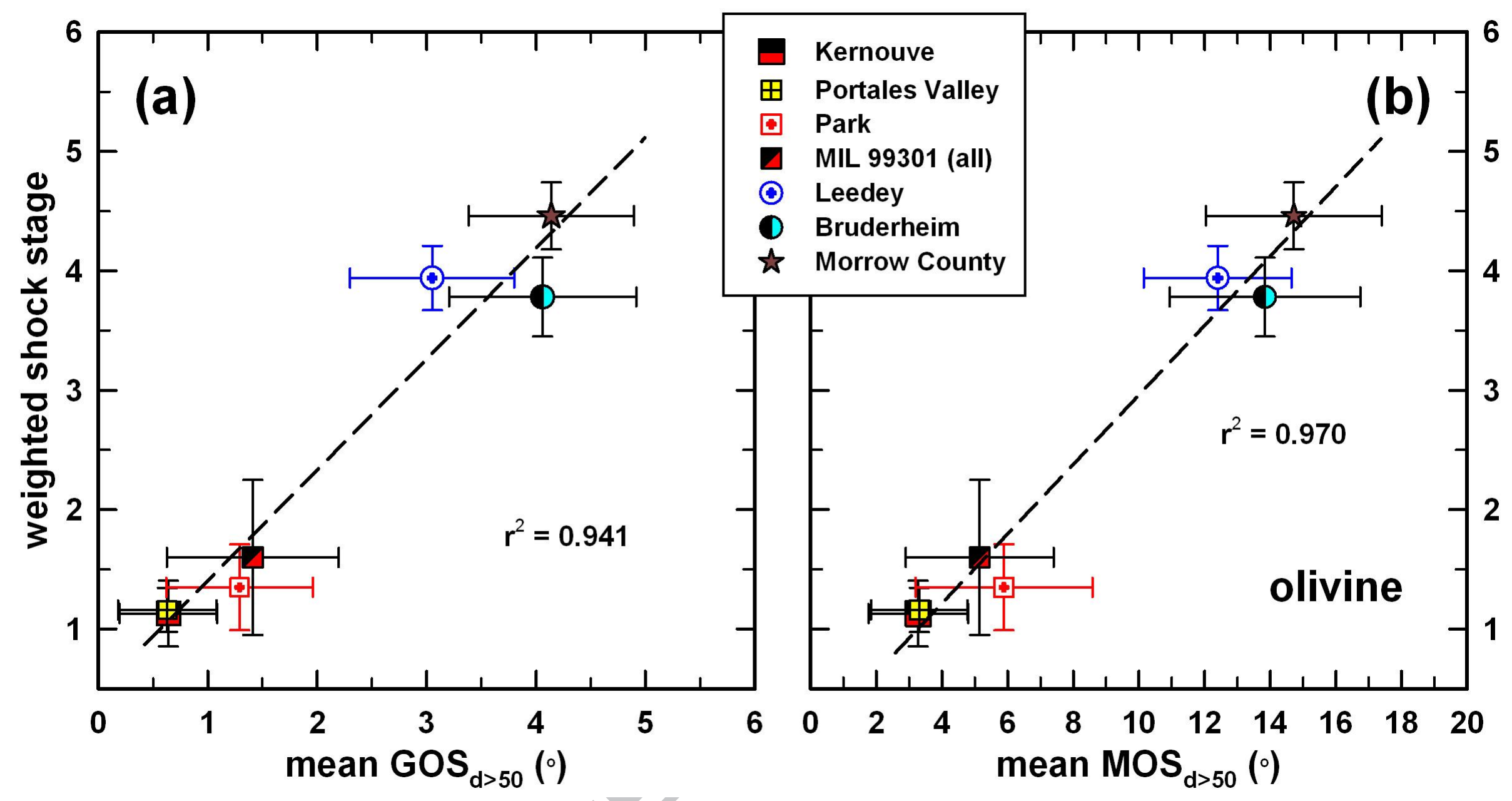

Fig. 8 
ACCEPTED MANUSCRIPT

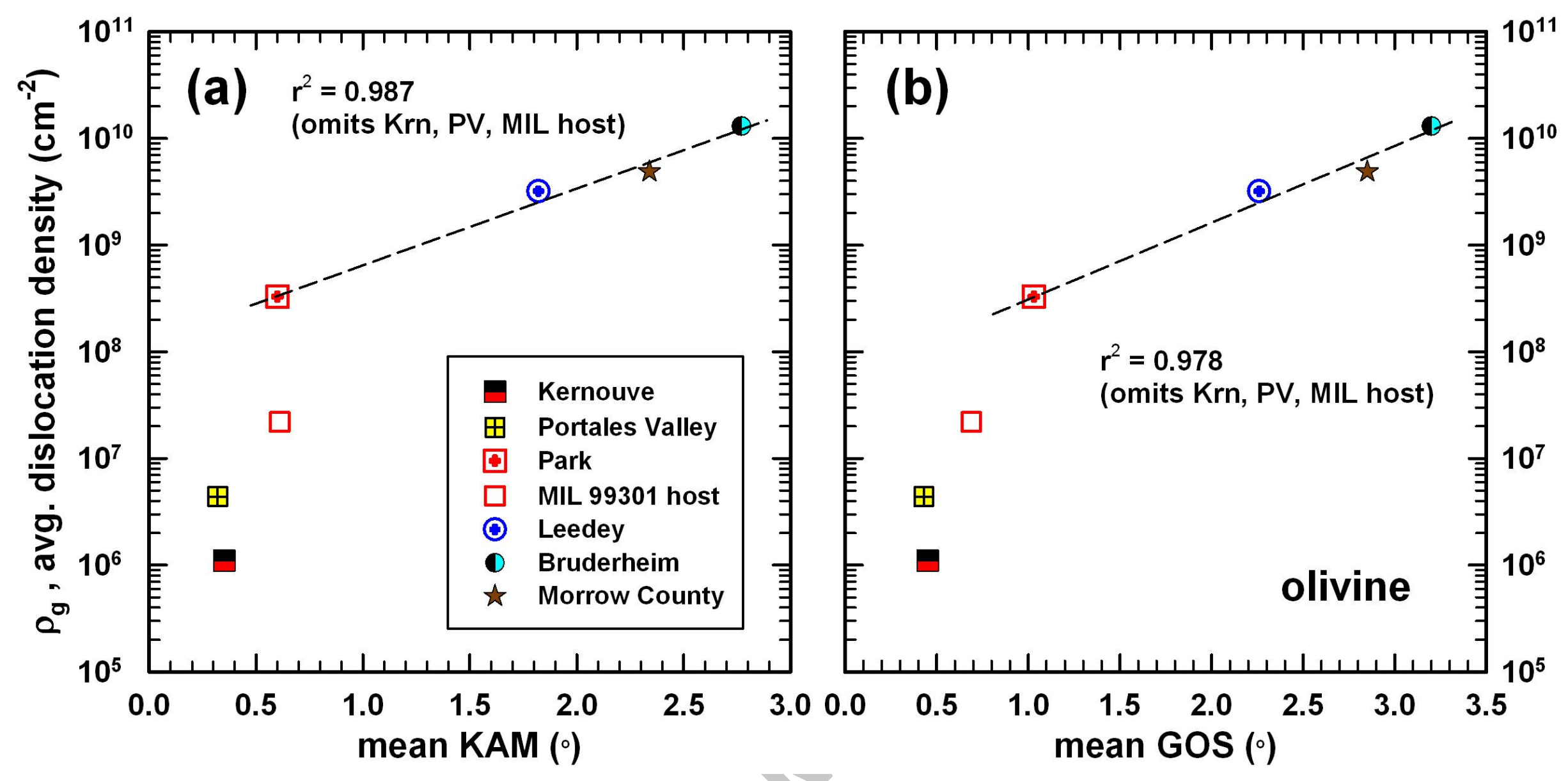




\section{ACCEPTED MANUSCRIPT}

Fig. 9a-f

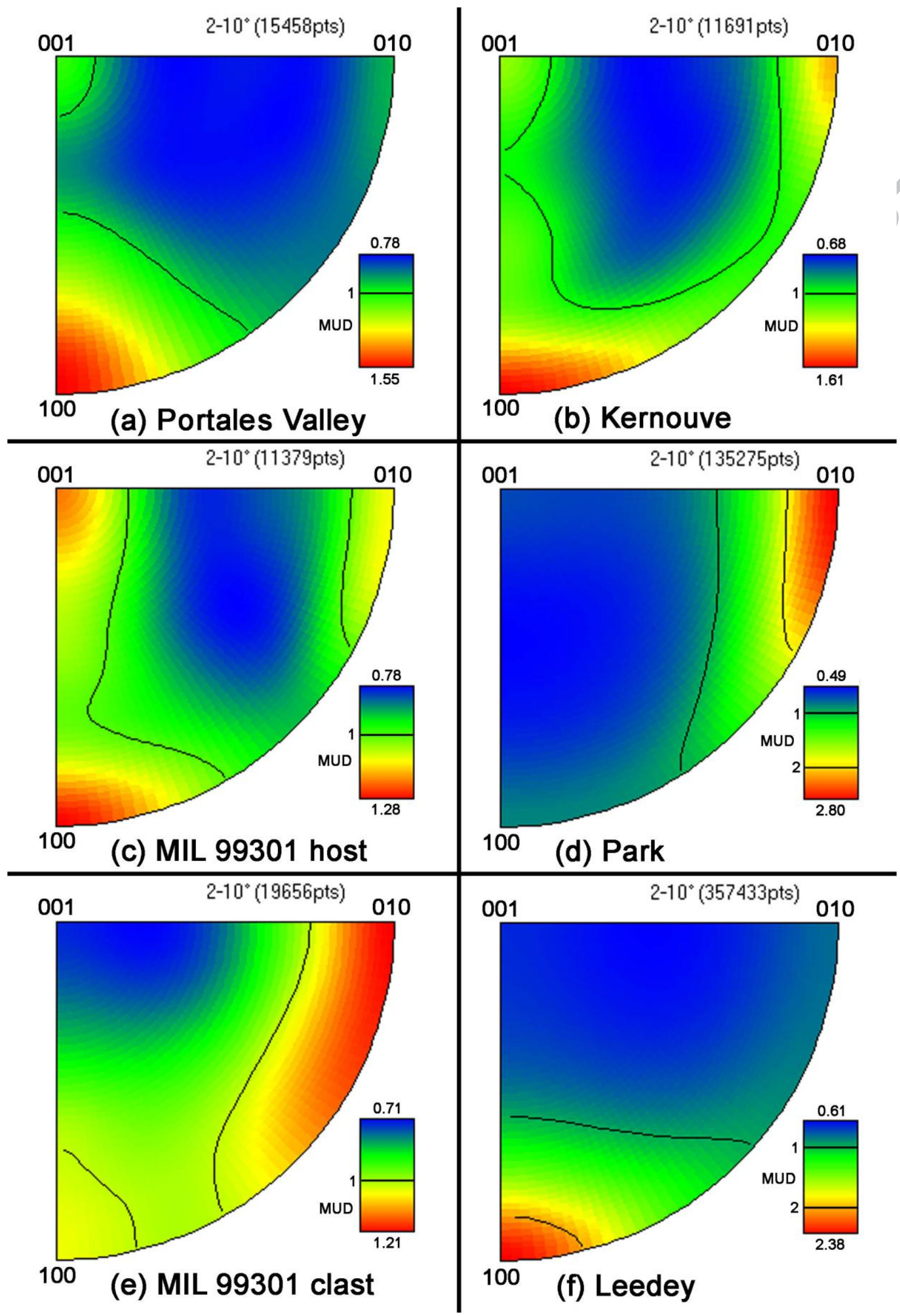


Fig. $9 g-h$
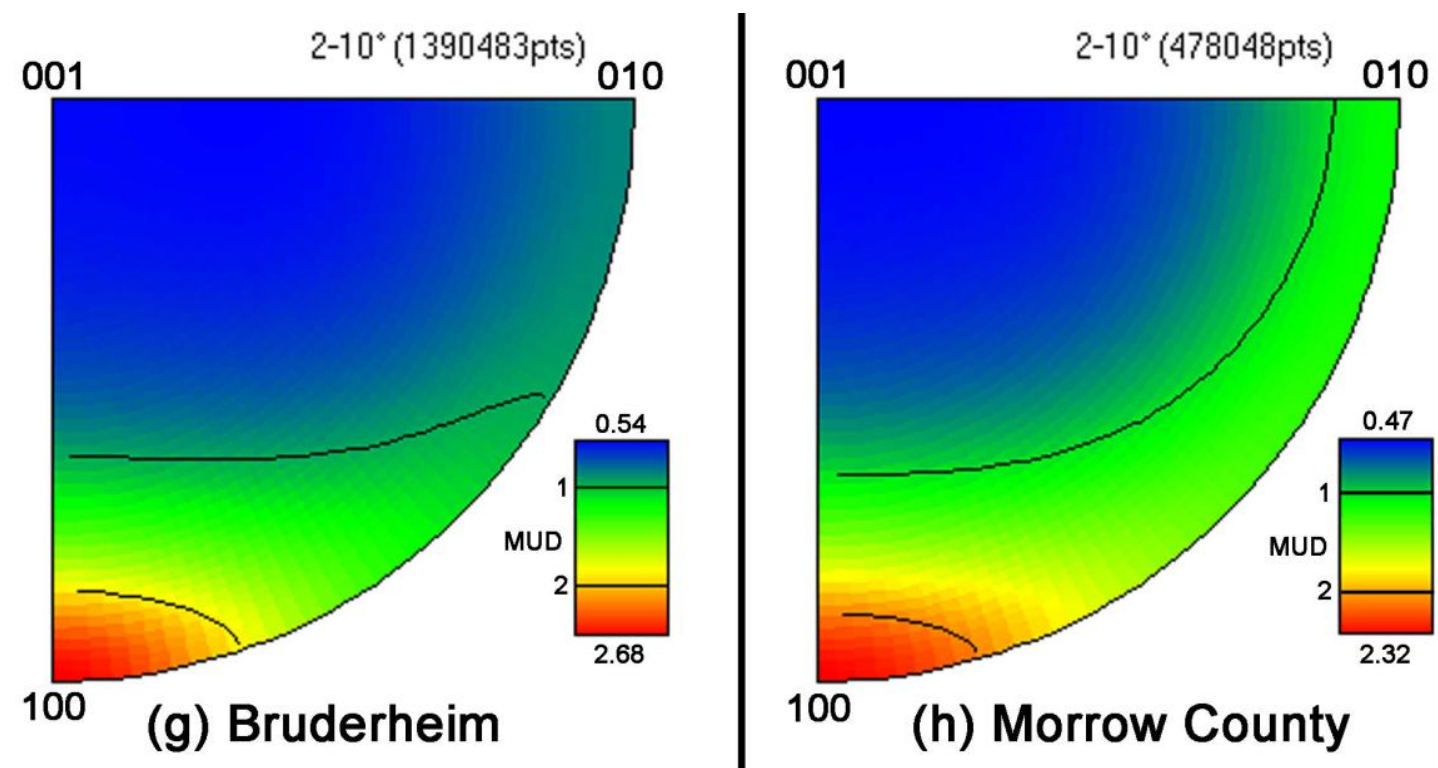

100 (h) Morrow County 
Fig. 10

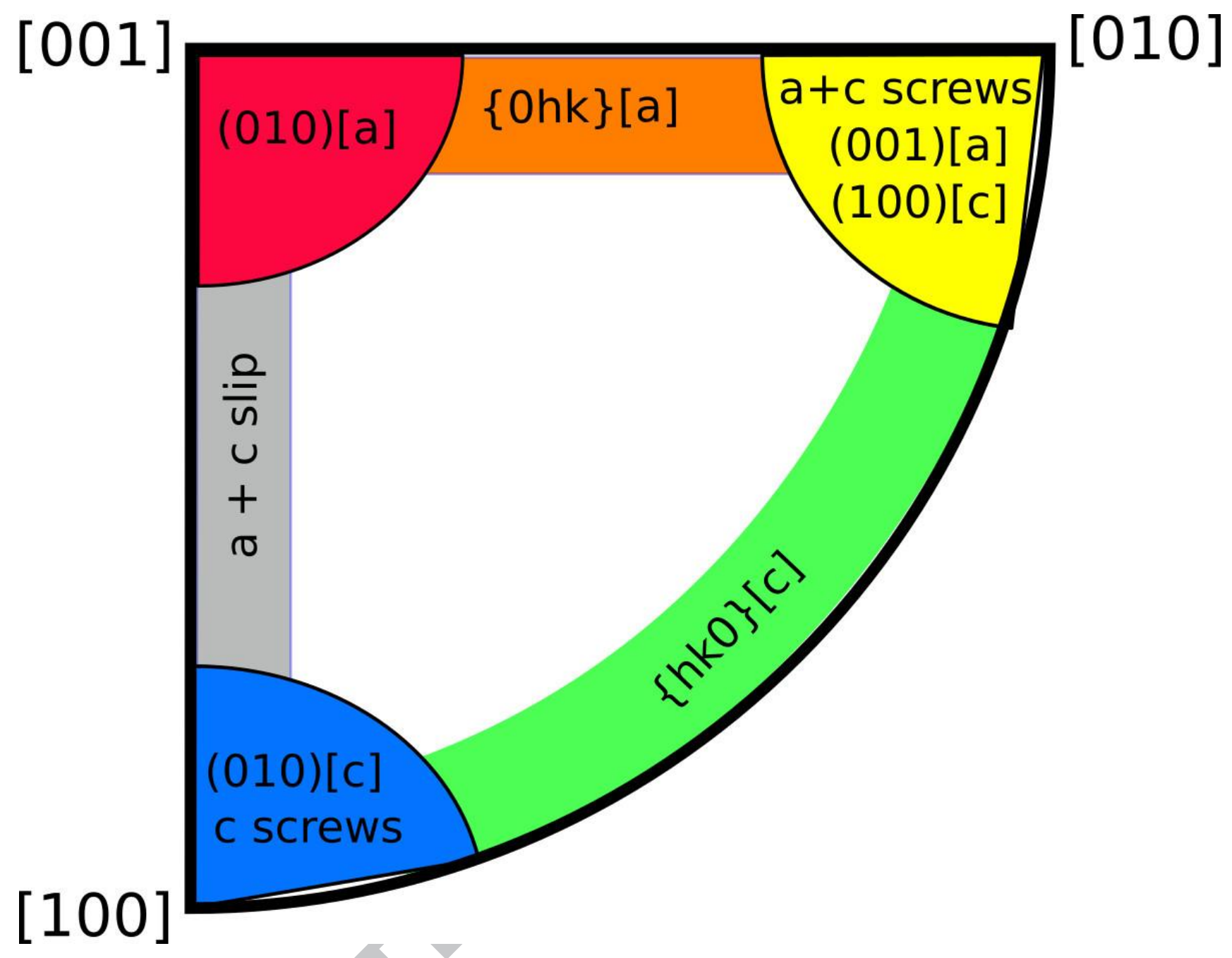

Fig. 11 
$0.5-2^{\circ}(X)$

\& $2-10^{\circ}$ (symbol)

$<001>$

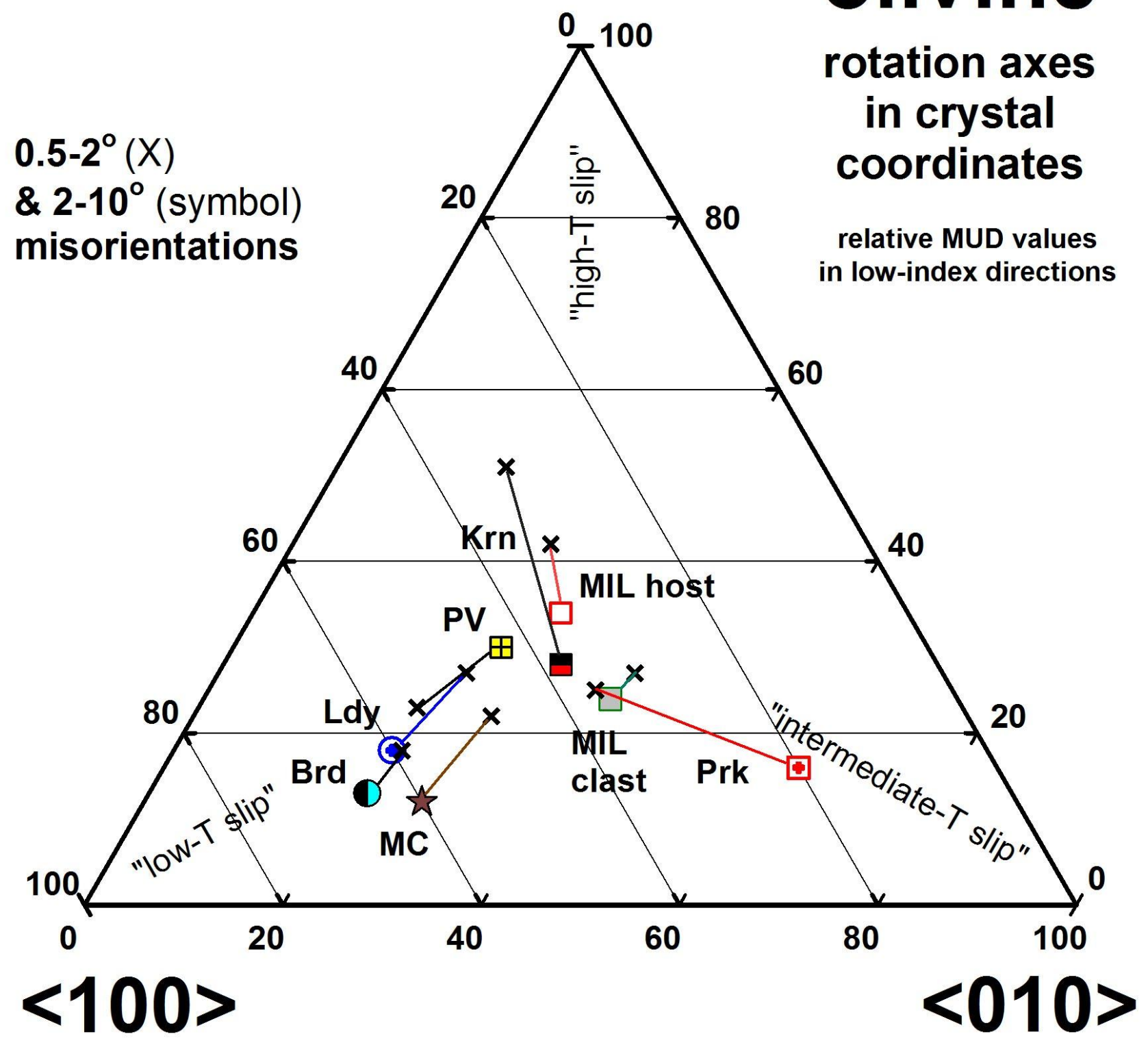

Fig. 12 


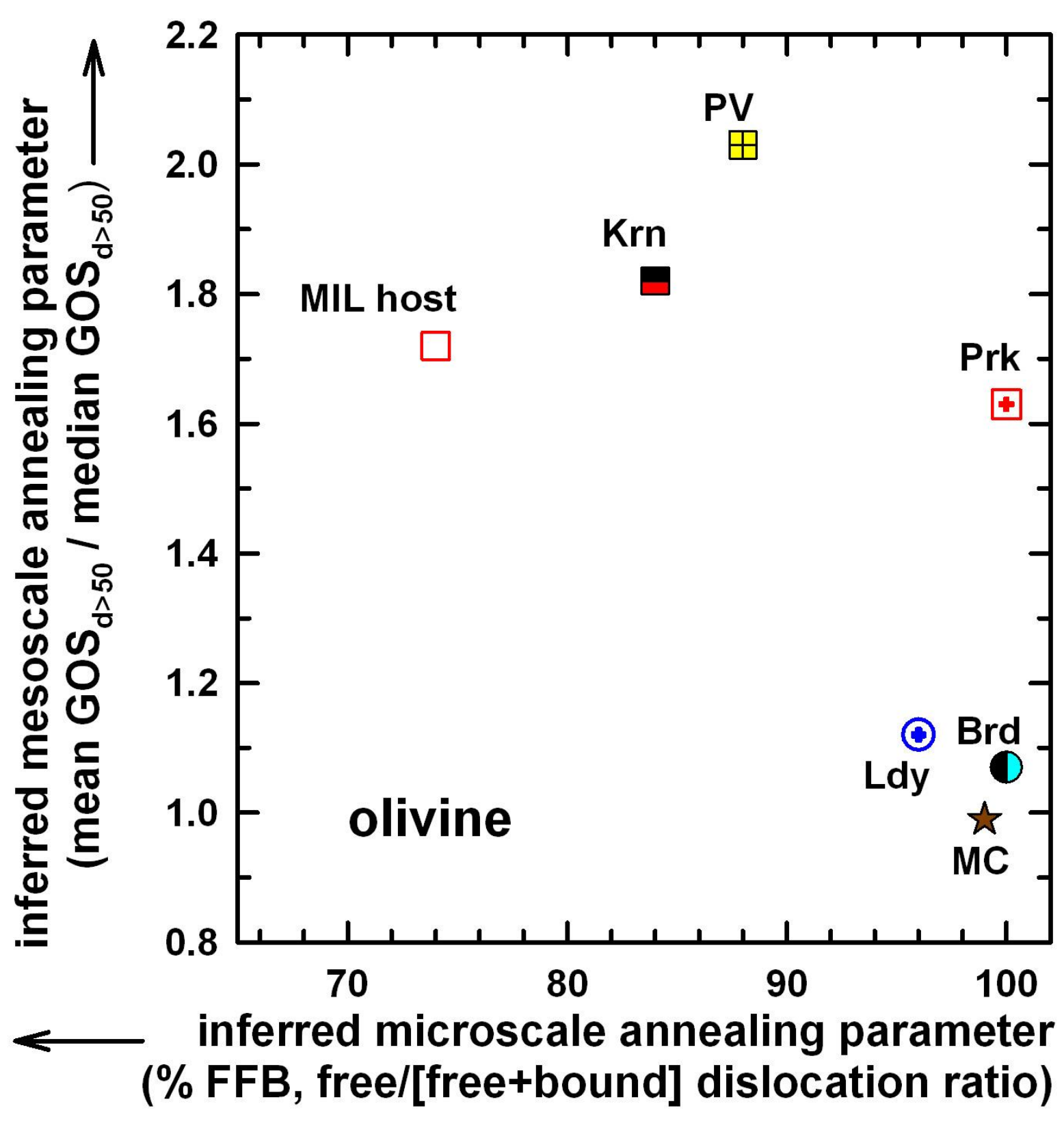

Fig. 13a-d 


\section{ACCEPTED MANUSCRIPT}
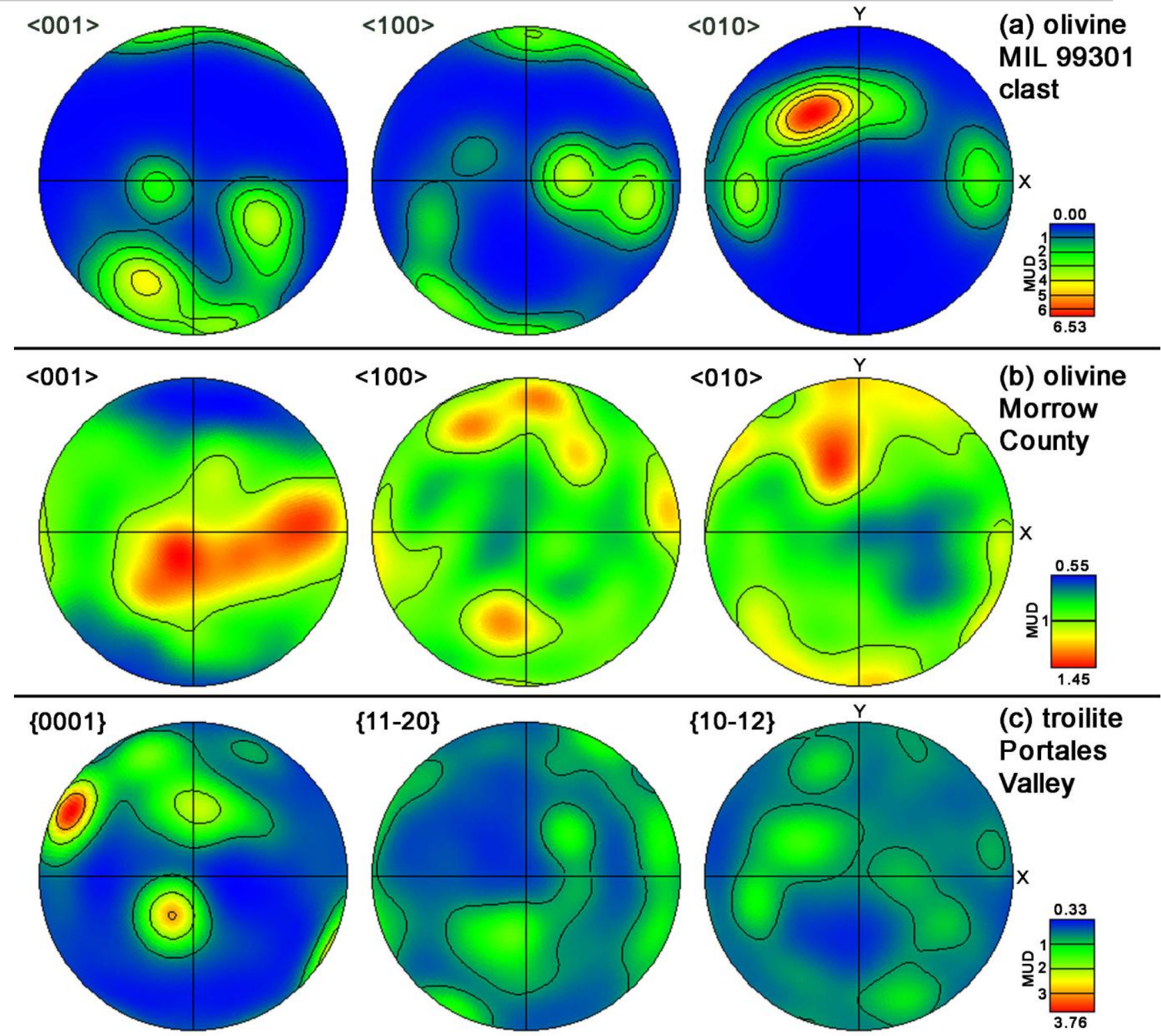

\{11-20\}

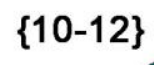

(c) troilite

Portales

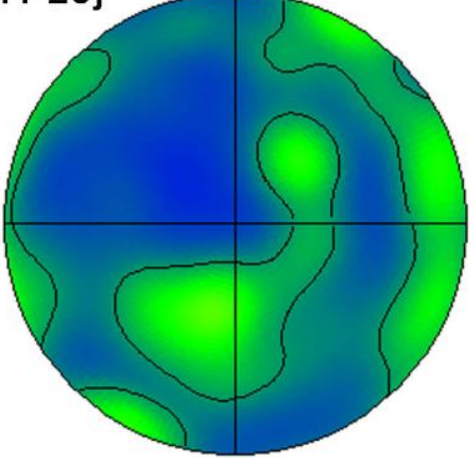

Valley
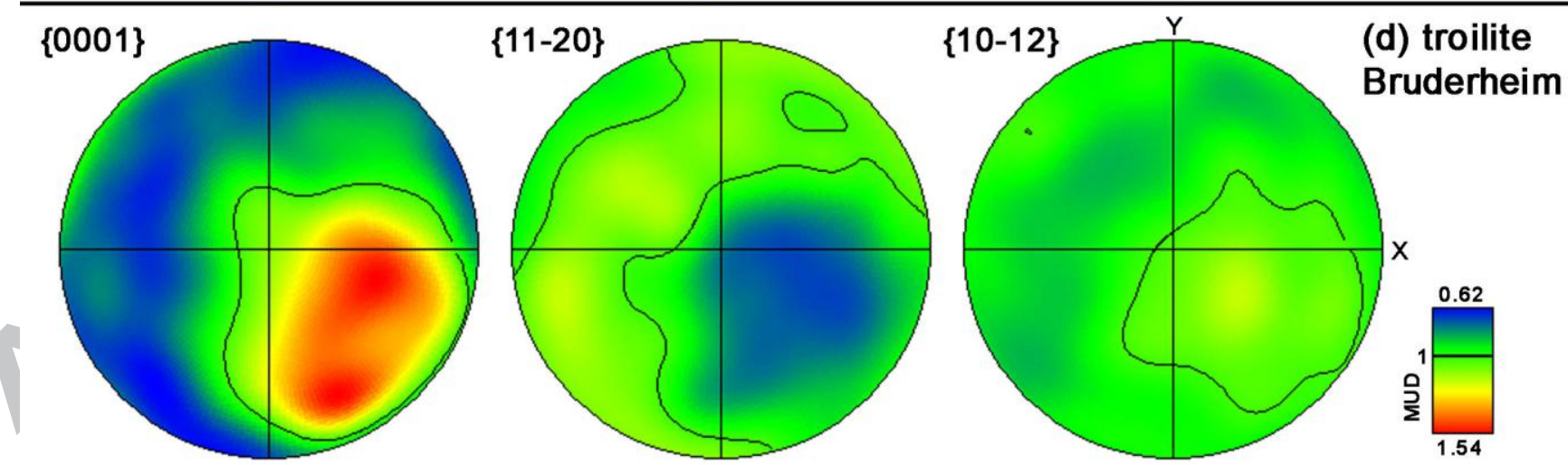
Fig. 13e-g

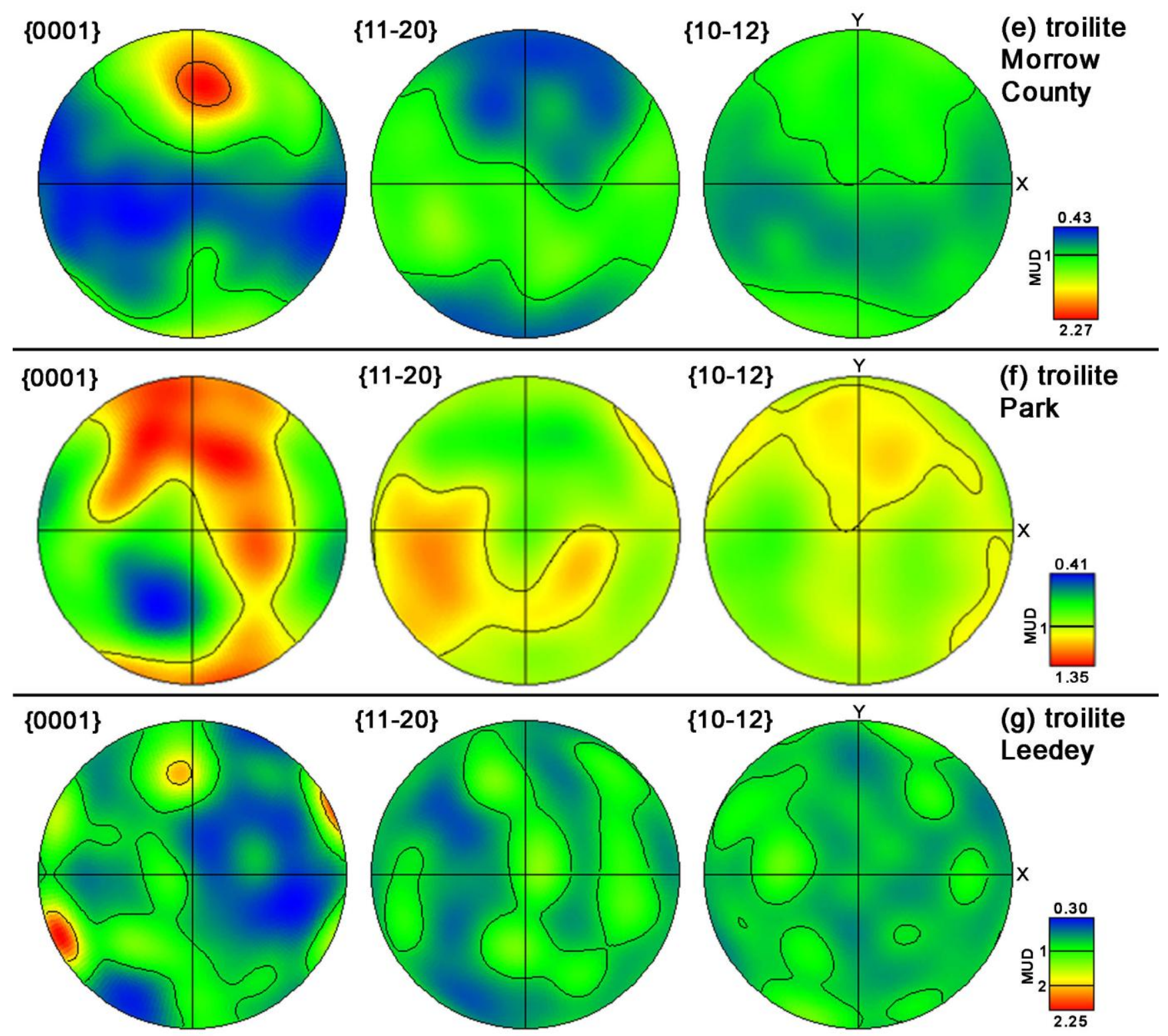

Fig. 14 


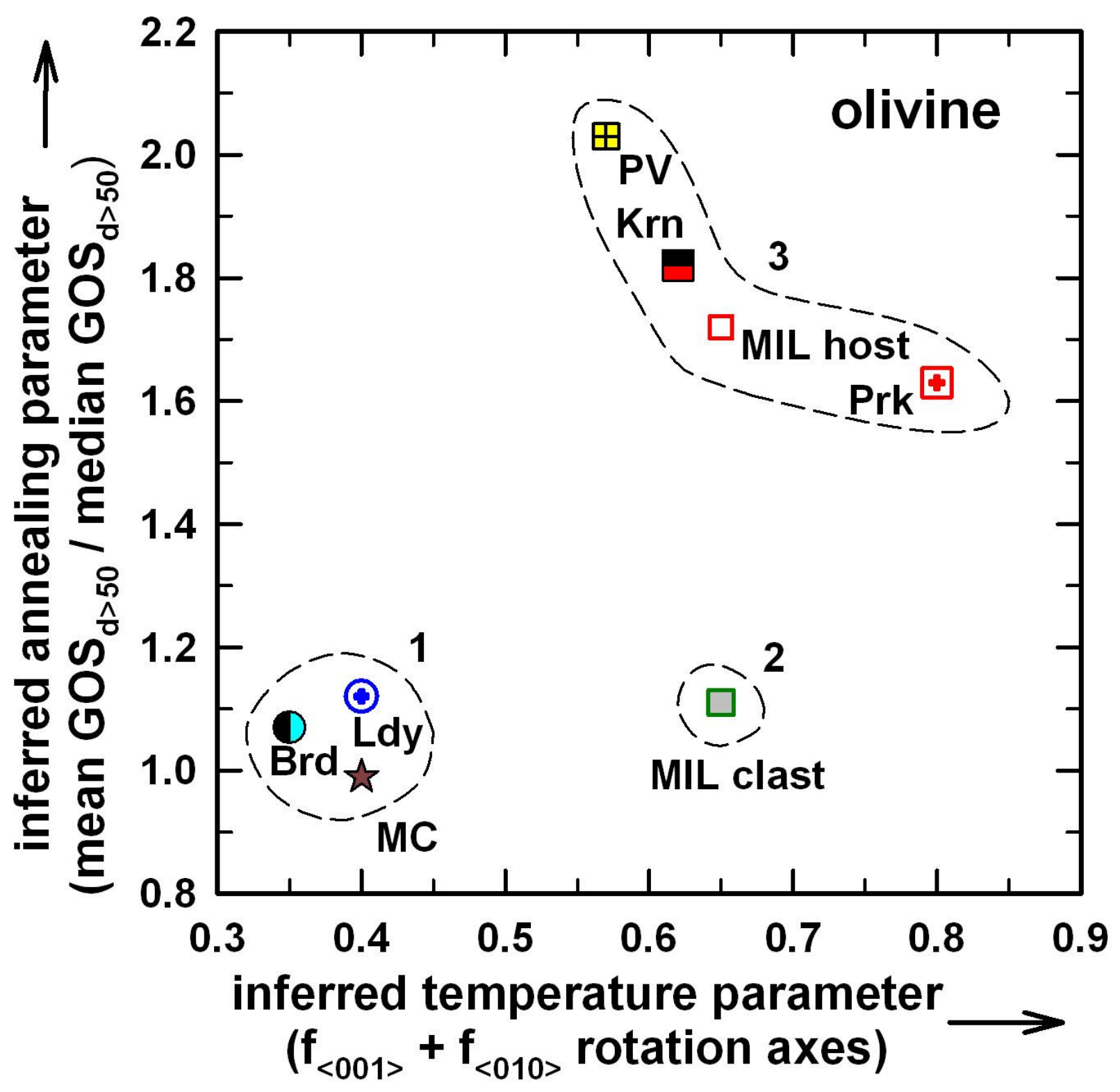

Fig. 15 


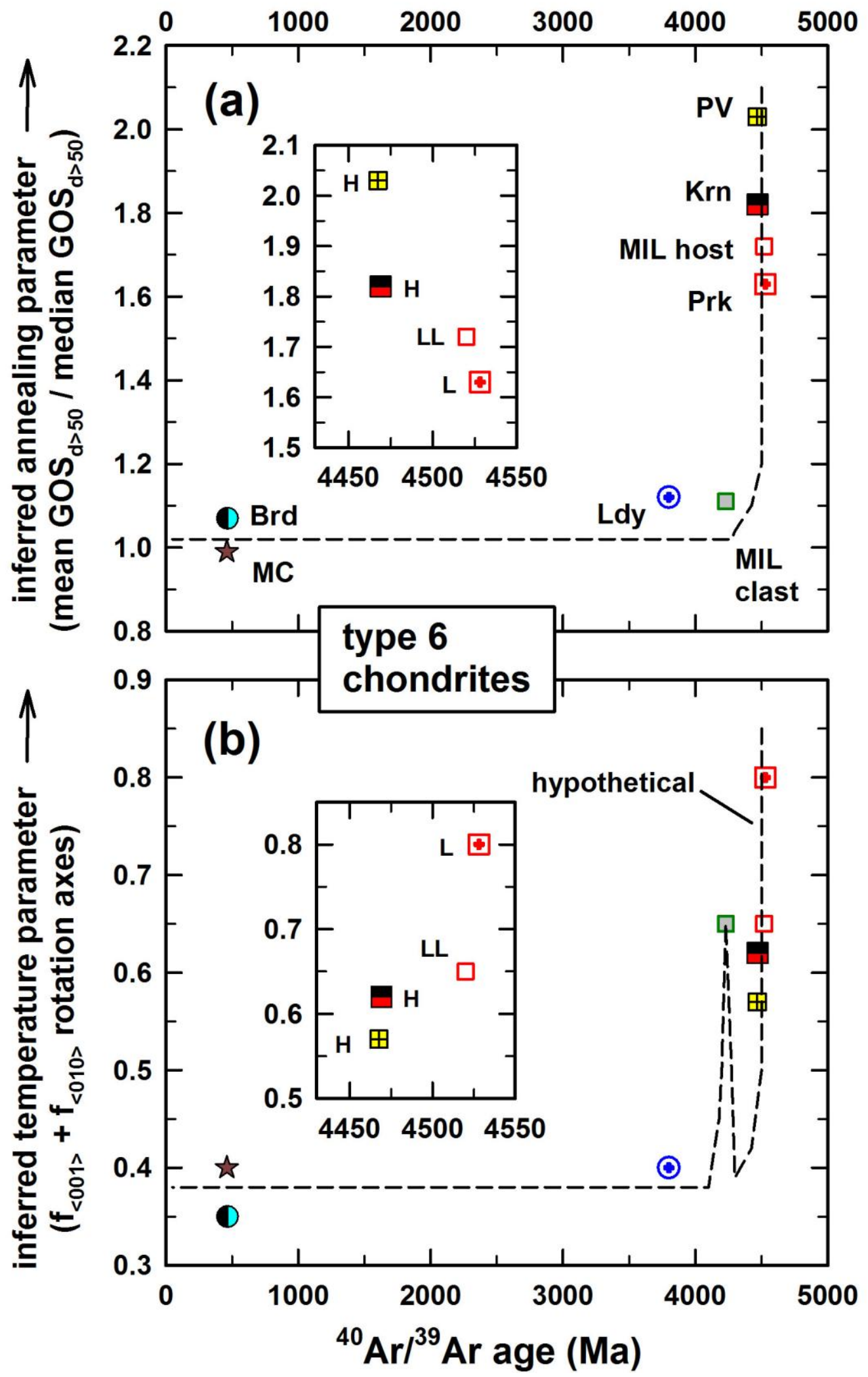


Table 1. Olivine deformation, misorientation, lattice preferred orientation, and grain size parameters derived from electron backscatter diffraction (EBSD) thin-section-scale (LAM) data for meteorites in this study. Meteorites are arranged left to right in order of increasing average GOS $(\mathrm{d}>50 \mu \mathrm{m})$ deformation parameter. OM data on shock stage shown for comparison.

\begin{tabular}{|c|c|c|c|c|c|c|c|c|c|}
\hline & $\begin{array}{c}\text { Portales } \\
\text { Valley } \\
(\mathrm{H} 6 / 7)\end{array}$ & $\begin{array}{c}\text { Kernouvé } \\
(\mathrm{H} 6)\end{array}$ & Park (L6) & & VIL 99301 (LL6 & & Leedey (L6) & $\begin{array}{l}\text { Bruderheim } \\
\text { (L6) }\end{array}$ & $\begin{array}{c}\text { Morrow } \\
\text { County (L6) }\end{array}$ \\
\hline \multicolumn{10}{|l|}{$O M$} \\
\hline shock stage $^{1}$ & S1 & S1 & S1 & & S1 & & S4 & S4 & S5 \\
\hline $\begin{array}{l}\text { weighted shock } \\
\text { stage }^{1}\end{array}$ & $1.16(0.37)$ & $1.13(0.55)$ & $1.35(0.72)$ & & $1.60(1.30)$ & & $3.94(0.54)$ & $3.78(0.66)$ & $4.46(0.56)$ \\
\hline$E B S D$ & & & & All & Host & Clast & & & \\
\hline Step size $(\mu \mathrm{m})$ & 4.0 & 4.0 & 4.0 & 4.0 & 4.0 & 4.0 & 4.0 & 5.7 & 4.0 \\
\hline Grains & 7410 & 8113 & 20679 & 9737 & 6808 & 2960 & 17304 & 39650 & 15329 \\
\hline Grain size, $d(\mu m)^{2}$ & $10-482$ & $10-574$ & $11-709$ & $10-684$ & $10-684$ & $10-250$ & $10-437$ & $14-772$ & $10-565$ \\
\hline $\operatorname{KAM}\left({ }^{\circ}\right)^{3}$ all d & 0.32 & 0.35 & 0.60 & 0.74 & 0.61 & 1.32 & 1.82 & 2.77 & 2.34 \\
\hline $\mathrm{d}>50 \mu \mathrm{m}$ & 0.31 & 0.33 & 0.49 & 0.64 & 0.55 & 1.22 & 1.52 & 2.66 & 2.04 \\
\hline $\mathrm{d}<50 \mu \mathrm{m}$ & 0.35 & 0.39 & 0.77 & 0.85 & 0.66 & 1.31 & 2.01 & 3.41 & 2.60 \\
\hline \multirow[t]{2}{*}{$\operatorname{GOS}\left({ }^{\circ}\right)^{4}$} & $0.43(0.63)$ & $0.45(0.64)$ & $1.03(1.27)$ & $1.01(2.36)$ & $0.69(0.84)$ & $1.75(1.43)$ & $2.26(1.48)$ & $3.20(1.78)$ & $2.85(1.52)$ \\
\hline & $0.63(0.90)$ & $0.64(0.89)$ & $1.29(1.34)$ & $1.41(1.57)$ & $0.91(1.00)$ & $3.69(1.63)$ & $3.05(1.50)$ & $4.06(1.71)$ & $4.14(1.51)$ \\
\hline $\mathrm{d}<50 \mu \mathrm{m}$ & $0.37(0.51)$ & $0.41(0.58)$ & $0.99(1.25)$ & $0.98(1.12)$ & $0.67(0.81)$ & $1.67(1.36)$ & $2.20(1.46)$ & $3.10(1.76)$ & 2.76 (1.47) \\
\hline $\operatorname{MOS}\left({ }^{\circ}\right)^{5}$ all d & $1.61(2.08)$ & $1.40(1.88)$ & $2.84(3.63)$ & $1.16(2.78)$ & $1.72(2.21)$ & $3.81(3.35)$ & $5.49(4.21)$ & $7.15(4.72)$ & 6.18 (4.17) \\
\hline$d>50 \mu \mathrm{m}$ & $3.31(2.94)$ & $3.28(3.03)$ & $5.89(5.39)$ & $5.15(4.51)$ & 4.03 (3.69) & $10.3(4.39)$ & $12.4(5.5)$ & $13.8(5.8)$ & $14.7(5.4)$ \\
\hline $\mathrm{d}<50 \mu \mathrm{m}$ & $1.12(1.43)$ & $1.07(1.34)$ & $2.41(3.07)$ & $2.14(2.48)$ & $1.52(1.89)$ & 3.52 (2.99) & $4.98(3.61)$ & $6.37(3.90)$ & $5.68(3.51)$ \\
\hline \multicolumn{10}{|l|}{ GOS mean/median } \\
\hline all d & 1.59 & 1.55 & 1.50 & 1.94 & 1.86 & 1.37 & 1.19 & 1.19 & 1.10 \\
\hline$d>50 \mu m^{6}$ & 2.03 & 1.82 & 1.63 & 2.27 & 1.72 & 1.11 & 1.12 & 1.12 & 0.99 \\
\hline$d<50 \mu m$ & 1.48 & 1.46 & 2.02 & 1.92 & 1.60 & 1.36 & 1.20 & 1.20 & 1.10 \\
\hline GROD angle $\left({ }^{\circ}\right)^{7}$ & 0.67 & 0.67 & 1.34 & 1.38 & 0.99 & 3.15 & 3.01 & 3.01 & 4.09 \\
\hline LAGB $_{0.5-2} / \mathrm{GB}(\%)^{8}$ & 75.4 & 78.9 & 74.0 & 83.0 & 85.7 & 74.6 & 66.8 & 66.8 & 55.6 \\
\hline $\mathrm{LAGB}_{2-10} / \mathrm{GB}(\%)^{9}$ & 5.9 & 4.4 & 12.2 & 6.2 & 2.9 & 17.2 & 25.7 & 25.7 & 36.8 \\
\hline $\mathrm{GB} \operatorname{avg}\left({ }^{\circ}\right)^{10}$ & 14.0 & 12.6 & 10.3 & 8.0 & 8.7 & 5.7 & 6.2 & 6.2 & 6.4 \\
\hline $\begin{array}{l}\text { LPO strength } \\
{\text { (MUD } \mathrm{max} / \mathrm{min})^{11}}^{11}\end{array}$ & $\begin{array}{c}0.41 \\
(1.19 / 0.78)\end{array}$ & $\begin{array}{c}0.33 \\
(1.15 / 0.82)\end{array}$ & $\begin{array}{c}0.31 \\
(1.11 / 0.80)\end{array}$ & $\begin{array}{l}-- \\
--\end{array}$ & $\begin{array}{c}0.61 \\
(1.39 / 0.78)\end{array}$ & $\begin{array}{c}6.53 \\
(6.53 / 0.00)\end{array}$ & $\begin{array}{c}0.44 \\
(1.19 / 0.75)\end{array}$ & $\begin{array}{c}0.35 \\
(1.14 / 0.79)\end{array}$ & $\begin{array}{c}0.90 \\
(1.45 / 0.55)\end{array}$ \\
\hline
\end{tabular}


${ }^{1}$ Conventional and weighted shock stage data (standard deviation in parentheses) from Ruzicka et al. (2015a) and Friedrich et al. (2017).

${ }^{2}$ Grain size is the effective grain diameter (diameter $d$ of circular grain with same area as measured).

${ }^{3}$ Mean Kernal Average Misorientation (KAM), the average angular misorientation among all neighboring (9) pixels within grains.

${ }^{4}$ Mean Grain Orientation Spread (GOS), the average angular misorientation within grains. Standard deviation in parentheses.

${ }^{5}$ Mean Maximum Orientation Spread (MOS), the maximum angular misorientation from the mean orientation within grains. Standard deviation in parentheses.

${ }^{6}$ Proposed annealing parameter. Not valid for MIL 99301 Host + Clast combined dataset (see Text).

${ }^{7}$ Mean Grain Reference Orientation Deviation angle (GROD angle), the average angular misorientation of a grain from a reference location in the grain.

${ }^{8} \mathrm{LAGB}_{0.5-2} / \mathrm{GB}$ refers to the number proportion of low-angle $\left(0.5-2^{\circ}\right.$ misorientation) grain boundaries (LAGBs, or subgrain boundaries) to the number of olivine grain boundaries (GBs) of all angular misorientations $\left(>0.5^{\circ}\right)$.

${ }^{9} \mathrm{LAGB}_{2-10} / \mathrm{GB}$ refers to the number proportion of low-angle (2-10 misorientation) grain boundaries (LAGBs, or subgrain boundaries) to the number of olivine grain boundaries (GBs) of all angular misorientations $\left(>0.5^{\circ}\right)$.

${ }^{10} \mathrm{~GB}_{\text {avg }}$ refers to the mean grain boundary misorientation $\left(>0.5^{\circ}\right)$.

${ }^{11}$ Lattice Preferred Orientation (LPO) strength based on Multiples of Uniform Density (MUD) values in pole figure plots, with one point per grain $\left(25^{\circ}\right.$ half-width contouring); LPO strength = maximum MUD - minimum MUD (maximum/minimum MUD in parentheses).

Table 2. Low-angle misorientation boundary data for olivine, derived from Crystal Rotation Axis (CRA) plots ${ }^{1}$.

\begin{tabular}{|c|c|c|c|c|c|c|c|}
\hline \multirow[t]{2}{*}{ Meteorite } & \multirow[t]{2}{*}{$\begin{array}{l}\text { Misorientation } \\
\text { across } \\
\text { boundary }\left({ }^{\circ}\right)\end{array}$} & \multirow[t]{2}{*}{$\begin{array}{l}\text { Number of } \\
\text { boundaries }\end{array}$} & \multicolumn{4}{|c|}{$\begin{array}{c}\text { Proportion of rotation axes in olivine crystal } \\
\text { directions } \\
\text { (MUD values) }^{2}\end{array}$} & \multirow[t]{2}{*}{$\begin{array}{l}\text { Deformation } \\
\text { temperature } \\
\text { parameter }^{3}\end{array}$} \\
\hline & & & $<100>$ & $<010>$ & $<001>$ & $\begin{array}{c}\text { Fraction } \\
\mathrm{f}_{<100>}: \mathrm{f}_{<010>}: \mathrm{f}_{<001>}\end{array}$ & \\
\hline \multirow{3}{*}{$\begin{array}{l}\text { Portales } \\
\text { Valley }\end{array}$} & $0.5-2$ & 199021 & 2.14 & 0.84 & 0.88 & $0.55: 0.22: 0.23$ & \\
\hline & $2-10$ & 15458 & & 0.96 & 1.09 & $0.43: 0.27: 0.30$ & 0.57 \\
\hline & $10-15$ & 1234 & 2.23 & 2.02 & 0.88 & $0.44: 0.43: 0.18$ & \\
\hline \multirow[t]{3}{*}{ Kernouvé } & $0.5-2$ & 213345 & 1.18 & 0.61 & 1.84 & $0.32: 0.17: 0.51$ & \\
\hline & $2-10$ & 11691 & 1.60 & 1.40 & 1.16 & $0.38: 0.34: 0.28$ & 0.62 \\
\hline & $10-15$ & 880 & 1.69 & 0.75 & 1.44 & $0.44: 0.19: 0.37$ & \\
\hline Park & $0.5-2$ & 828722 & 1.28 & 1.38 & 0.87 & $0.36: 0.39: 0.25$ & \\
\hline
\end{tabular}




\begin{tabular}{|c|c|c|c|c|c|c|c|}
\hline & $2-10$ & 135275 & 0.88 & 2.80 & 0.70 & $0.20: 0.64: 0.16$ & 0.80 \\
\hline & $10-15$ & 8941 & 1.01 & 3.76 & 0.66 & $0.19: 0.69: 0.12$ & \\
\hline \multirow{3}{*}{$\begin{array}{l}\text { MIL } 99301 \\
\text { all }\end{array}$} & $0.5-2$ & 418423 & 0.92 & 0.83 & 1.11 & $0.32: 0.29: 0.39$ & \\
\hline & $2-10$ & 31013 & 1.12 & 1.18 & 0.90 & $0.35: 0.37: 0.28$ & 0.65 \\
\hline & $10-15$ & 2423 & 1.22 & 0.76 & 1.02 & $0.41: 0.25: 0.34$ & \\
\hline \multirow{3}{*}{$\begin{array}{l}\text { MIL } 99301 \\
\text { host }\end{array}$} & $0.5-2$ & 334590 & 0.94 & 0.76 & 1.21 & $0.32: 0.26: 0.42$ & \\
\hline & $2-10$ & 11379 & 1.27 & 1.10 & 1.20 & $0.35: 0.31: 0.34$ & 0.65 \\
\hline & $10-15$ & 848 & 1.84 & 1.64 & 0.79 & $0.43: 0.38: 0.19$ & \\
\hline \multirow{3}{*}{$\begin{array}{l}\text { MIL } 99301 \\
\text { clast }\end{array}$} & $0.5-2$ & 84286 & 0.84 & 1.14 & 0.71 & $0.31: 0.42: 0.27$ & \\
\hline & $2-10$ & 19656 & 1.03 & 1.21 & 0.73 & $0.35: 0.41: 0.24$ & 0.65 \\
\hline & $10-15$ & 1586 & 0.88 & 0.29 & 1.17 & $0.38: 0.12: 0.50$ & \\
\hline \multirow[t]{3}{*}{ Leedey } & $0.5-2$ & 929914 & 1.50 & 0.77 & 0.84 & $0.48: 0.25: 0.27$ & \\
\hline & $2-10$ & 357433 & 2.36 & 0.85 & 0.70 & $0.60: 0.22: 0.18$ & 0.40 \\
\hline & $10-15$ & 9154 & 2.61 & 1.40 & 0.74 & $0.55: 0.29: 0.16$ & \\
\hline \multirow[t]{3}{*}{ Bruderheim } & $0.5-2$ & 1249221 & 2.12 & 0.81 & 0.64 & $0.59: 0.23: 0.18$ & \\
\hline & $2-10$ & 1390483 & 2.65 & 0.89 & 0.55 & $0.65: 0.22: 0.13$ & 0.35 \\
\hline & $10-15$ & 85302 & 2.99 & 1.21 & 0.58 & $0.63: 0.25: 0.12$ & \\
\hline \multirow{3}{*}{$\begin{array}{l}\text { Morrow } \\
\text { County }\end{array}$} & $0.5-2$ & 719428 & & 0.94 & 0.67 & $0.48: 0.30: 0.22$ & \\
\hline & $2-10$ & 478048 & 2.30 & 1.09 & 0.47 & $0.60: 0.28: 0.12$ & 0.40 \\
\hline & $10-15$ & 9852 & 3.99 & 1.77 & 0.37 & $0.65: 0.29: 0.06$ & \\
\hline
\end{tabular}

\footnotetext{
${ }^{1}$ Data are based on CRA plots with $25^{\circ}$ half-width contouring derived from large area maps (LAMs). Other EBSD parameters are the same as in Tables 1 and SM-1.

${ }^{2}$ Proportion of rotation axis directions in the $\langle 100\rangle,\langle 010\rangle$ and $\left.<001\right\rangle$ directions of olivine, given in terms of Multiples of Uniform Density (MUD).
} 
${ }^{3}$ Proposed deformation temperature parameter, equated to $f_{<010\rangle}+f_{<001\rangle}$ for $2-10^{\circ}$ misorientations based on LAM data (see Text). 
Table 3. Olivine KAM, GOS, misorientation rotation axis, and grain size parameters derived from EBSD targeted maps (with > 55,000 data cells).

\begin{tabular}{|c|c|c|c|c|c|c|c|}
\hline Meteorite & $\begin{array}{c}\text { EBSD } \\
\text { targeted } \\
\text { map }\end{array}$ & Grains & $\begin{array}{l}\text { Grain } \\
\text { size, d } \\
(\mu \mathrm{m})^{1}\end{array}$ & $\begin{array}{c}\operatorname{KAM}\left({ }^{\circ}\right)^{2} \\
\text { all } d\end{array}$ & $\begin{array}{c}\operatorname{GOS}\left({ }^{\circ}\right)^{3} \\
\text { all } d\end{array}$ & $\begin{array}{c}\mathrm{GOS}_{\mathrm{d}>50}{ }^{4} \\
\text { mean/median }\end{array}$ & $f_{<010>+<001>}$ \\
\hline $\begin{array}{l}\text { Portales } \\
\text { Valley }\end{array}$ & Gr14 & 69 & $6-446$ & 0.15 & $0.25(0.32)$ & 1.45 & 0.72 \\
\hline $\begin{array}{c}\text { Portales } \\
\text { Valley }\end{array}$ & Gr39 & 58 & $5-351$ & 0.14 & $0.34(0.48)$ & 2.64 & 0.22 \\
\hline $\begin{array}{c}\text { Portales } \\
\text { Valley }\end{array}$ & Gr40 & 161 & 7-115 & 0.19 & $0.42(0.88)$ & 3.92 & 0.72 \\
\hline $\begin{array}{l}\text { Portales } \\
\text { Valley }\end{array}$ & Gr59 & 86 & $6-364$ & $0.79 *$ & $0.60(0.85)$ & 2.80 & 0.13 \\
\hline Park & 6 Field & 899 & $3-320$ & 0.36 & 1.35 (1.61) & 1.38 & 0.82 \\
\hline Park & Area 1 & 389 & $2-157$ & 0.23 & $0.97(1.32)$ & 1.40 & 0.88 \\
\hline Park & Area 2 & 400 & 3-281 & 0.17 & $0.66(1.17)$ & 2.34 & 0.84 \\
\hline Park & Area 3 & 396 & $3-330$ & 0.23 & $1.15(1.72)$ & 1.66 & 0.84 \\
\hline Park & Area 6 & 608 & $4-383$ & 0.23 & $0.98(1.50)$ & 1.47 & 0.83 \\
\hline $\begin{array}{l}\text { MIL } 99301 \\
\text { host }\end{array}$ & 6 Field & 3030 & $4-429$ & 0.27 & $0.65(1.12)$ & 1.96 & 0.64 \\
\hline $\begin{array}{l}\text { MIL } 99301 \\
\text { clast }\end{array}$ & 6 Field & 4231 & $4-254$ & 0.60 & $1.28(1.54)$ & 1.04 & 0.68 \\
\hline $\begin{array}{l}\text { MIL } 99301 \\
\text { clast }\end{array}$ & BSE8 & 499 & $5-244$ & 0.56 & $0.84(1.06)$ & 1.49 & 0.65 \\
\hline Leedey & 5 Field & 3755 & $3-336$ & $1.91^{*}$ & $2.42(1.75)$ & 1.16 & 0.42 \\
\hline Bruderheim & Site 22 & 736 & 6-124 & $1.57 *$ & $3.08(1.90)$ & 1.12 & 0.34 \\
\hline Bruderheim & Site 78 & 492 & $6-376$ & $2.23^{*}$ & $4.00(2.23)$ & 1.04 & 0.40 \\
\hline Bruderheim & 4 Field & 2663 & $3-234$ & $1.26^{*}$ & $2.40(1.77)$ & 1.11 & 0.45 \\
\hline $\begin{array}{l}\text { Morrow } \\
\text { County }\end{array}$ & 6 Field & 4377 & $3-232$ & $3.24 *$ & $3.29(2.04)$ & 1.07 & 0.49 \\
\hline
\end{tabular}

${ }^{1}$ Grain size is the effective grain diameter (diameter $d$ of circular grain with same area as measured).

${ }^{2}$ Mean value of Kernal Average Misorientation (KAM), the average angular misorientation among all neighboring (9) pixels within grains. Values with asterisks are averages that exclude data with apparent artificial low values (misorientations below apparent detection limit), as identified by anomalous high frequency of low misorientations.

${ }^{3}$ Mean value of Grain Orientation Spread (GOS), the average angular misorientation within grains. Standard deviation in parentheses.

${ }^{4}$ (Mean GOS)/(median GOS) for d $>50 \mu \mathrm{m}$ grains.

${ }^{5}$ The proportion of crystal rotation axes in the $\left.<010\right\rangle$ and $<001>$ directions $\left(f_{<010\rangle}+f_{<001\rangle}\right)$ for $2-10^{\circ}$ misorientations, based on CRA plots with $25^{\circ}$ half-width contouring. 
Table 4. EBSD data for troilite. GOS values and LPO strengths for troilite are based on large area map data. Meteorites are arranged left to right in order of increasing mean $G O S_{d>50}$ values for olivine (Table 1). OM data on shock stage shown for comparison.

\begin{tabular}{|c|c|c|c|c|c|c|c|}
\hline & $\begin{array}{c}\text { Portales } \\
\text { Valley }\end{array}$ & Kernouvé & $\begin{array}{c}\text { MIL } 99301 \\
\text { host }\end{array}$ & Park & Leedey & Bruderheim & $\begin{array}{c}\text { Morrow } \\
\text { County }\end{array}$ \\
\hline Shock stage $^{1}$ & S1 & S1 & S1 & S1 & S4 & S4 & S5 \\
\hline Number grains & 1641 & 1040 & 757 & 1948 & 2223 & 5693 & 1559 \\
\hline Comments & $\begin{array}{l}\text { Monocrystals; } \\
\text { strong LPO } \\
\text { over mm- } \\
\text { scale domains }\end{array}$ & Monocrystals & Monocrystals & $\begin{array}{c}\text { Finely } \\
\text { recrystallized, } \\
\text { partly } \\
\text { deformed }\end{array}$ & $\begin{array}{c}\text { Partly } \\
\text { recrystallized, } \\
\text { partly } \\
\text { deformed }\end{array}$ & $\begin{array}{c}\text { Partly } \\
\text { recrystallized, } \\
\text { partly } \\
\text { deformed }\end{array}$ & $\begin{array}{c}\text { Mostly } \\
\text { recrystallized, } \\
\text { partly } \\
\text { deformed }\end{array}$ \\
\hline
\end{tabular}

${ }^{1}$ Conventional shock stage data from Ruzicka et al. (2015a) and Friedrich et al. (2017).

${ }^{2}$ Grain Orientation Spread (GOS), the average angular misorientation within grains.

${ }^{3}$ Lattice Preferred Orientation (LPO) strength based on Multiples of Uniform Density (MUD) values in pole figure plots of $\{0001\}$ with 1 point per grain $\left(25^{\circ}\right.$ half-width contouring); LPO strength = maximum MUD - minimum MUD (maximum/minimum MUD in parentheses). 
Electronic Annex to accompany "Electron Back Scatter Diffraction (EBSD) study of seven heavily metamorphosed chondrites: Deformation systematics and variations in pre-shock temperature and post-shock annealing",

by Alex M. Ruzicka and Richard C. Hugo

Includes: Table EA-1, Table EA-2, Figs. EA-1, EA-2, EA-3, EA-4, EA-5, EA-6 
Table EA-1. Acquisition metadata for EBSD Large Area Maps (LAMs).

\begin{tabular}{|c|c|c|c|c|c|c|c|}
\hline & $\begin{array}{l}\text { Kernouvé (H6) } \\
\text { LAM }\end{array}$ & $\begin{array}{l}\text { Portales Valley } \\
(\mathrm{H} 6 / 7) \text { LAM }\end{array}$ & $\begin{array}{l}\text { Park (L6) } \\
\text { LAM }\end{array}$ & $\begin{array}{l}\text { MIL } 99301 \\
\text { (LL6) LAM } \\
\end{array}$ & $\begin{array}{l}\text { Leedey (L6) } \\
\text { LAM }\end{array}$ & $\begin{array}{l}\text { Bruderheim (L6) } \\
\text { LAM }\end{array}$ & $\begin{array}{l}\text { Morrow County } \\
\text { (L6) LAM }\end{array}$ \\
\hline Thin section & CML0666-2A & CML0056-3 & CML617-1A & CML0422-1 & CML0504-1A & CML0618-2A & CML0497-6A \\
\hline Step size $(\mu \mathrm{m})$ & 4.0 & 4.0 & 4.0 & 4.0 & 4.0 & 5.7 & 4.0 \\
\hline Field size (mm) & $0.77 \times 0.58$ & $0.59 \times 0.45$ & $1.13 \times 0.85$ & $1.24 \times 0.94$ & $1.19 \times 0.90$ & $1.63 \times 1.22$ & $0.74 \times 0.56$ \\
\hline Fields & 119 & 200 & 111 & 27 & 50 & 103 & 128 \\
\hline Montage cells & $3,392,225$ & $3,088,530$ & $6,115,365$ & $2,504,965$ & $3,254,823$ & $6,234,870$ & $3,694,231$ \\
\hline $\begin{array}{l}\text { Montage area } \\
\left(\mathrm{mm}^{2}\right)\end{array}$ & 31.8 & 49.1 & 97.8 & 40.1 & 52.1 & 205.7 & 59.1 \\
\hline $\begin{array}{l}\text { EBSD camera } \\
\text { binning (pixels) }\end{array}$ & $4 \times 4$ & $4 \times 4$ & $4 \times 4$ & $8 \times 8$ & $8 \times 8$ & & $8 \times 8$ \\
\hline $\begin{array}{l}\text { Camera } \\
\text { exposure (ms) }\end{array}$ & 17.8 & 24.4 & 20.0 & 4.0 & 4.6 & 24.4 & 4.3 \\
\hline $\begin{array}{l}\text { Hough } \\
\text { resolution }\end{array}$ & 100 & 100 & 100 & 100 & 90 & 100 & 100 \\
\hline Indexing mode & $\begin{array}{l}\text { Optimized } \\
\text { EBSD }\end{array}$ & $\begin{array}{l}\text { Optimized } \\
\text { EBSD }\end{array}$ & $\begin{array}{l}\text { Optimized } \\
\text { EBSD }\end{array}$ & $\begin{array}{l}\text { Optimized } \\
\text { EBSD }\end{array}$ & $\begin{array}{l}\text { Optimized } \\
\text { EBSD }\end{array}$ & Refined Accuracy & $\begin{array}{l}\text { Optimized } \\
\text { EBSD }\end{array}$ \\
\hline $\begin{array}{l}\text { Noise reduction } \\
\text { (frames/field) }\end{array}$ & 2 & 2 & 1 & 1 & 1 & 1 & 2 \\
\hline Hit rate $(\%)^{1}$ & 85.0 & 92.9 & 81.3 & 67.5 & 65.5 & 81.1 & 58.5 \\
\hline $\begin{array}{l}\text { Olivine MAD } \\
\left({ }^{\circ}\right)^{2}\end{array}$ & 0.55 & 0.51 & 0.53 & 0.64 & 0.73 & 0.41 & 0.78 \\
\hline $\begin{array}{l}\text { Post-acquisition } \\
\text { processing }^{3}\end{array}$ & No & No & No & No & No & No & No \\
\hline
\end{tabular}

processing $^{3}$

${ }^{1}$ Hit rate includes all pixels indexed as a phase; non-indexed pixels include Kikuchi pattern data that do not fit the crystal match files, such as for poorly-crystalline areas, holes, or areas of epoxy surrounding the section.

${ }^{2}$ Mean Angular Deviation (MAD) value for olivine, which represents the average angular deviation between the measured and reference position of Kikuchi bands in olivine.

${ }^{3}$ Processing to remove wild spikes and zero solutions. 


\begin{tabular}{|c|c|c|c|c|c|c|c|c|c|c|}
\hline Meteorite & $\begin{array}{l}\text { EBSD } \\
\text { targeted } \\
\text { map }\end{array}$ & $\begin{array}{l}\text { Step size } \\
\quad(\mu \mathrm{m})\end{array}$ & $\begin{array}{l}\text { Map } \\
\text { area } \\
\left(\mathrm{mm}^{2}\right)\end{array}$ & Map cells & $\begin{array}{l}\text { EBSD } \\
\text { camera } \\
\text { binning } \\
\text { (pixels) }\end{array}$ & $\begin{array}{c}\text { Camera } \\
\text { exposure } \\
\text { (ms) }\end{array}$ & $\begin{array}{l}\text { Hough } \\
\text { resolution }\end{array}$ & Indexing mode & $\begin{array}{c}\text { Noise } \\
\text { reduction } \\
\text { (frames/ } \\
\text { field) }\end{array}$ & $\begin{array}{c}\text { Post- } \\
\text { acquisition } \\
\text { processing* }\end{array}$ \\
\hline $\begin{array}{l}\text { Portales } \\
\text { Valley }\end{array}$ & Gr14 & 2.5 & 0.35 & 56,180 & $4 \times 4$ & 16.0 & 100 & Refined Accuracy & 1 & $\overline{\mathrm{N}}$ \\
\hline $\begin{array}{l}\text { Portales } \\
\text { Valley }\end{array}$ & Gr39 & 2.1 & 0.25 & 56,180 & $4 \times 4$ & 16.0 & 100 & Refined Accuracy & 1 & $\mathrm{~N}$ \\
\hline $\begin{array}{l}\text { Portales } \\
\text { Valley }\end{array}$ & Gr40 & 2.7 & 0.42 & 56,420 & $4 \times 4$ & 19.0 & 100 & Optimized EBSD & 1 & $\mathrm{~N}$ \\
\hline $\begin{array}{l}\text { Portales } \\
\text { Valley }\end{array}$ & Gr59 & 2.5 & 0.36 & 57,456 & $4 \times 4$ & 19.0 & 100 & Optimized EBSD & 1 & $N$ \\
\hline Park & 6 Field & 1.0 & 1.31 & $13,004,301$ & $4 \times 4$ & 17.1 & 60 & Refined Accuracy & 1 & $\mathrm{~N}$ \\
\hline Park & Area 1 & 0.76 & 0.33 & 577,943 & $4 \times 4$ & 22.0 & 100 & Refined Accuracy & 2 & $\mathrm{~N}$ \\
\hline Park & Area 2 & 1.2 & 0.83 & 577,949 & $4 \times 4$ & 22.0 & 100 & Refined Accuracy & 2 & $\mathrm{~N}$ \\
\hline Park & Area 3 & 1.0 & 0.61 & 610,654 & $4 \times 4$ & 22.0 & 100 & Refined Accuracy & 2 & $\mathrm{~N}$ \\
\hline Park & Area 6 & 1.4 & 1.11 & 577,943 & $4 \times 4$ & 22.0 & 100 & Refined Accuracy & 2 & $\mathrm{~N}$ \\
\hline $\begin{array}{c}\text { MIL } 99301 \\
\text { host }^{\S}\end{array}$ & 6 Field & 1.8 & 5.63 & $1,839,100$ & $4 \times 4$ & 18.4 & 60 & Refined Accuracy & 5 & $N$ \\
\hline $\begin{array}{l}\text { MIL } 99301 \\
\text { clast }^{\S}\end{array}$ & 6 Field & 1.8 & 5.63 & $1,839,100$ & $4 \times 4$ & 18.4 & 60 & Refined Accuracy & 5 & $\mathrm{~N}$ \\
\hline $\begin{array}{l}\text { MIL } 99301 \\
\text { clast }\end{array}$ & BSE8 & 1.8 & 0.28 & 85,560 & $4 \times 4$ & 18.4 & 60 & Refined Accuracy & 5 & $\mathrm{~N}$ \\
\hline Leedey & 5 Field & 1.0 & 2.83 & $2,829,816$ & $4 \times 4$ & 17.1 & 120 & Refined Accuracy & 2 & $\mathrm{~N}$ \\
\hline Bruderheim & Site 22 & 2.2 & 1.11 & 223,860 & $4 \times 4$ & 20.9 & 100 & Refined Accuracy & 2 & $\mathrm{~N}$ \\
\hline Bruderheim & Site 78 & 2.3 & 0.63 & 125,256 & $4 \times 4$ & 20.9 & 100 & Refined Accuracy & 2 & $\mathrm{~N}$ \\
\hline Bruderheim & 4 Field & 1.0 & 0.95 & 950,718 & $4 \times 4$ & 19.0 & 120 & Optimized EBSD & 1 & $\mathrm{~N}$ \\
\hline $\begin{array}{l}\text { Morrow } \\
\text { County }\end{array}$ & 6 Field & 1.0 & 2.07 & $2,081,436$ & $4 \times 4$ & 16.0 & 100 & Refined Accuracy & 1 & $\mathrm{~N}$ \\
\hline
\end{tabular}

${ }^{*}$ Processing or zero solution removal and wild spike removal. $\mathrm{N}=$ No. ${ }^{\S}$ Host and clast data were extracted as comparably-sized subsets from the same map. 
Fig. EA-1. An example of post-acquisition processing on the GOS distribution for olivine in the Bruderheim LAM dataset. Two different processing methods, \#1 and \#2, were used here, which both involve (a) wild spike removal, and (b) zero solution filling based on 7 neighbors, using the Kurahawa method, differing in details for how zero solution filling occurred. As can be seen, both processing methods result in similar results that differ significantly from the original distribution, with an increase in the number of low-GOS grains and a change in shape of the GOS distribution. This suggests that post-acquisition processing has an adverse affect on the statistical treatment of GOS data. Explanation: Wild spikes are pixels that have a phase different from all nearest neighbors and are surrounded by 8 pixels of another phase or has a solution of no pixels. Wild spike removal replaces these wild spikes with the neighborhood phase, and with the average orientation of the 8 pixels of this neighborhood phase (or with non-orientation in the case of 8 neighboring pixels of no solution). Zero solution filling based on 7 neighbors applies if pixels of zero solution are surrounded by 7 neighboring pixels of the same phase, replacing the zero solution with this phase and the average orientation of the 7 neighboring pixels. Processing \#1 does zero solution filling with 1 pass only, whereas processing \#2 does zero solution filling iteratively until all zero solutions are filled using the specified criteria. Interpretation: both processing methods \#1 and \#2 distort the original data by creating many new (likely artificial) grains, which have GOS values similar to the prevailing low-GOS values in the original distribution. Whether or not zero solutions are filled with one pass or iteratively (methods \#1 or \#2) makes little difference. The distortion occurs despite the most conservative assumptions: zero solutions to be surrounded by 7 pixels of the same phase, or wild spikes surrounded by 8 pixels of the same phase (or non-phase). We conclude that even "conservative" post-acquisition processing involving wild spike or zero solution removal introduces data artifacts.

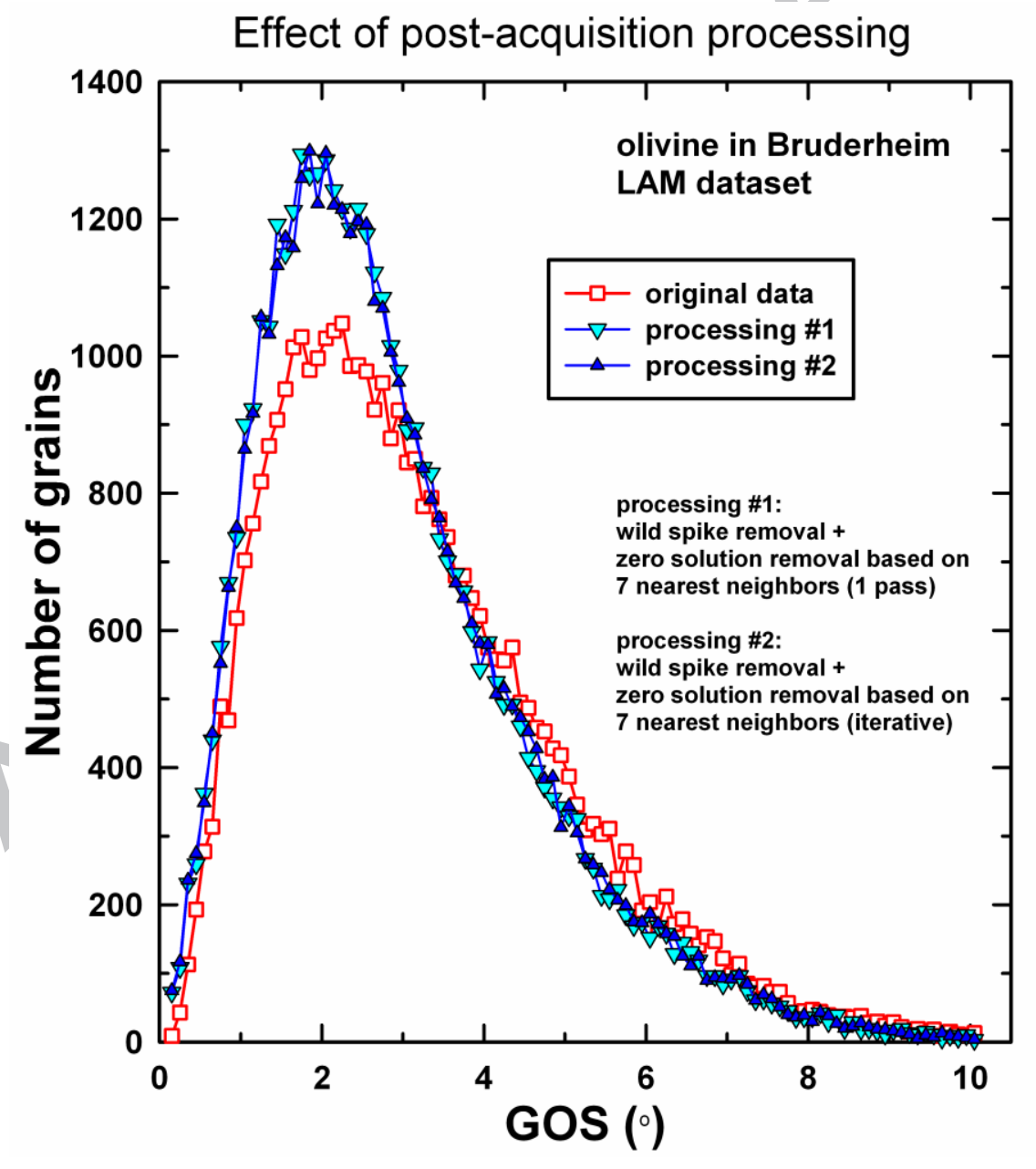


Fig. EA-2. Comparison of EBSD metrics mean KAM and mean GOS for olivine in large area maps (large symbols) and targeted maps (smaller symbols, same patterns) for Portales Valley (PV), Park (Prk), Leedey (Ldy), Morrow County (MC), MIL 99301 (MIL), and Bruderheim (Brd); data from

Tables 1 and 3 . Step sizes for the targeted maps are shown next to the corresponding symbols, as this could affect $K A M$ values. The LAM trend and correlation coefficient corresponds to that shown in Fig. $6 \mathrm{~b}$ in the Text. GOS values in targeted maps generally fall within the standard deviations of GOS based on large area maps, whereas KAM values in targeted maps tend to be highly variable.

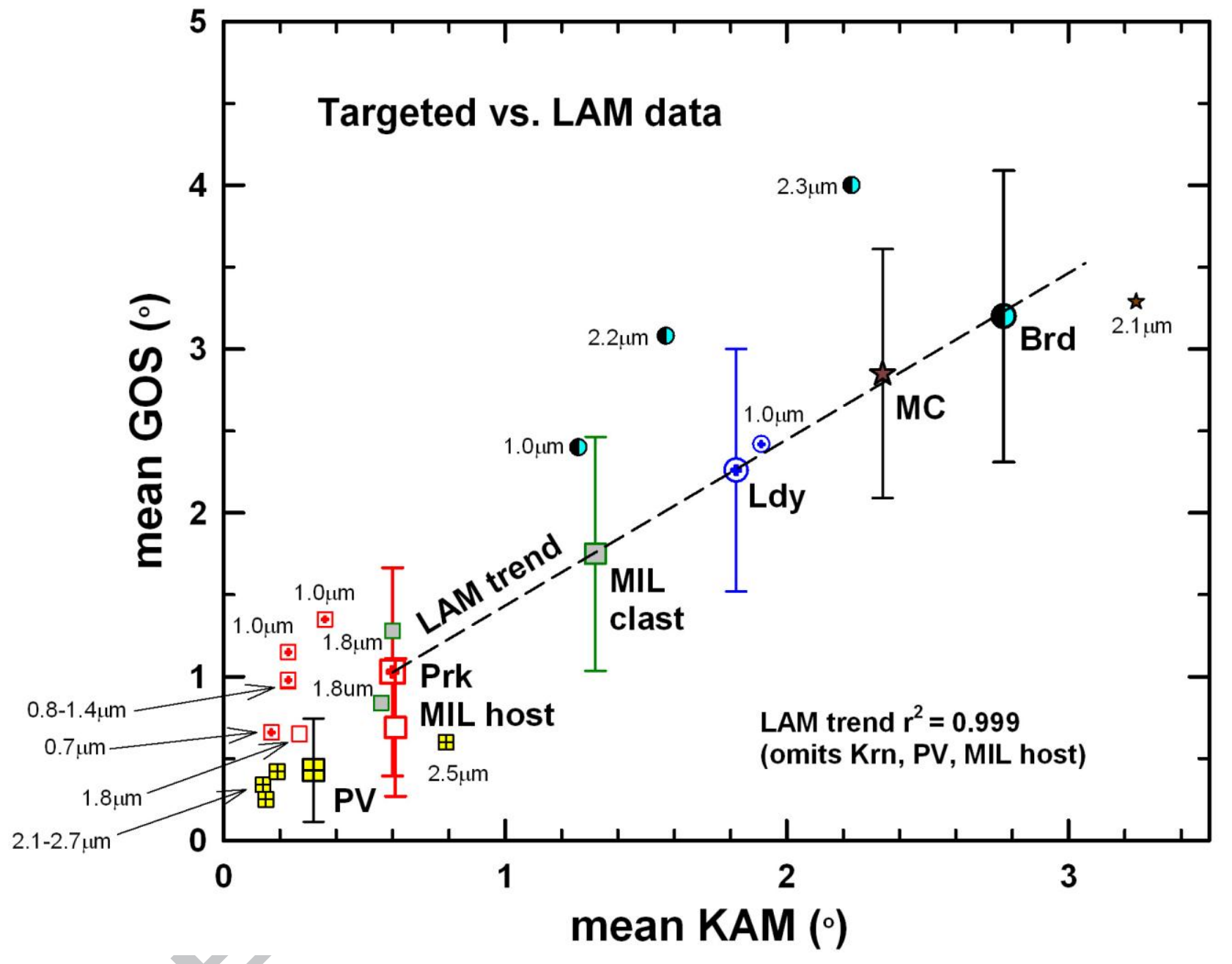

Fig. EA-3. Comparison of deformation data for larger (effective diameter $d>50 \mu \mathrm{m}$ ) and smaller $(d<50 \mu \mathrm{m})$ olivine grains based on large area map GOS and KAM deformation metrics. Data fall into a field with mean $G O S_{d>50} /$ mean $G O S_{d<50}>1$ and mean $K A M_{d>50} /$ mean $K A M_{d<50}<1$, suggesting that larger grains are more deformed than smaller grains on the scale of the grains but are less deformed than smaller on a 9-pixel scale. $\mathrm{Krn}=$ Kernouvé, other meteorite symbols and abbreviations same as in Fig. EA-2. 


\section{Deformation in large vs. small olivine grains}

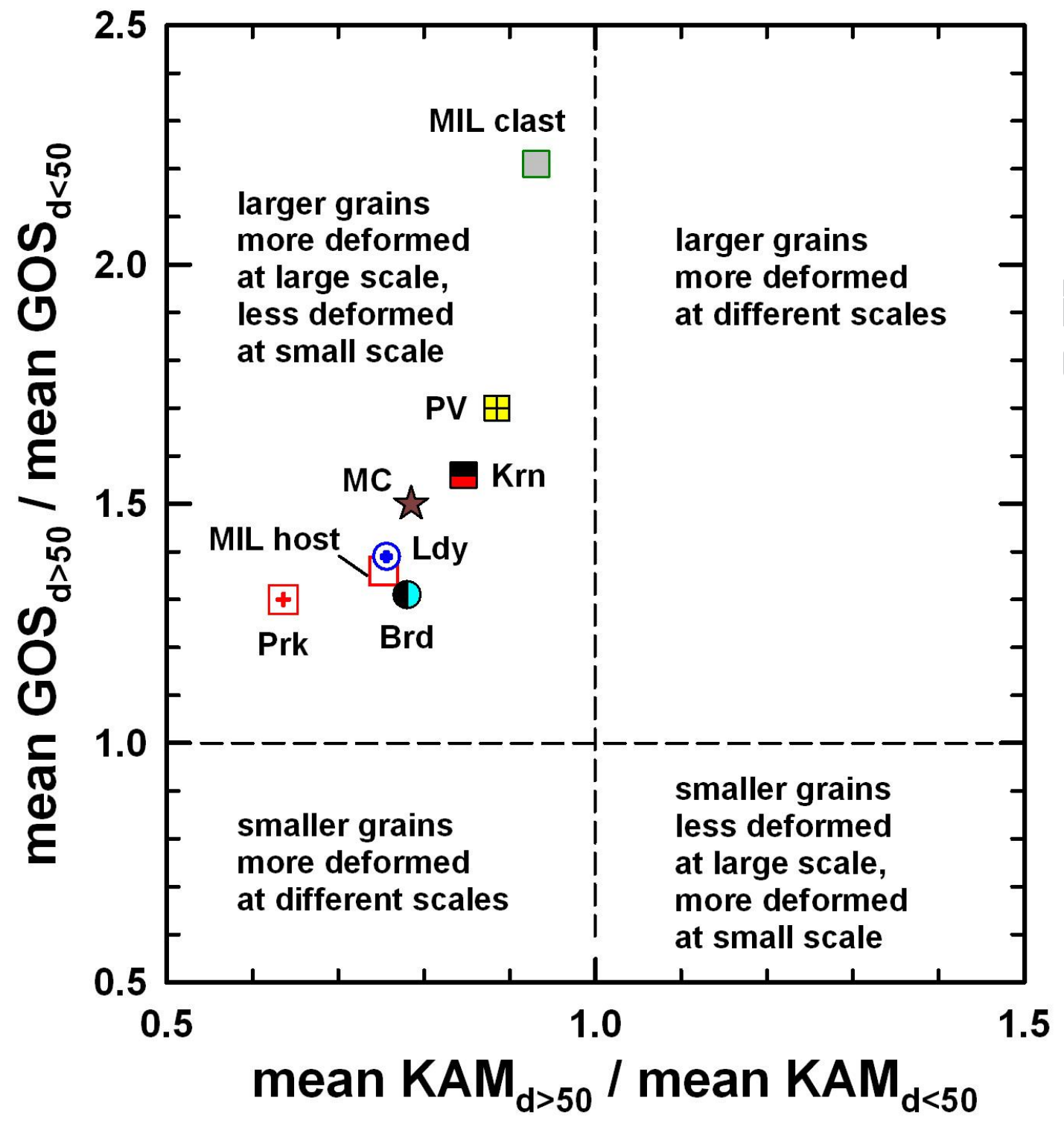

Fig. EA-4. Relationship for olivine between mean GOS and the relative number of boundaries of different misorientations, including low-angle grain boundaries (LAGBs) with $0.5-2^{\circ}$ and $2-10^{\circ}$ misorientation (Table 1) and high-angle $\left(>10^{\circ}\right)$ grain boundaries (HAGBs) (large area map data). Although the absolute number of subgrains with both $0.5-2^{\circ}$ and $2-10^{\circ}$ misorientations is higher in more-deformed (higher GOS) meteorites (Table 2), less-deformed meteorites have a higher proportion of $0.5-2^{\circ}$ and more-deformed meteorites have a higher proportion of $2-10^{\circ}$ boundaries. Meteorite abbreviations same as in Fig. EA-2 and EA-3. 


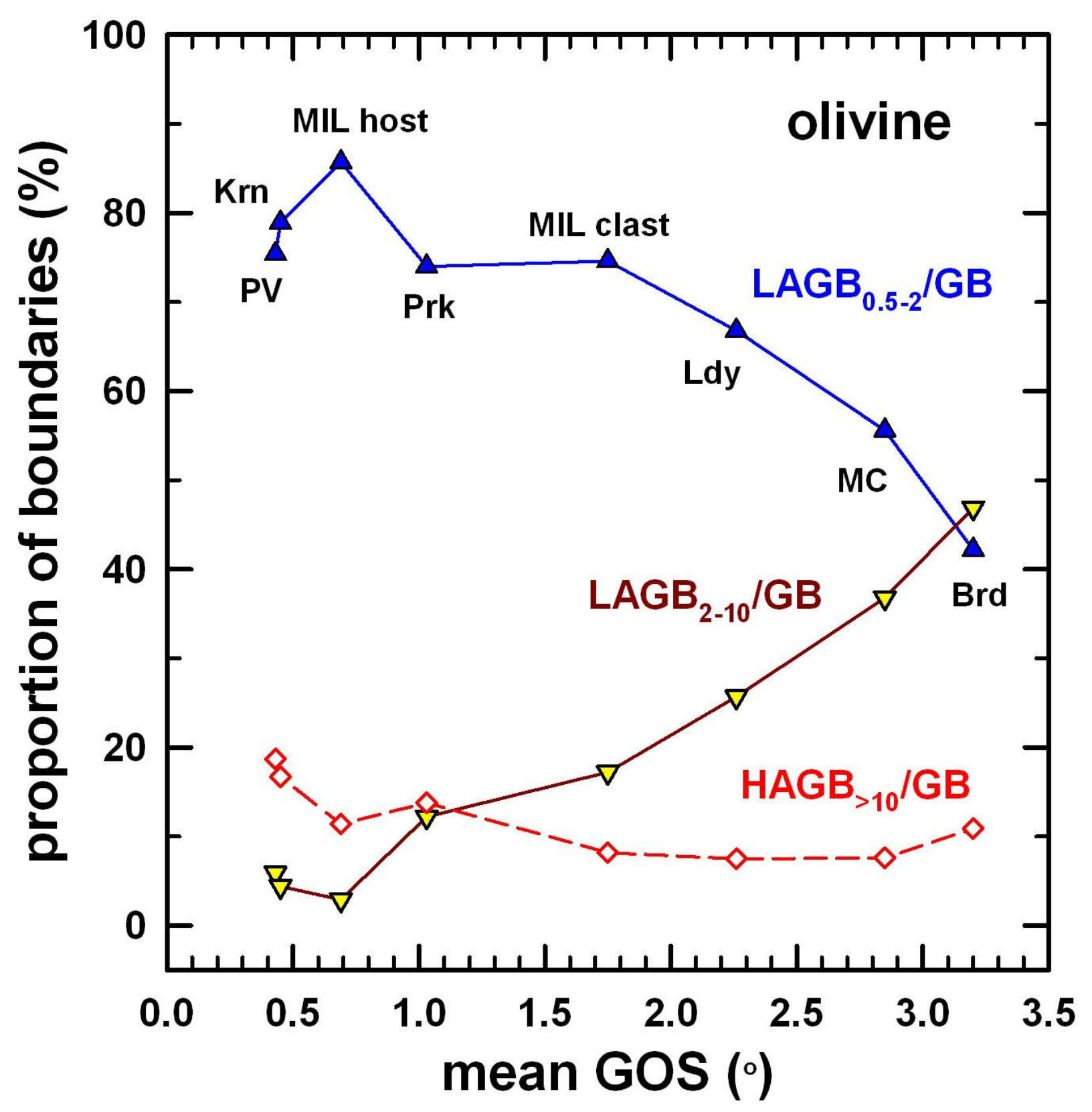


Fig. EA-5. Comparison of targeted and large area map data for inferred annealing parameter (mean $G O S_{d>50}$ /median $G O S_{d>50}$ ) and inferred deformation temperature parameter (fraction of $<001>$ and $<010>$ rotation axes for 2-10 misorientations) in olivine, based on data in Tables 1-3. Larger symbols represent LAM data, smaller symbols targeted maps. Data for Leedey, Bruderheim and Morrow County distribute into a well-defined field with inferred low annealing extent and lowtemperature deformation for both targeted and LAM data; data for Kernouvé, MIL 99301 host, Park and the Portales Valley LAM distribute into a broader field with inferred high annealing extent and high-temperature deformation for both targeted and LAM data; data for the MIL 99301 clast correspond to inferred high-temperature deformation. Portales Valley targeted data scatter widely. Meteorite symbols and abbreviations same as in Fig. EA-2 and EA-3.

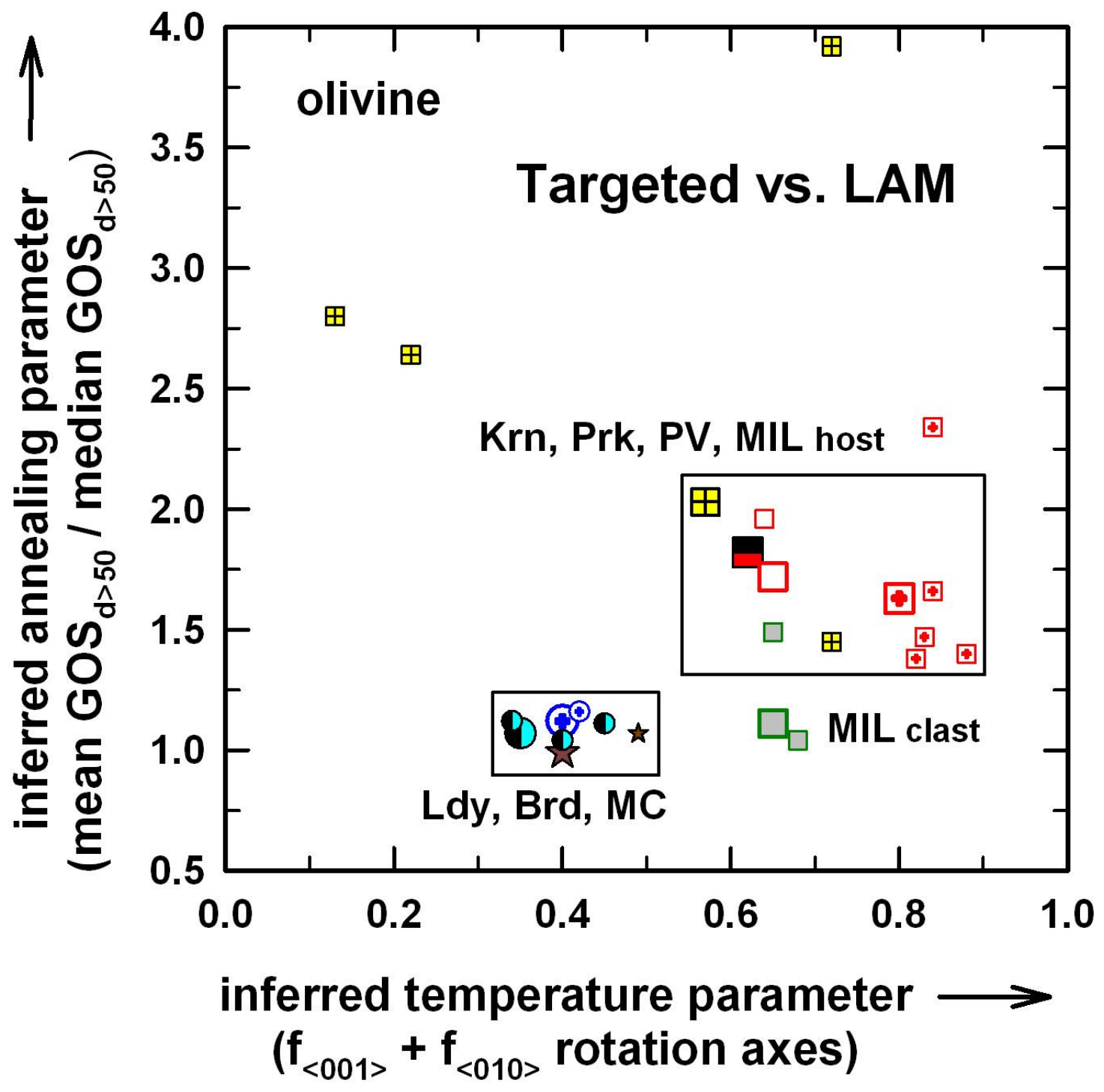


Fig. EA-6. Pole figure plots (equal area, upper hemisphere, 1 point per grain) for olivine based on large area map data. Plots are arranged according to increasing mean $G O S_{d>50}$ for olivine and contoured ( $25^{\circ}$ half width) in terms of Multiples of Uniform Density (MUD) values, with redder areas indicating higher MUD values and bluer indicating lower MUD values (though scales are different for each part; maximum [max] / minimum [min] MUD values are listed).

(a) Portales Valley. $\mathrm{N}=7410$ grains. MUD Max $/ \min =1.19 / 0.78, \Delta=0.41$.
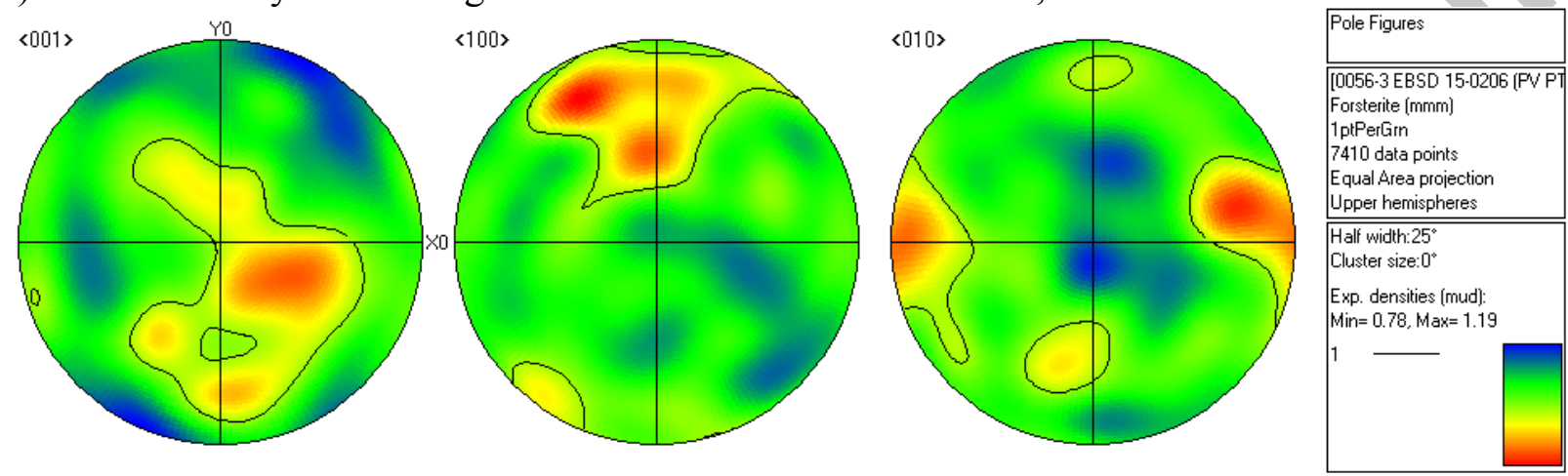

(b) Kernouvé. $\mathrm{N}=8113$ grains. $\mathrm{MUD} \operatorname{Max} / \min =1.15 / 0.82, \Delta=0.33$.
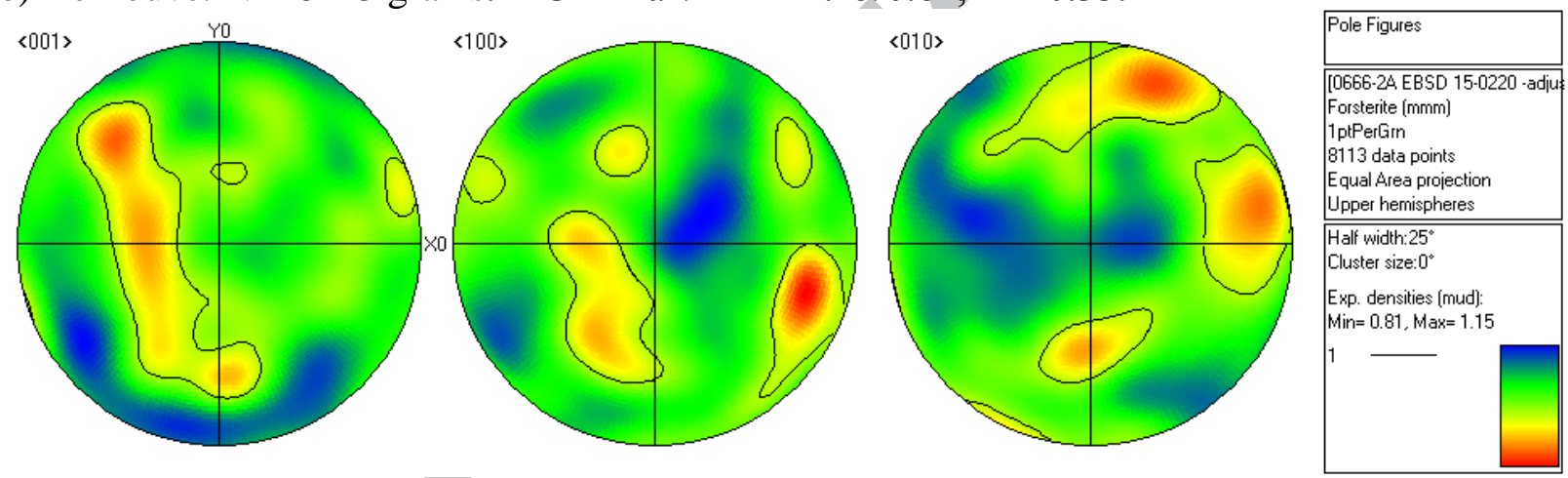

(c) MIL host. $\mathrm{N}=6808$ grains. MUD $\max / \min =1.39 / 0.78, \Delta=0.61$.
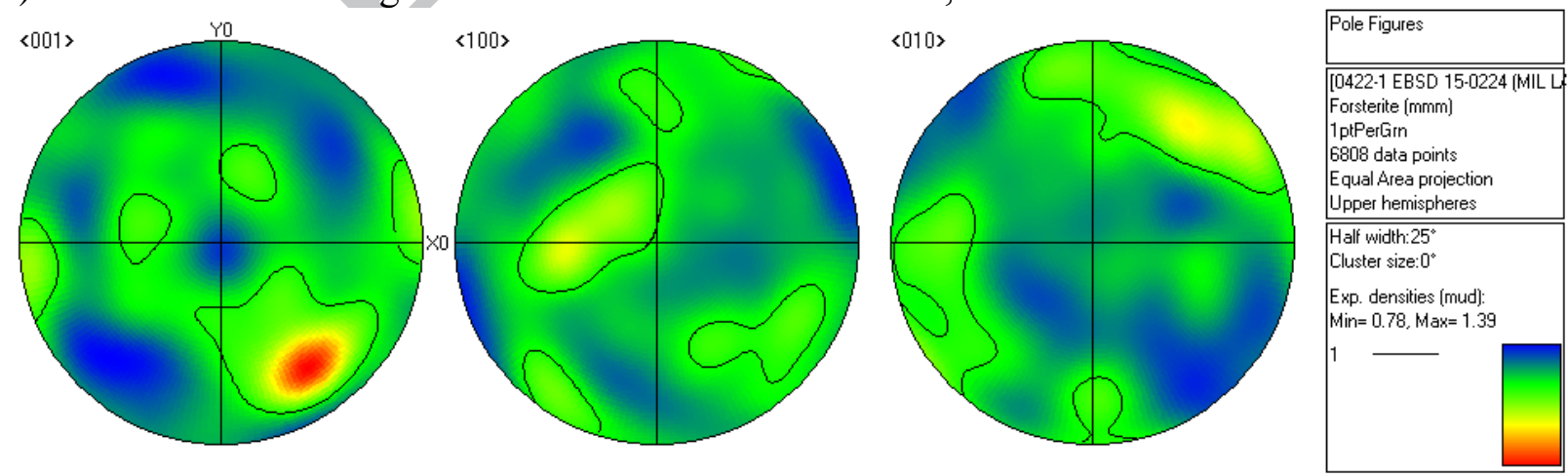
(d) Park. $\mathrm{N}=22955$ grains. MUD $\max / \min =1.11 / 0.80, \Delta=0.31$.
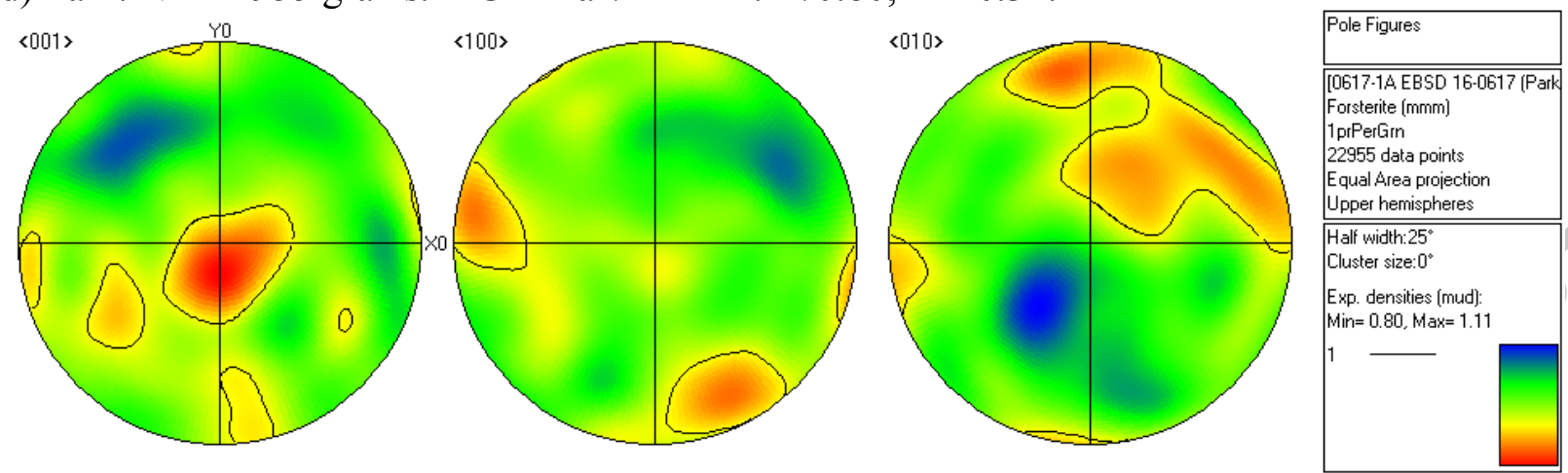

(e) Leedey. $\mathrm{N}=17304$ grains. MUD $\max / \min =1.19 / 0.75, \Delta=0.44$.
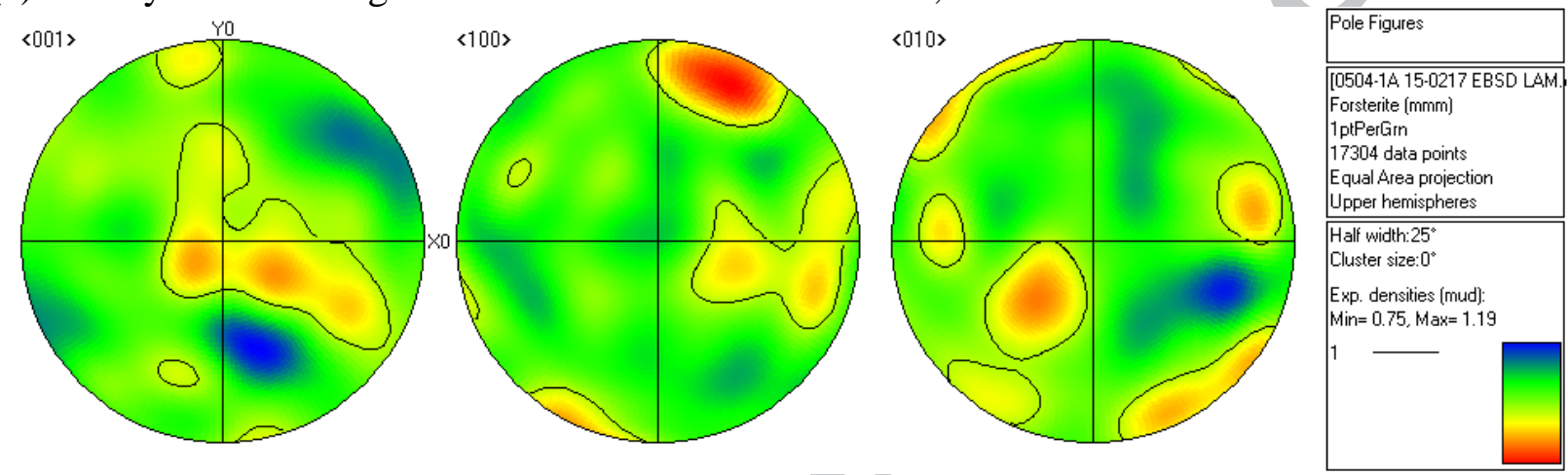

(f) MIL Clast. $\mathrm{N}=2960$. MUD $\max / \mathrm{min}=6.53 / 0.00, \Delta=6.53$.
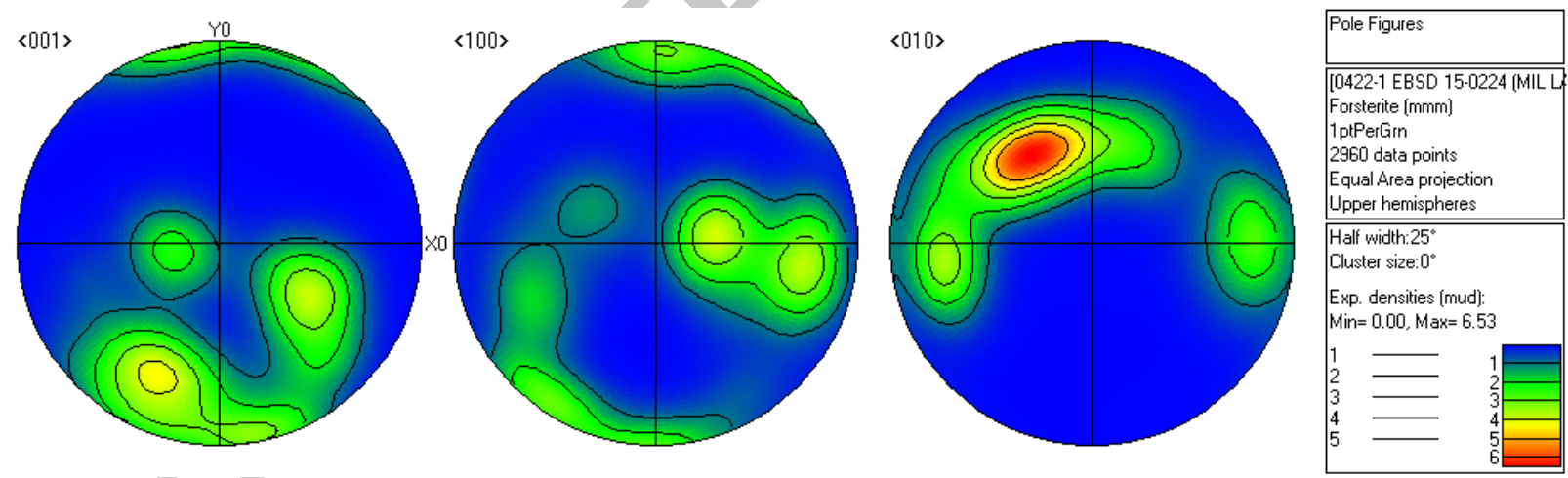

(g) Bruderheim. $\mathrm{N}=39650$ grains. MUD $\max / \min =1.14 / 0.79, \Delta=0.35$.
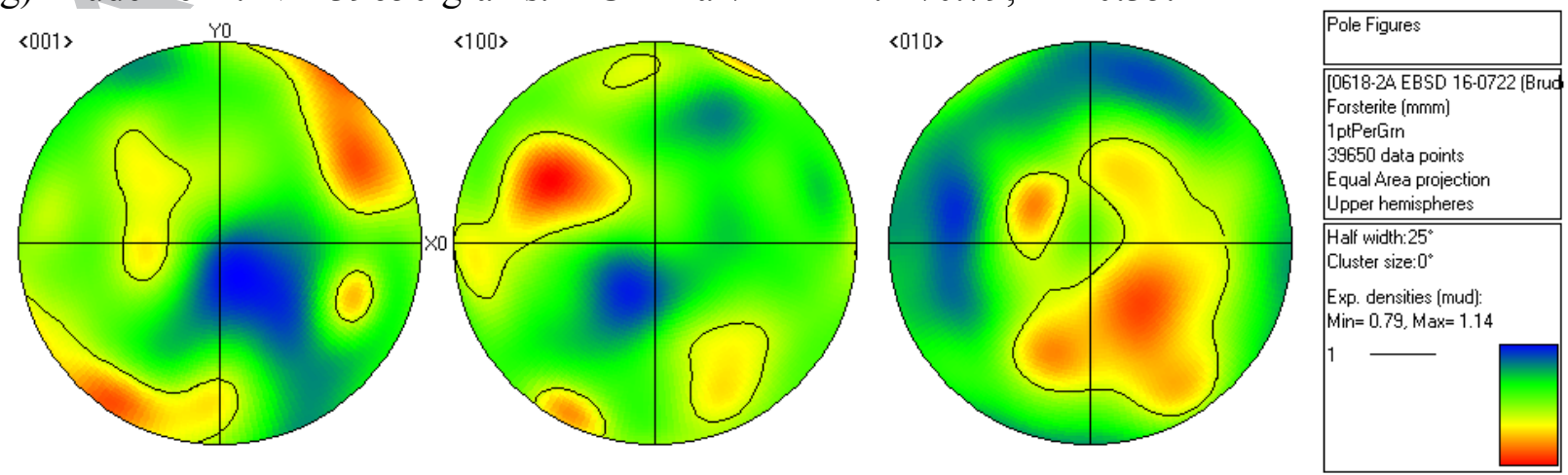
(h) Morrow County. $\mathrm{N}=15329$ grains. MUD $\max / \min =1.45 / 0.55, \Delta=0.90$.
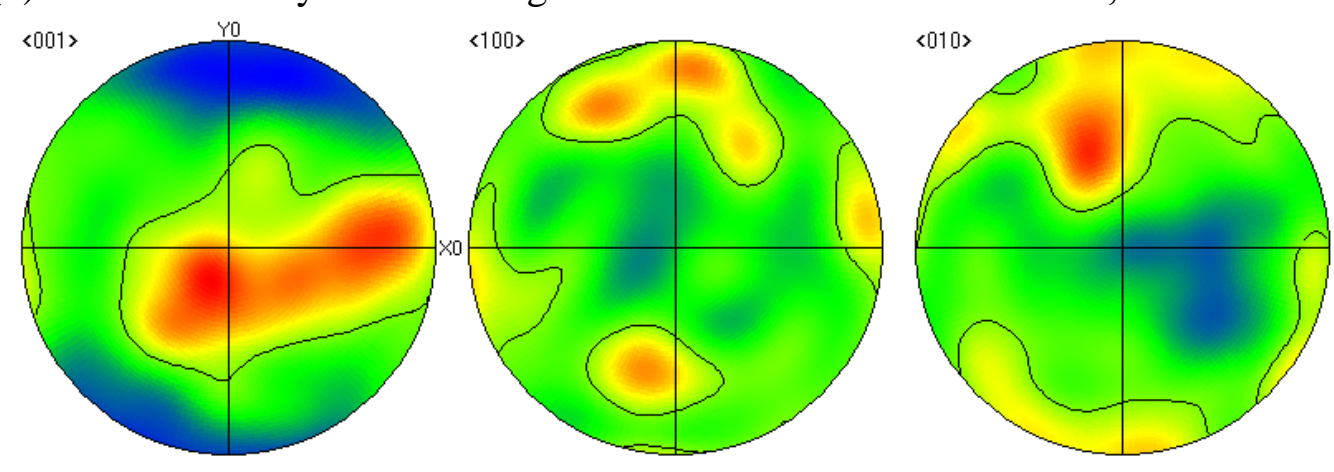

Pole Figures

[0497-6A EBSD LAM.cpr]

Forsterite $(\mathrm{mmm})$

$1 \mathrm{ptPerGin}$

15329 data points

Equal Area projection

Upper hemispheres

Half width: $25^{\circ}$

Cluster size: $0^{\circ}$

Exp. densities (mud):

Min= 0.55, Max $=1.45$

1

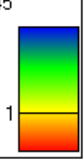


Fig. EA-7. Pole figure plots (equal area, upper hemisphere, 1 point per grain) for troilite based on large area map data. Plots are arranged according to increasing mean $G O S_{d>50}$ for olivine, and contoured ( $25^{\circ}$ half width) in terms of Multiples of Uniform Density (MUD) values, with redder areas indicating higher MUD values and bluer indicating lower MUD values (though scales are different for each part; maximum [max] / minimum [min] MUD values are listed).

(a) Portales Valley. $\mathrm{N}=1641$ grains. MUD Max $/ \min =3.76 / 0.33, \Delta=3.43$.
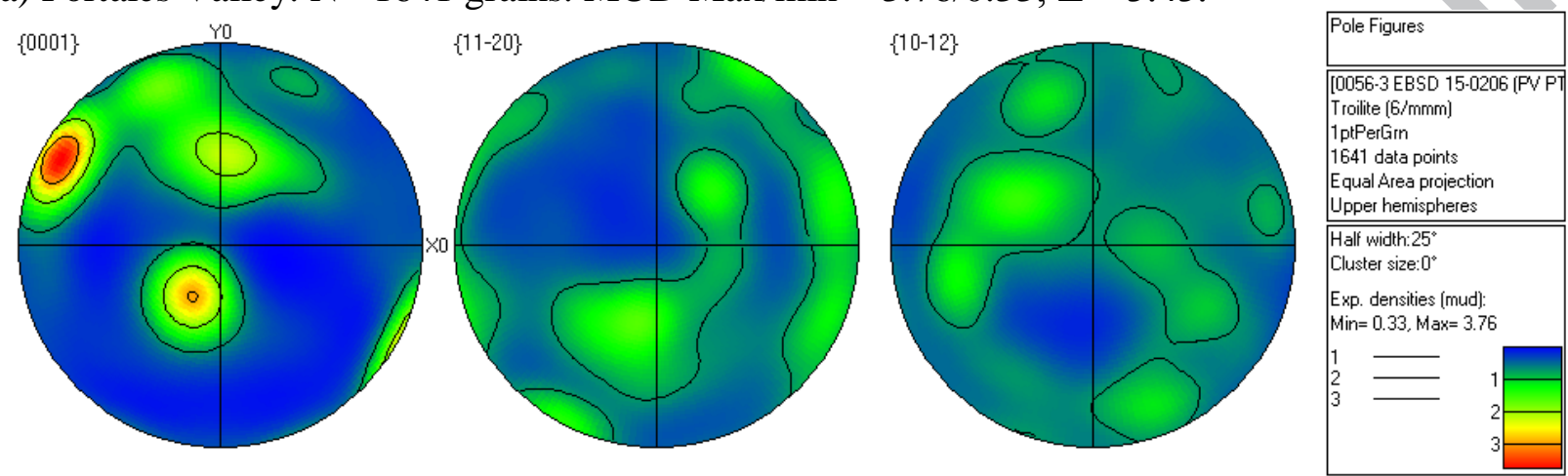

(b) Kernouvé. $\mathrm{N}=1040$ grains. MUD Max/min $=1.74 / 0.44, \Delta=1.30$.
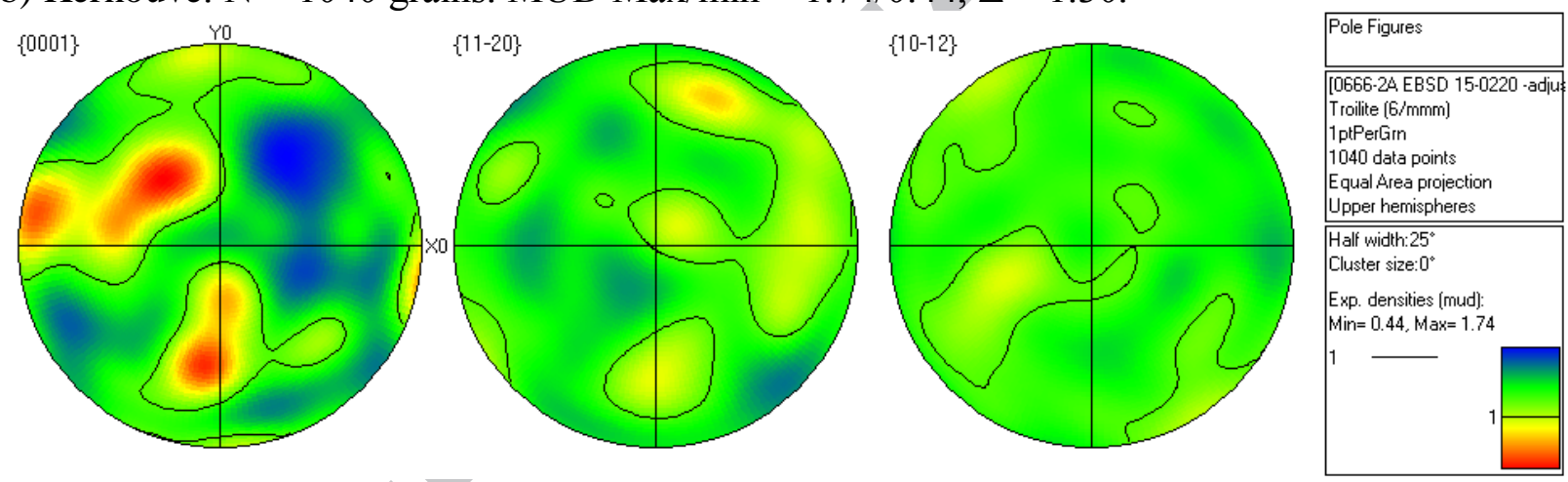

(c) MIL host. $\mathrm{N}=757$ grains. MUD $\max / \min =2.33 / 0.15, \Delta=1.87$.
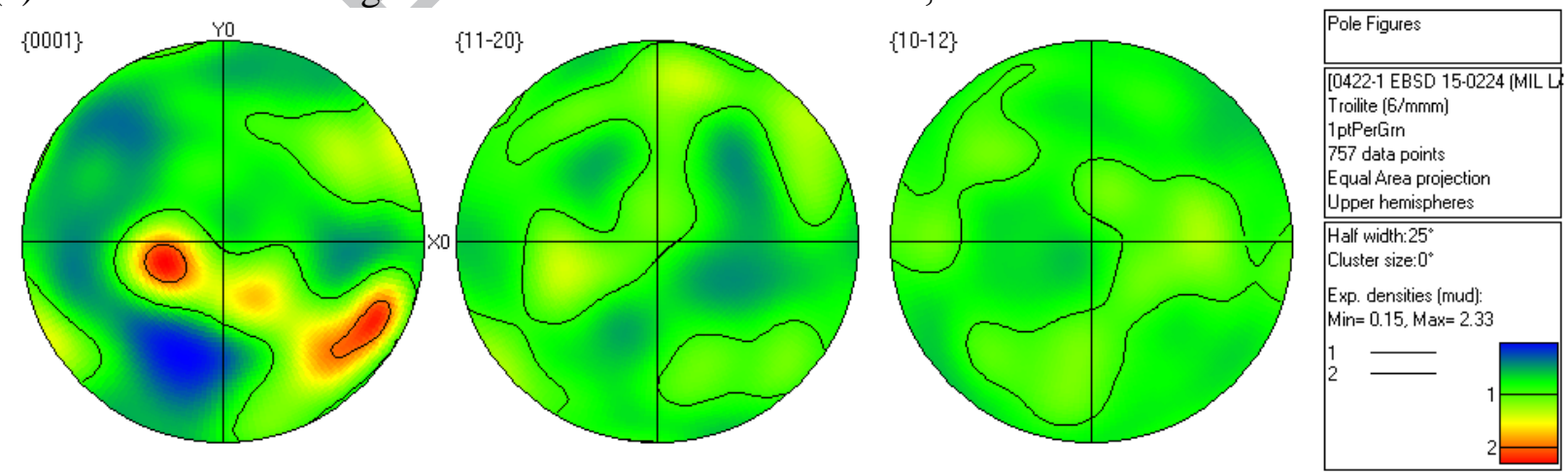
(d) Park. $\mathrm{N}=1948$ grains. MUD $\max / \min =1.35 / 0.41, \Delta=0.94$.
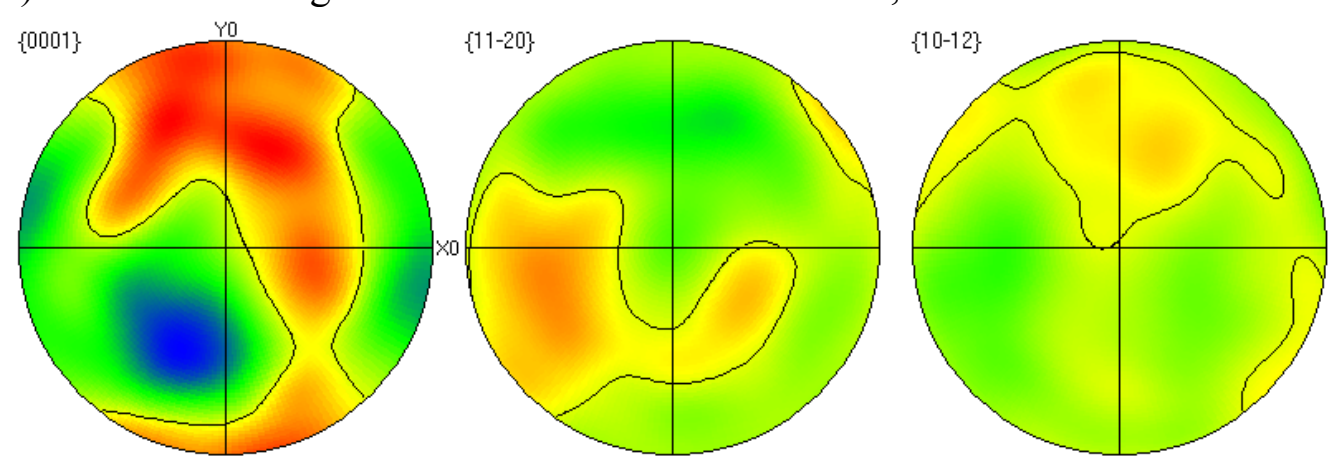

Pole Figures

[0617-1A EBSD 16-0617 (Park Troilite $[6 / \mathrm{mmm}]$

1prPerGin

1948 data points

Equal Area projection

Upper hemispheres

Half width: $25^{\circ}$

Cluster size: $0^{\circ}$

Exp. densities (mud):

Min $=0.41$, Max $=1.35$

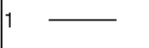

(e) Leedey. $\mathrm{N}=2223$ grains. MUD $\max / \min =2.75 / 0.30, \Delta=2.45$.
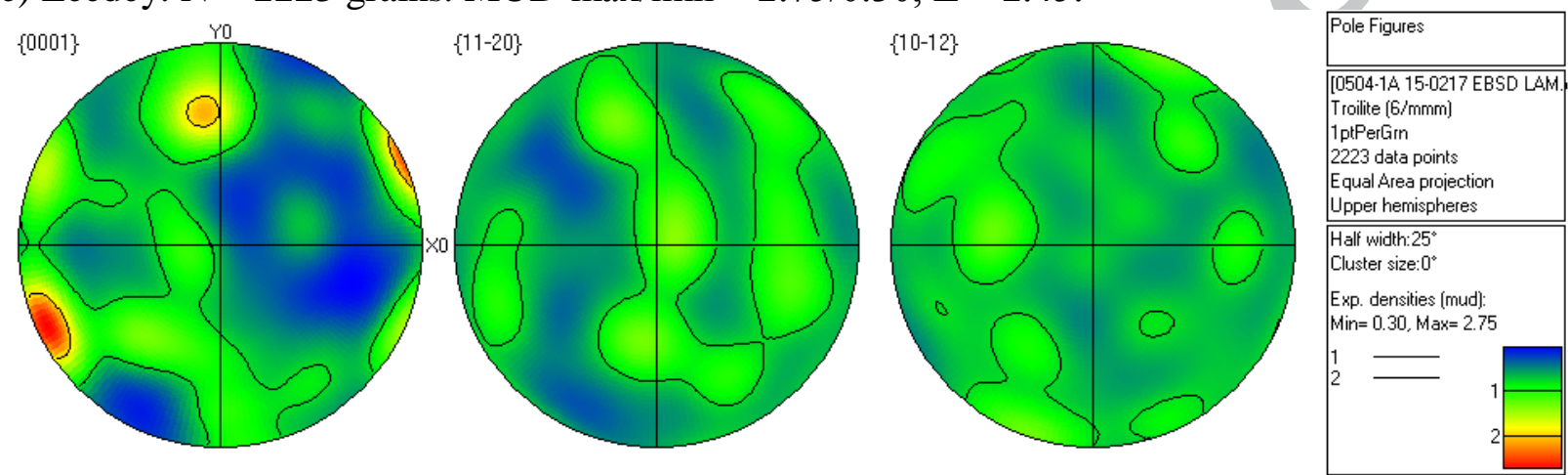

(f) Bruderheim. $\mathrm{N}=5693$ grains. MUD max $/ \mathrm{min}=1.54 / 0.62, \Delta=0.92$.
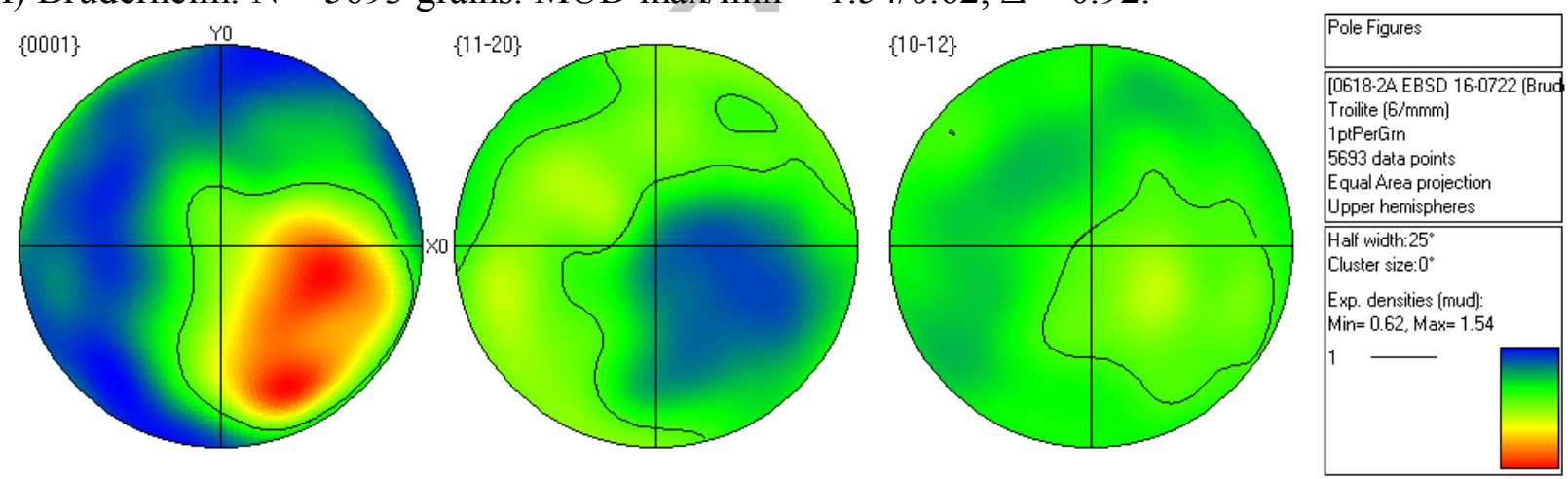

(g) Morrow County. $\mathrm{N}=1559$ grains. MUD $\max / \min =2.27 / 0.43, \Delta=1.84$.
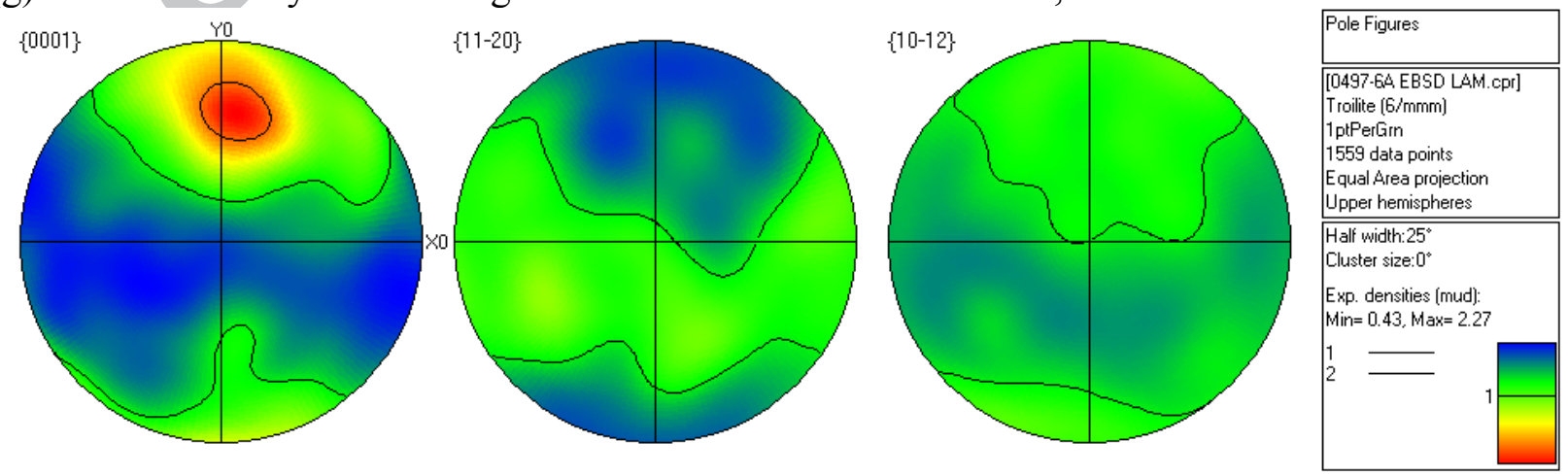